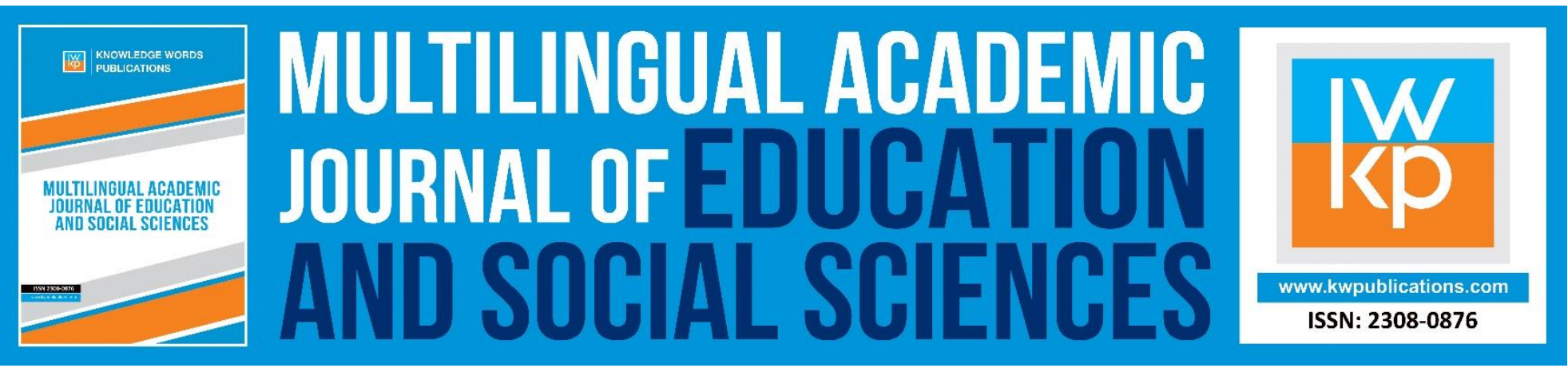

\title{
The Pedagogic and Instructive Use of Art in Primary School: The Case of Shadow Puppet Theatre
}

Antonios Vassiliou

To Link this Article: http://dx.doi.org/10.46886/MAJESS/v5-i1/2434

DOI: 10.46886/MAJESS/v5-i1/2434

Received: 02 June 2017, Revised: 06 July 2017, Accepted: 10 September 2017

Published Online: 17 October 2017

In-Text Citation: (Vassiliou, 2017)

To Cite this Article: Vassiliou, A. (2017). The Pedagogic and Instructive Use of Art in Primary School: The Case of Shadow Puppet Theatre. Multilingual Academic Journal of Education and Social Sciences, 5(1), 110136.

\section{Copyright: () The Authors 2017}

Published by Knowledge Words Publications (www.kwpublications.com)

This article is published under the Creative Commons Attribution (CC BY 4.0) license. Anyone may reproduce, distribute, translate and create derivative works of this article (for both commercial and non-commercial purposes), subject to full attribution to the original publication and authors. The full terms of this license may be seen

at: http://creativecommons.org/licences/by/4.0/legalcode

Vol. 5, No. 1, 2017, Pg. 110 - 136

https://kwpublications.com/journals/journaldetail/MAJESS

JOURNAL HOMEPAGE

Full Terms \& Conditions of access and use can be found at https://kwpublications.com/pages/detail/publication-ethics 


\title{
The Pedagogic and Instructive Use of Art in Primary School: The Case of Shadow Puppet Theatre
}

\author{
Antonios Vassiliou \\ PhD, University of Western Macedonia
}

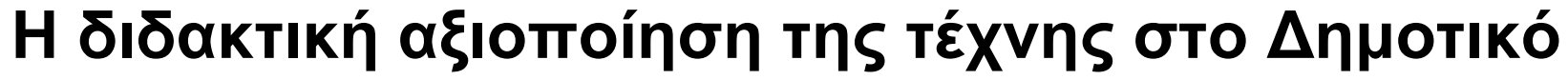

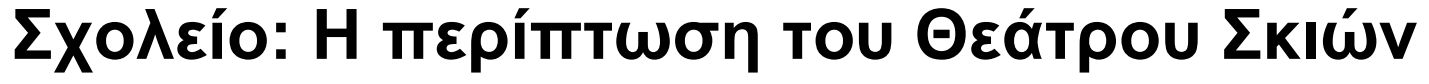

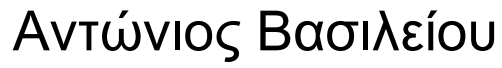 \\ $\mathrm{PhD}$, University of Western Macedonia
}

\begin{abstract}
The present study focuses on the pedagogic and instructive use of art and more specifically of the Shadow Puppet Theatre in Primary School. Initially, we briefly present the objectives of education - those who concern the popular tradition, the art and the promotion of culture as these are formulated in Act 1566 of 1985. Furthermore, we discuss modern methods of teaching that are included in various institutional texts, which concern the above school level, such as the Cross Thematic Curriculum Framework (D.E.P.P.S.) and the "Analytic Curricoulae" (A.P.S.). Several approaches are also presented regarding the particularities of this form of drama and the advantages and disadvantages in regard to its introduction in the educational process. Then, the possibility of integration of Shadow Puppet Theatre in the teaching of various instructive subjects of Primary School is discussed, while presenting evidence for its presence in the textbooks which are taught today in Primary Education. Finally, instructive proposals are presented on the use of this form of drama - in the frame of Cross Thematic Approach of Education - for almost all subjects taught in Primary School. In conclusion, the study of all the above mentioned elements leads to the ascertainment that the Shadow Puppet Theatre can be instrumental in the enrichment and modernisation of teaching and general educational process at school.
\end{abstract}

Key words: Primary/Elementary School, Shadow Puppet Theatre, Audiovisual Literacy, Cross Thematic Curriculum Framework.

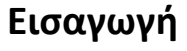

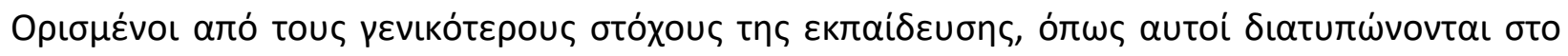

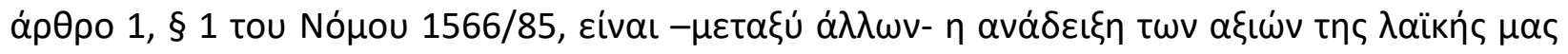

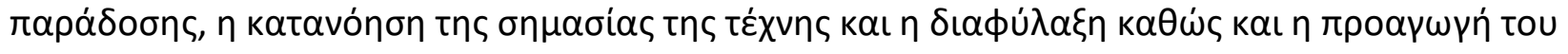


MULTILINGUAL ACADEMIC JOURNAL OF EDUCATION AND SOCIAL SCIENCES

Vol. 5 No. 1, 2017, E-ISSN: 2308-0876 @ 2017 KWP

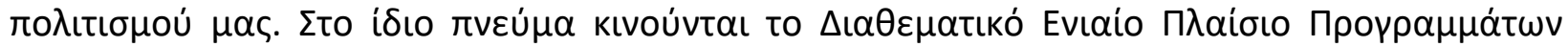

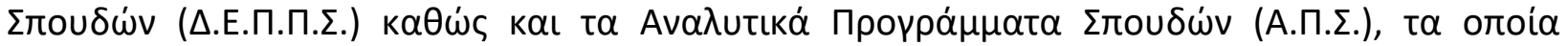

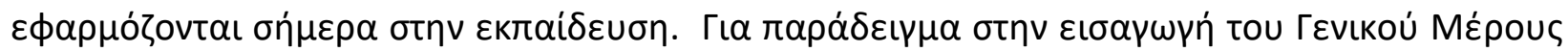

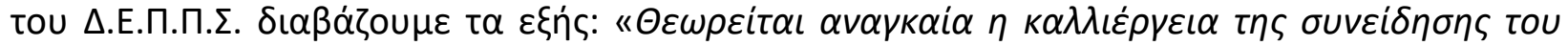

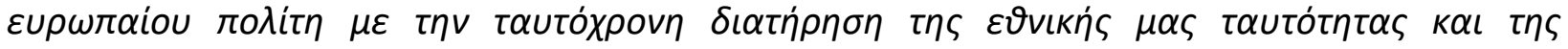

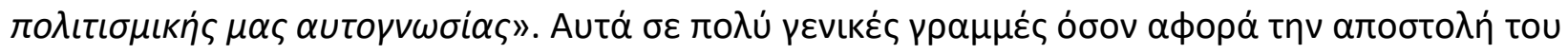

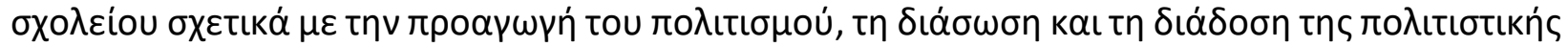

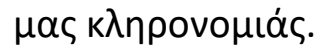

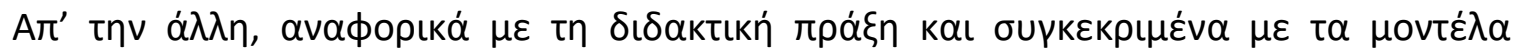

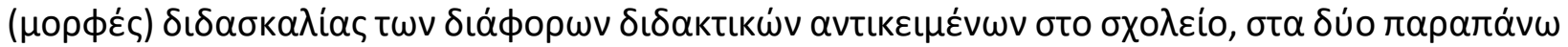

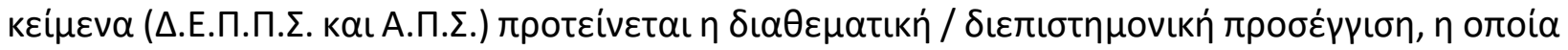

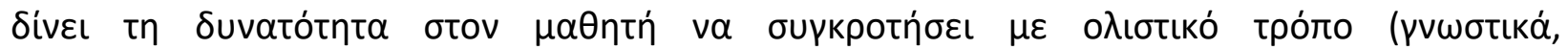

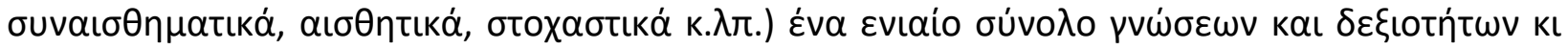

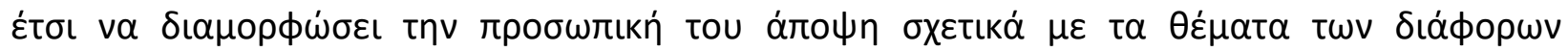

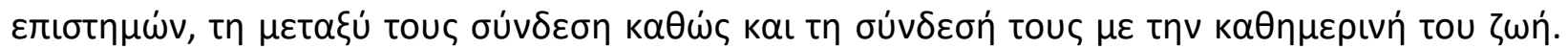

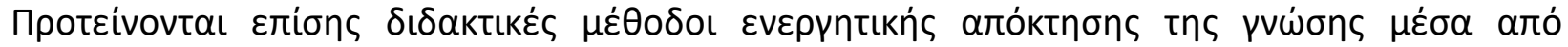

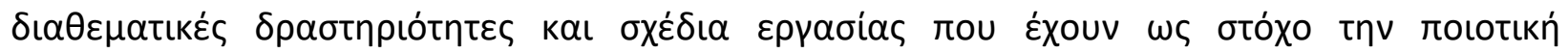

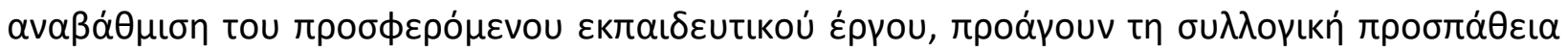

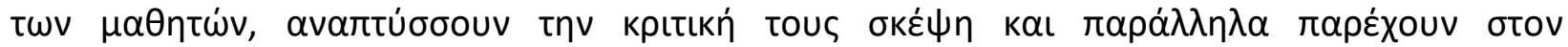

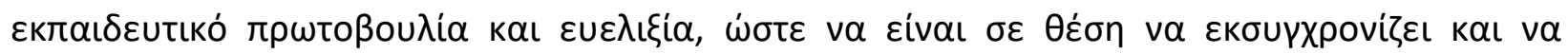

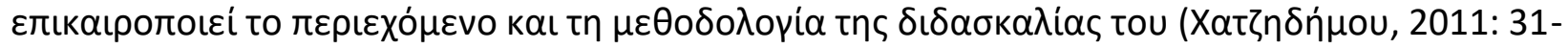
41).

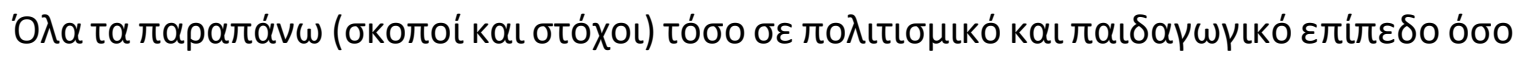

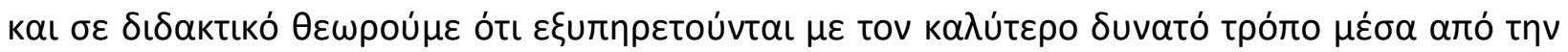

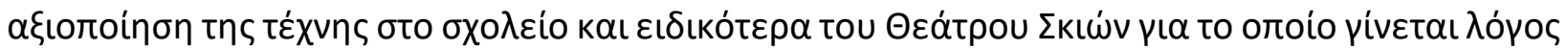

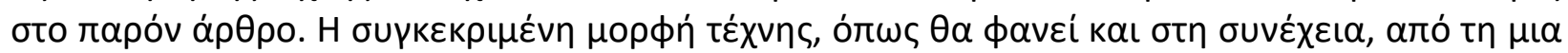

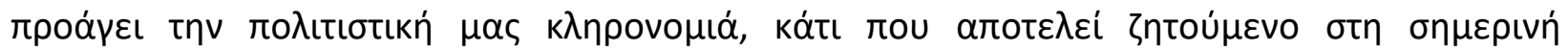

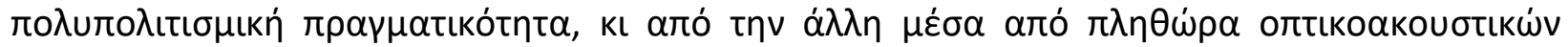

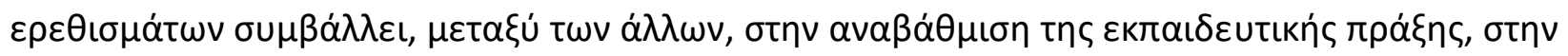

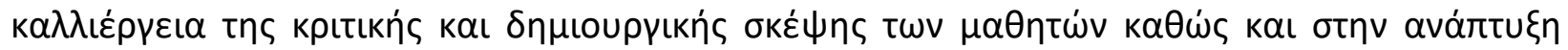

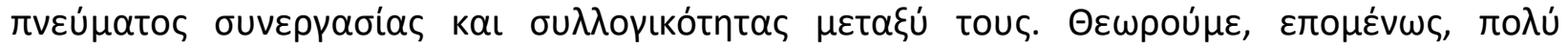

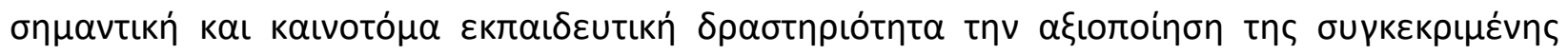

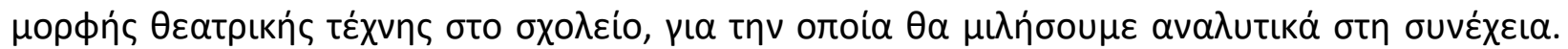

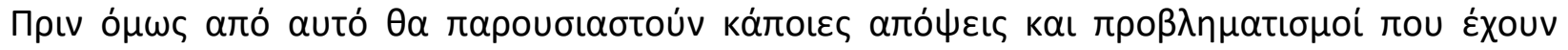

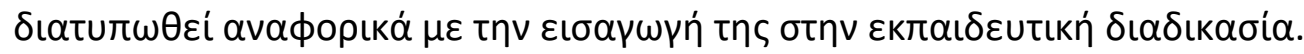

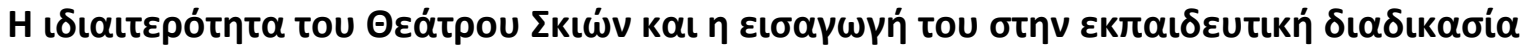

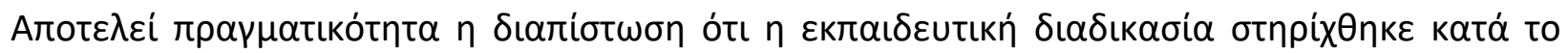

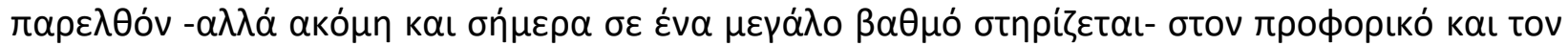

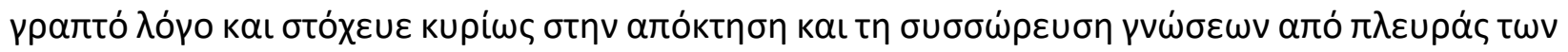

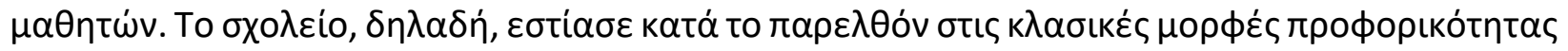

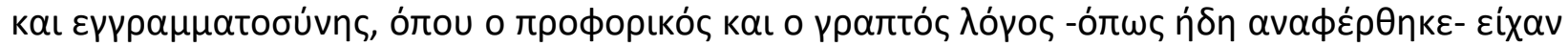

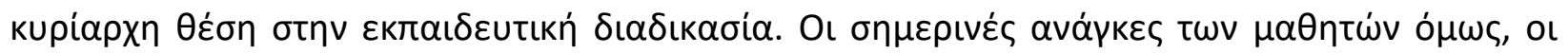

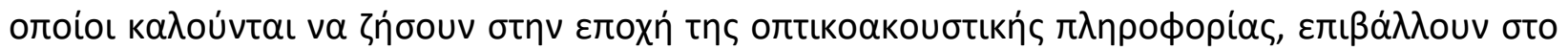


MULTILINGUAL ACADEMIC JOURNAL OF EDUCATION AND SOCIAL SCIENCES

Vol. 5 No. 1, 2017, E-ISSN: 2308-0876 @ 2017 KWP

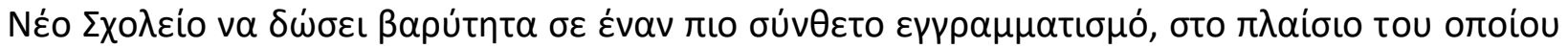

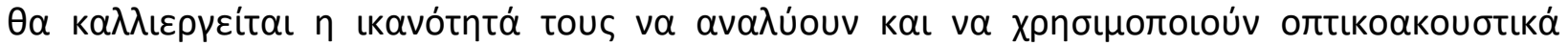

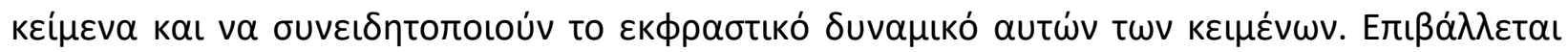

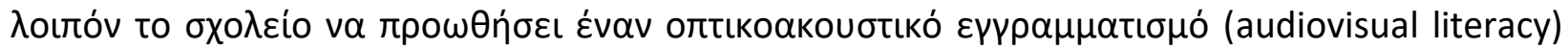

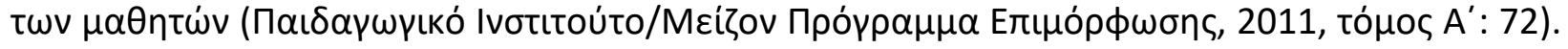

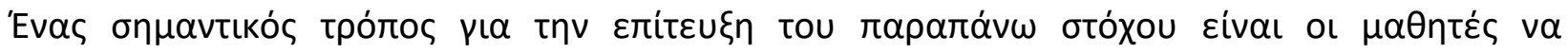

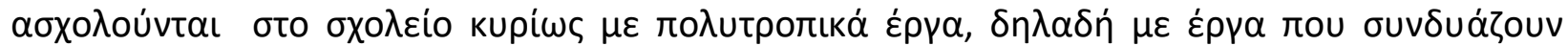

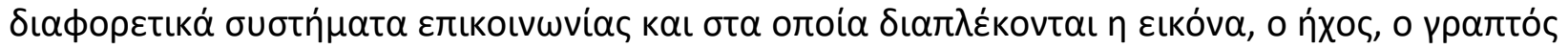

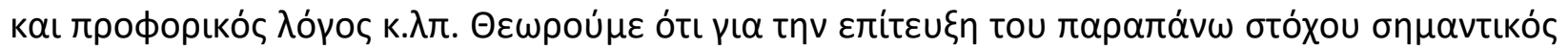

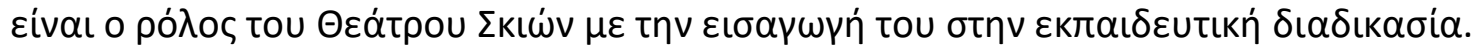

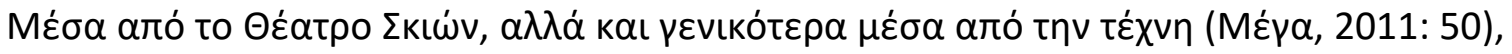

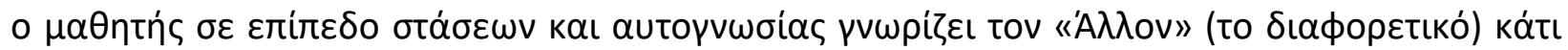

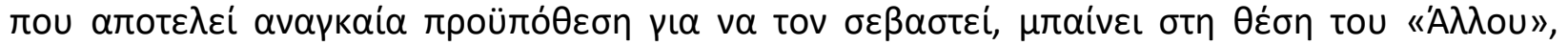

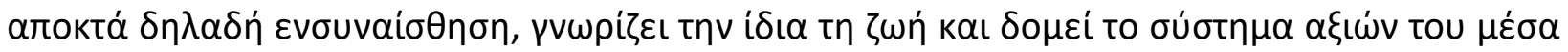

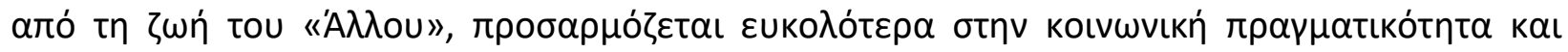

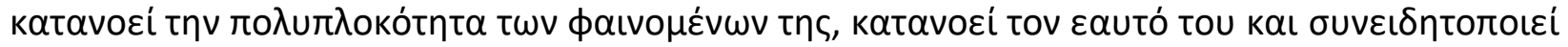

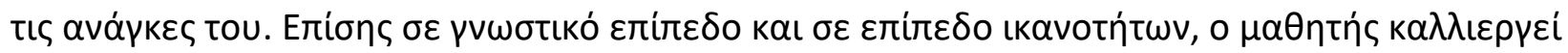

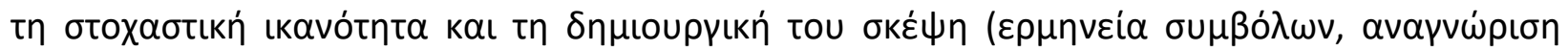

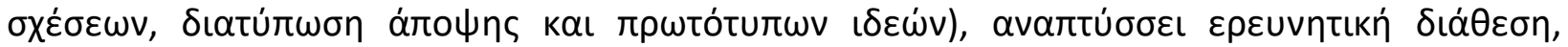

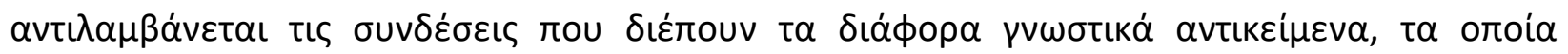

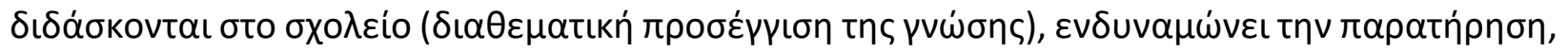

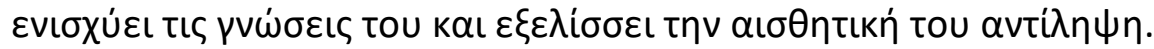

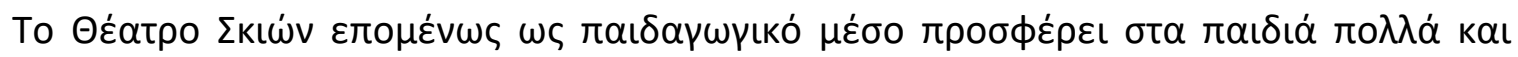

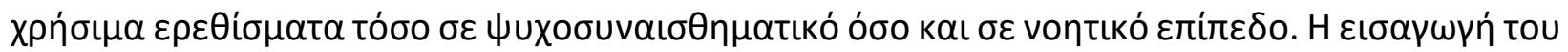

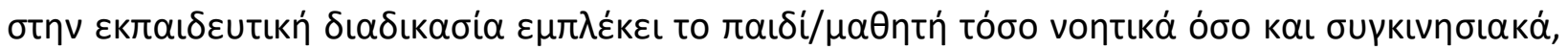

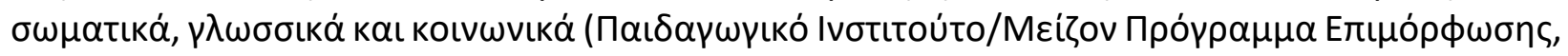

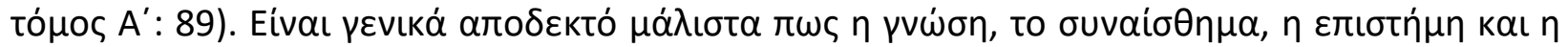

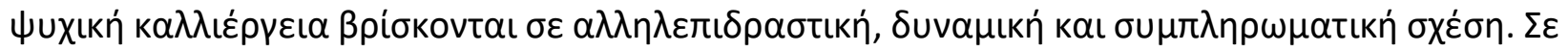

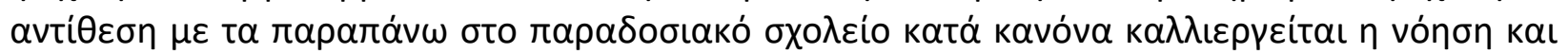

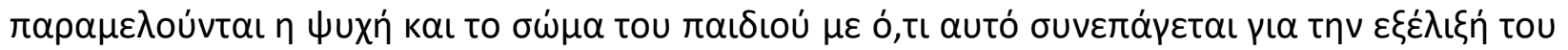

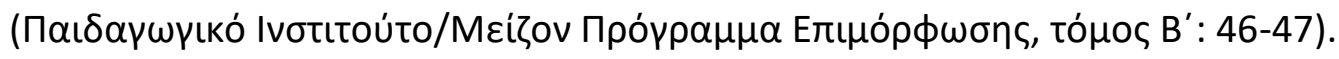

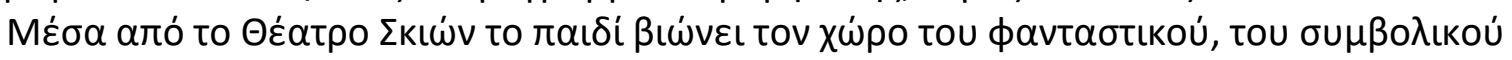

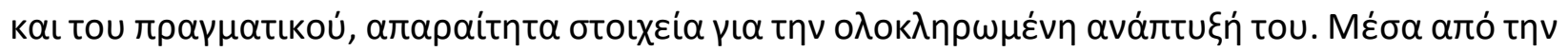

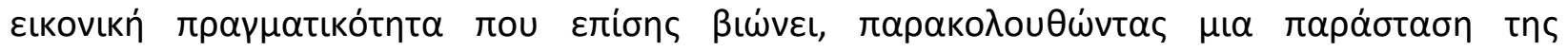

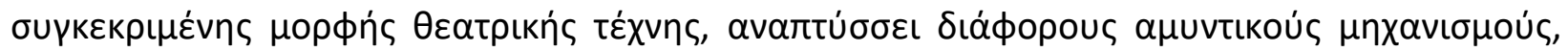
о́

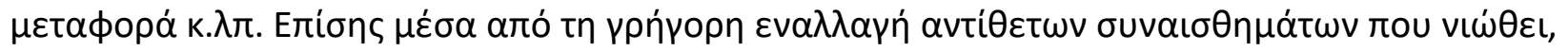

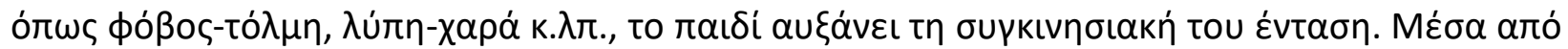

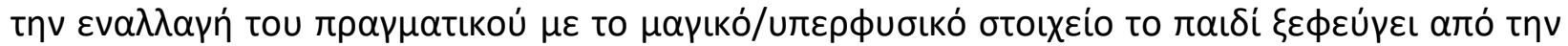

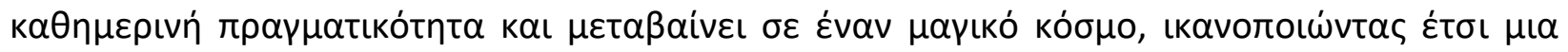

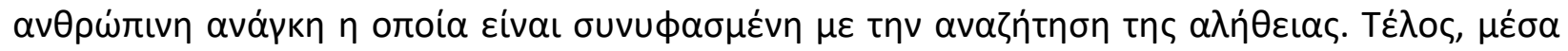

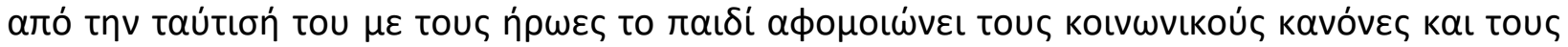

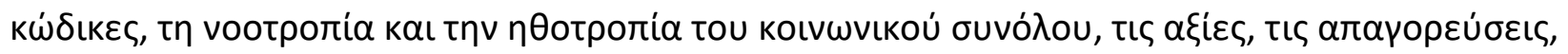

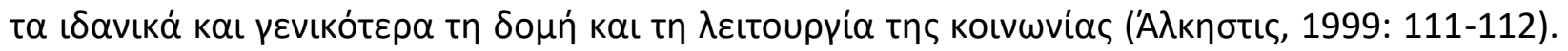


MULTILINGUAL ACADEMIC JOURNAL OF EDUCATION AND SOCIAL SCIENCES

Vol. 5 No. 1, 2017, E-ISSN: 2308-0876 @ 2017 KWP

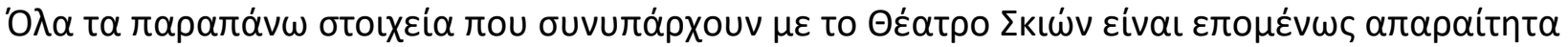

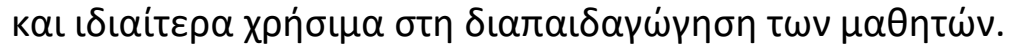

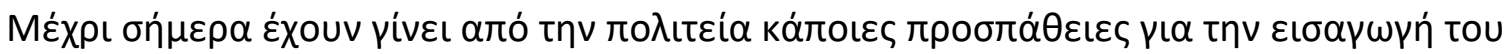

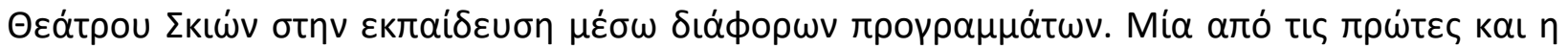

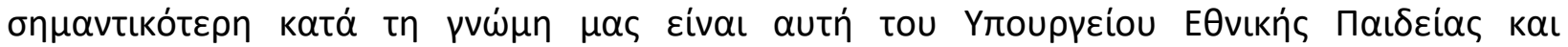

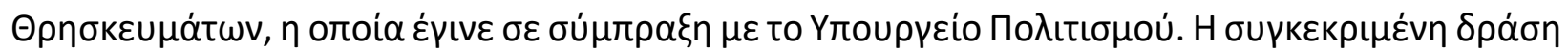

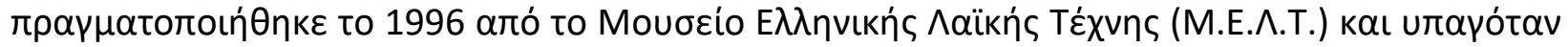

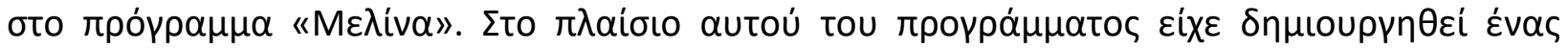

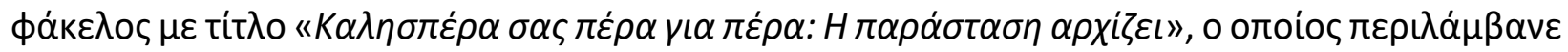

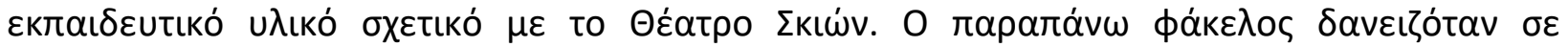

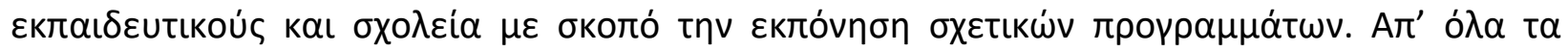

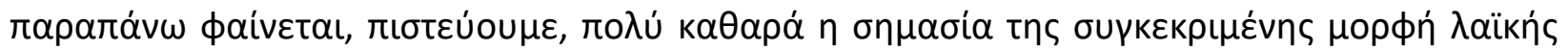

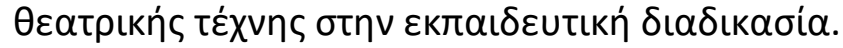

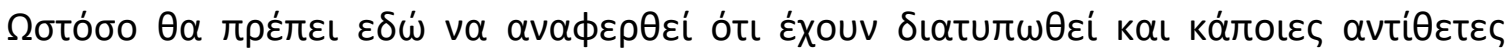

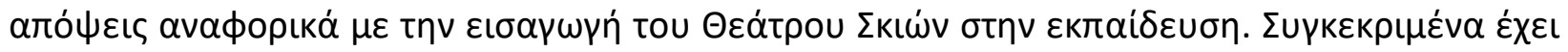

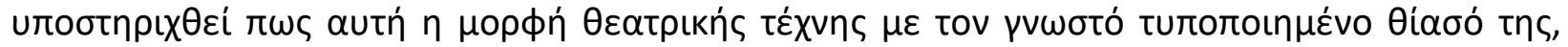

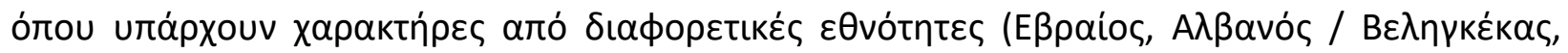

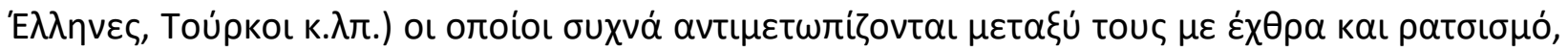

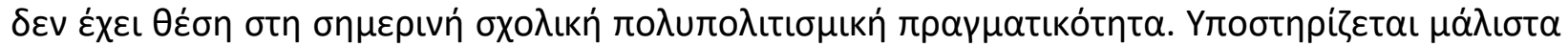

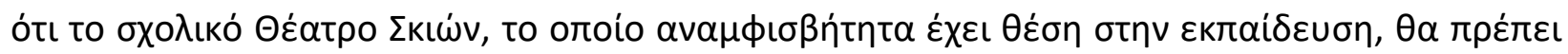

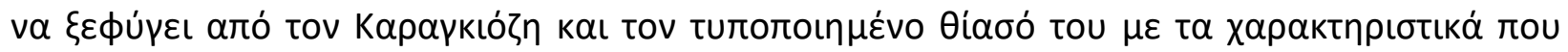

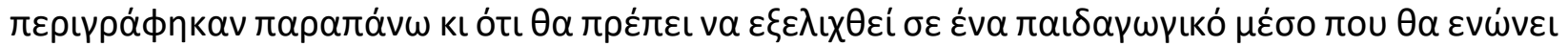

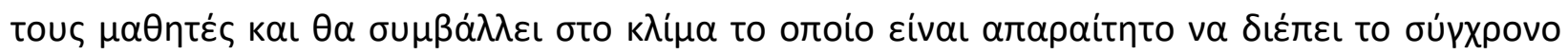

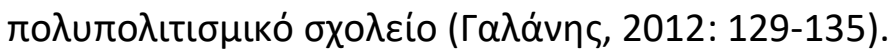

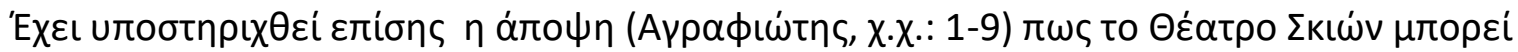

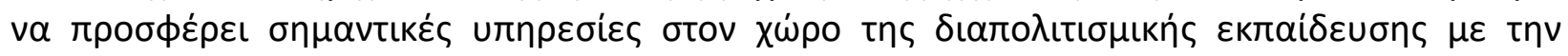

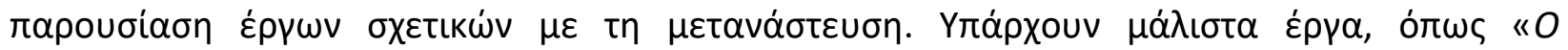

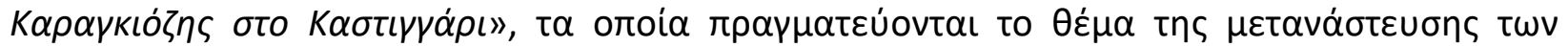

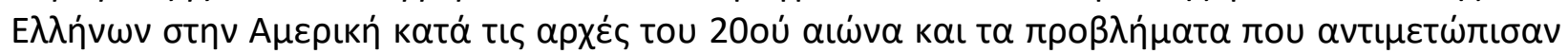

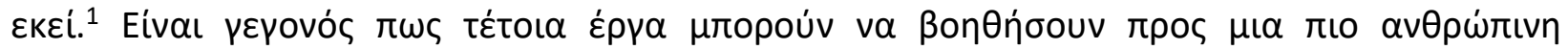

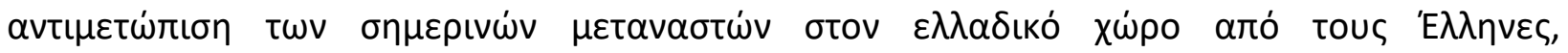

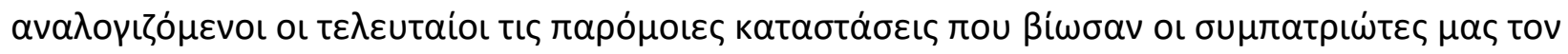

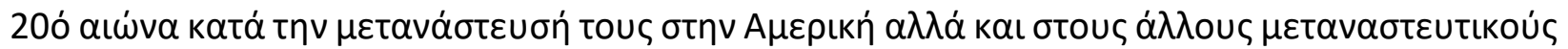

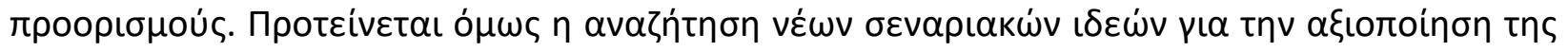

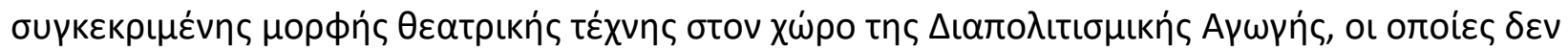

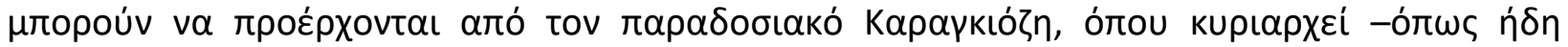

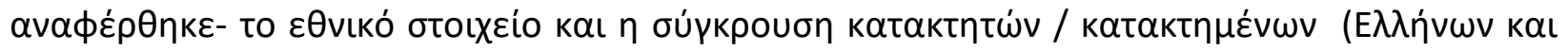

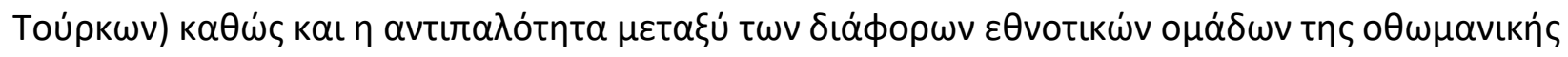
aчтократоріас.

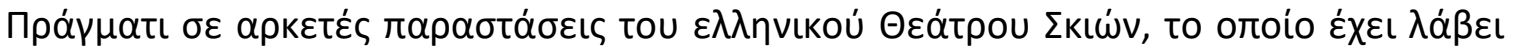

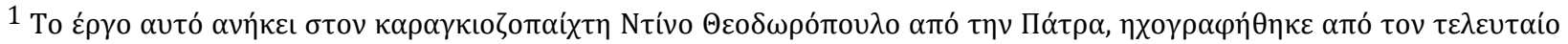

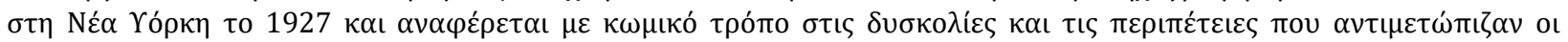

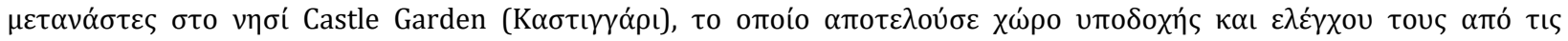
$\alpha \mu \varepsilon \rho \iota \kappa \alpha \nu \iota \kappa \varepsilon ́ \varsigma$ $\alpha \rho \chi \varepsilon ́ \varsigma$.
} 
MULTILINGUAL ACADEMIC JOURNAL OF EDUCATION AND SOCIAL SCIENCES

Vol. 5 No. 1, 2017, E-ISSN: 2308-0876 @ 2017 KWP

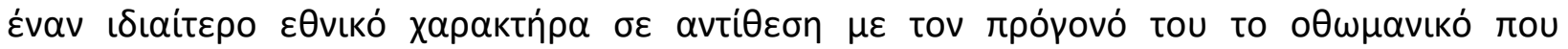

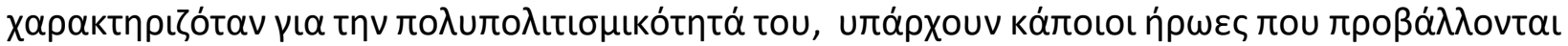

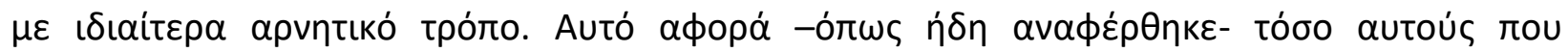

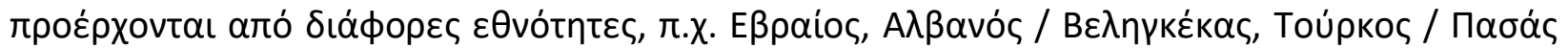

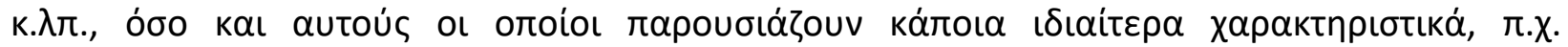

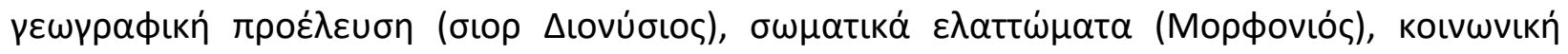

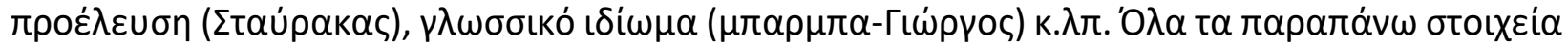

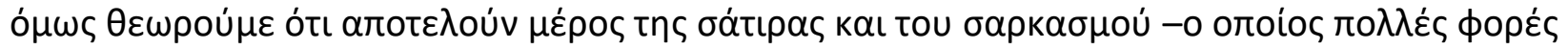

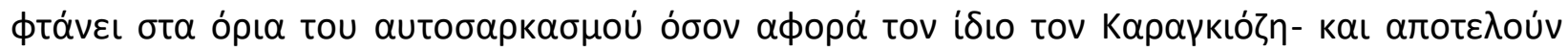

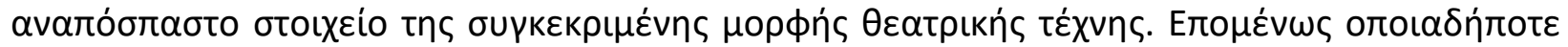

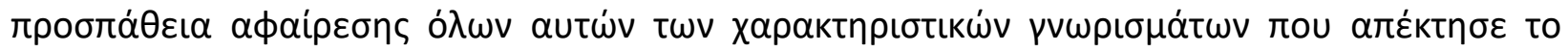

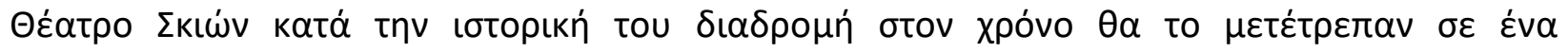

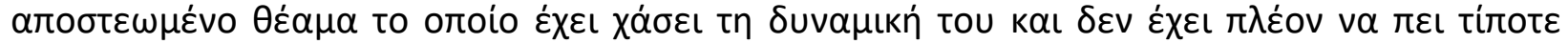

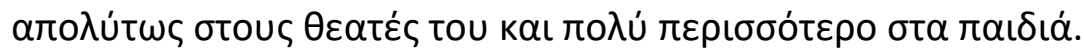

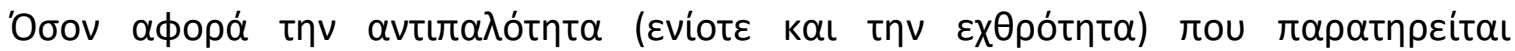

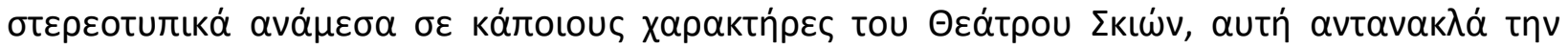

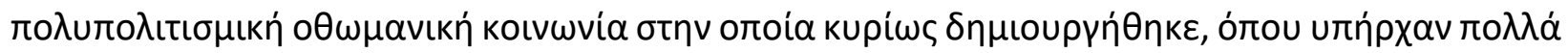

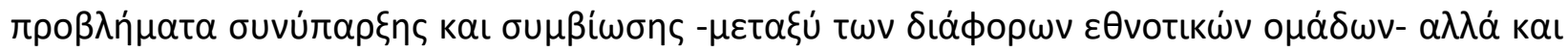

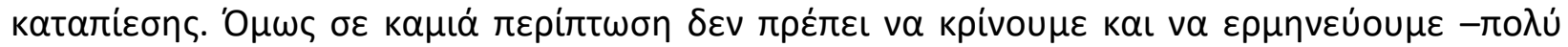

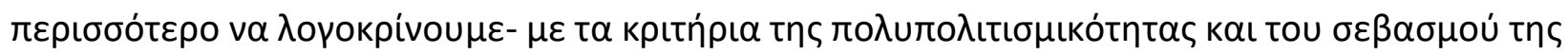

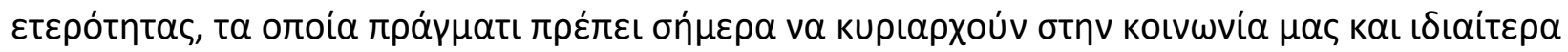

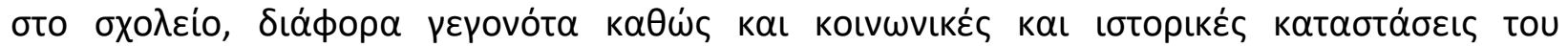

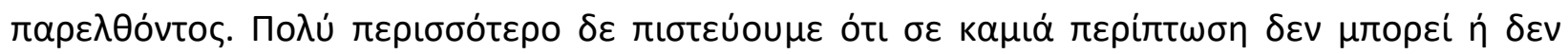

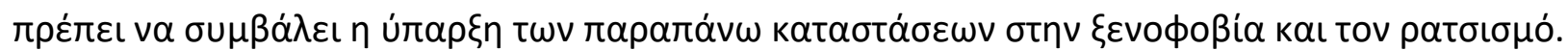

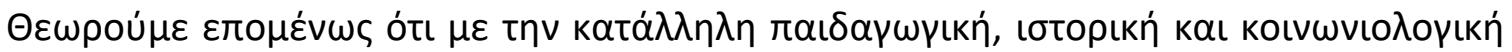

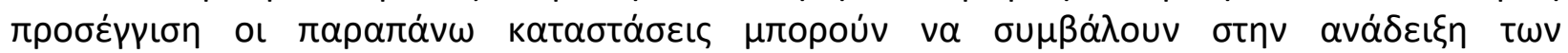

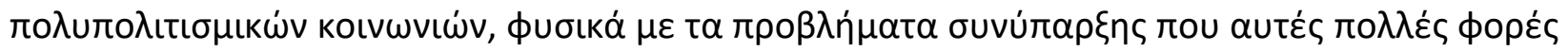

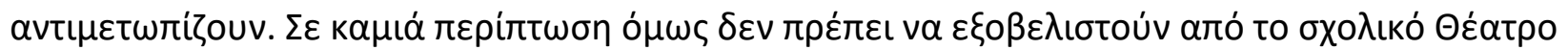

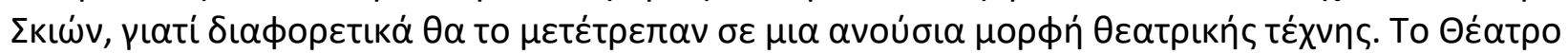

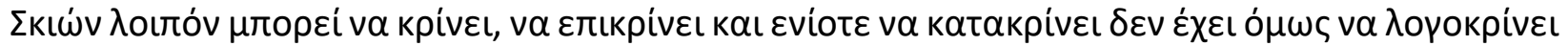

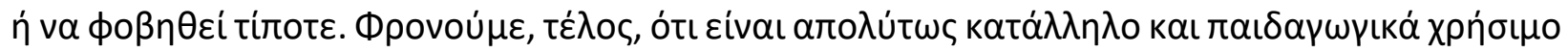

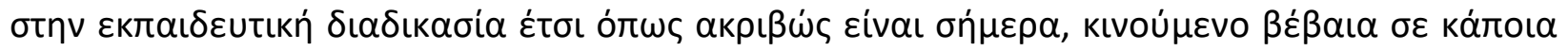

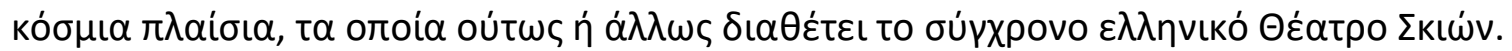

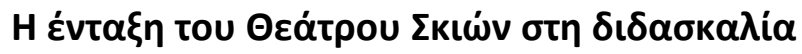

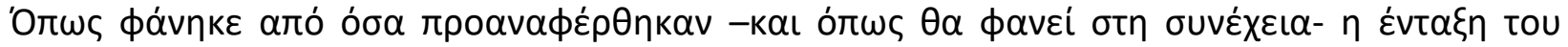

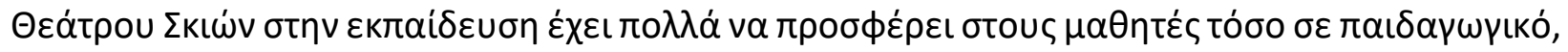

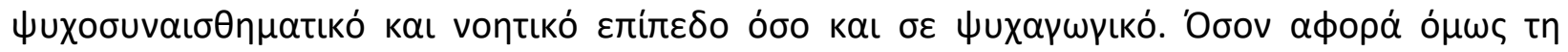

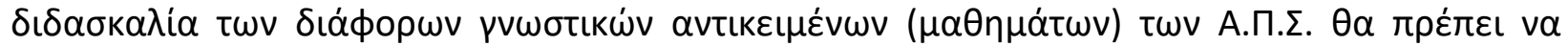

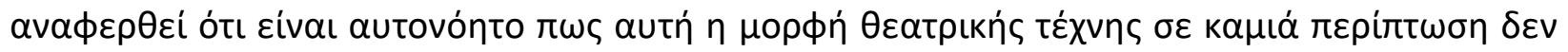

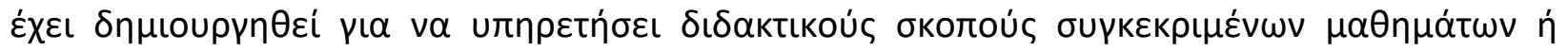

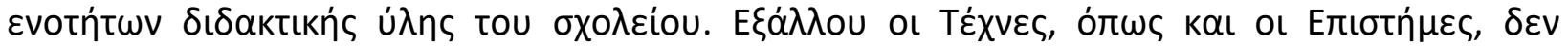

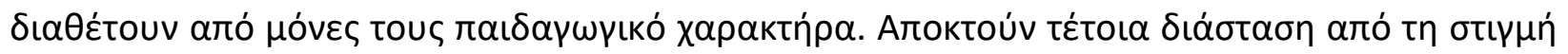

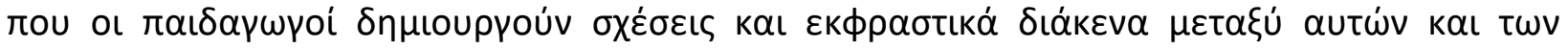


MULTILINGUAL ACADEMIC JOURNAL OF EDUCATION AND SOCIAL SCIENCES

Vol. 5 No. 1, 2017, E-ISSN: 2308-0876 @ 2017 KWP

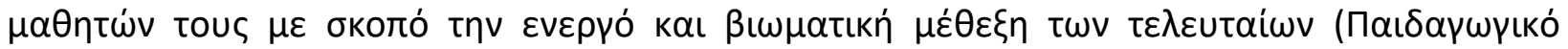

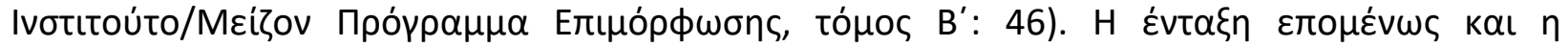

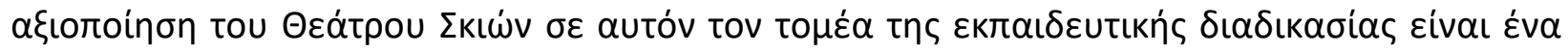

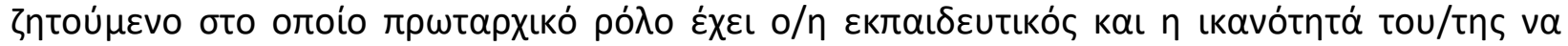

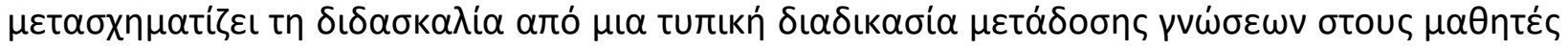

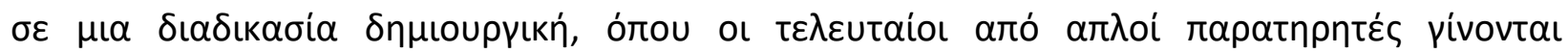

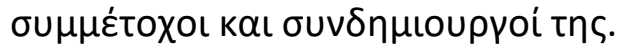

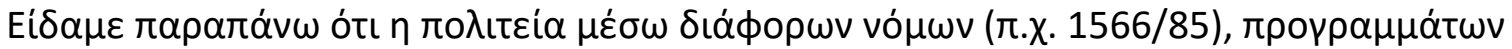

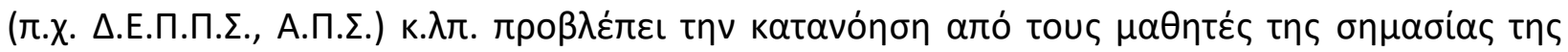

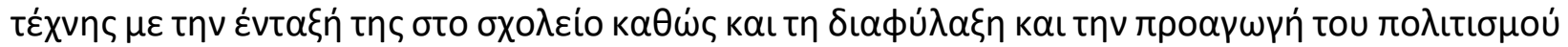

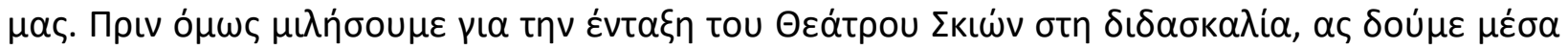

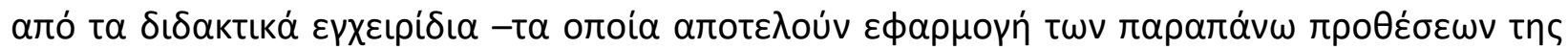

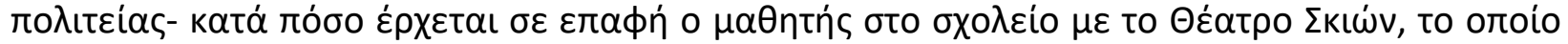
$\alpha v \alpha \mu \phi ı \sigma \eta \dot{\tau} \tau \alpha$ a

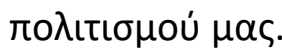

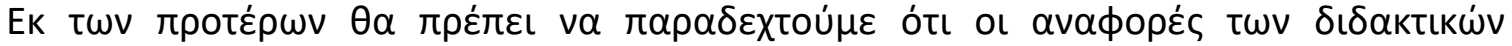

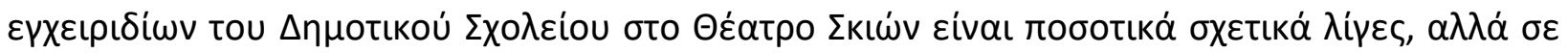

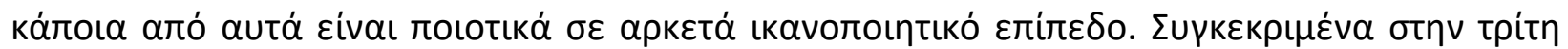

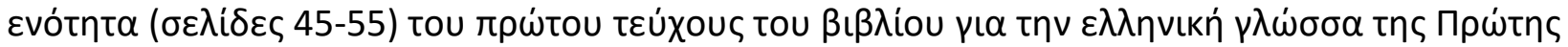

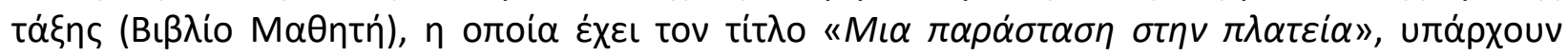

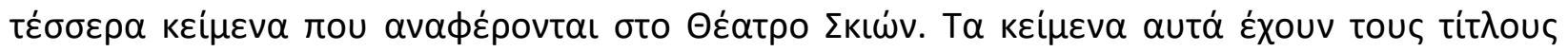

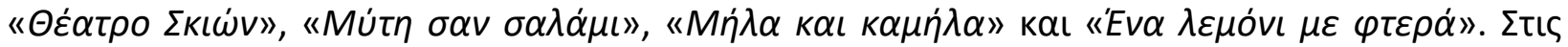

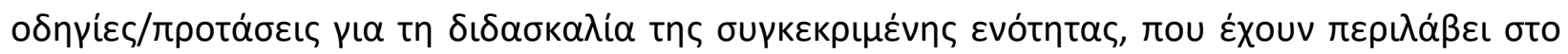

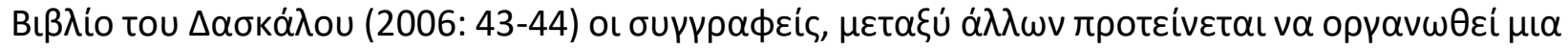

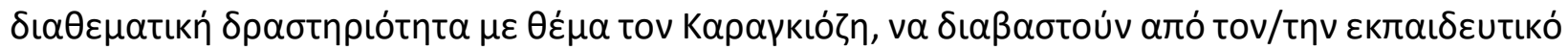

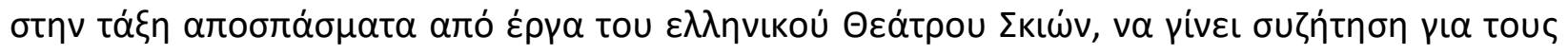

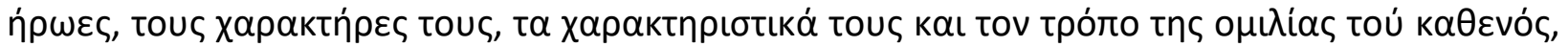

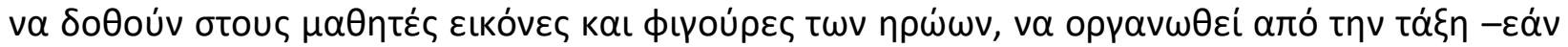

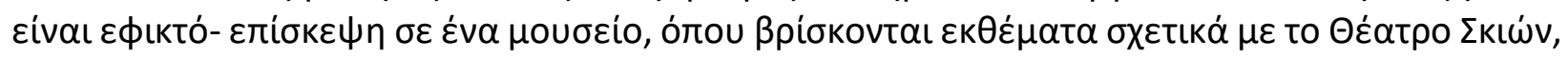

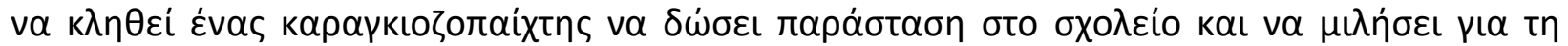

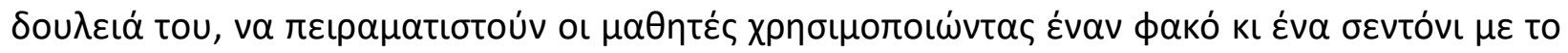

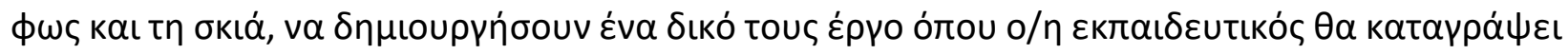

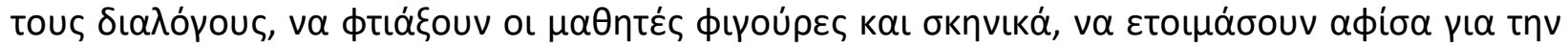

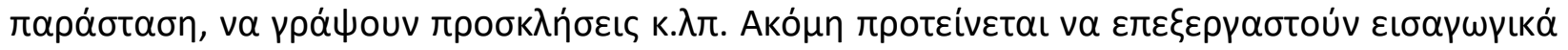

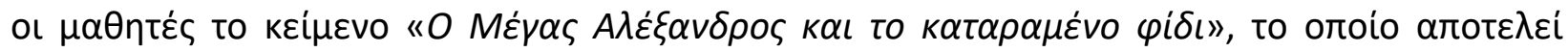

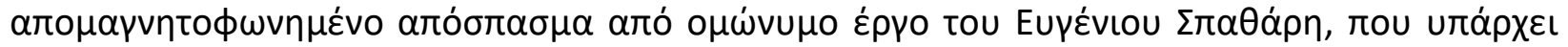

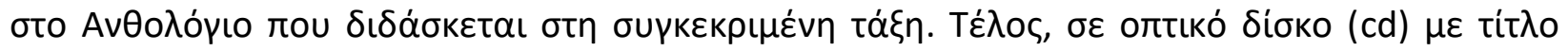

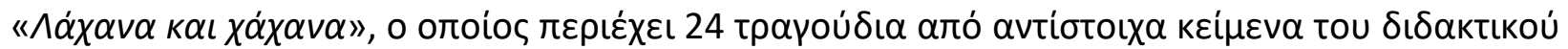

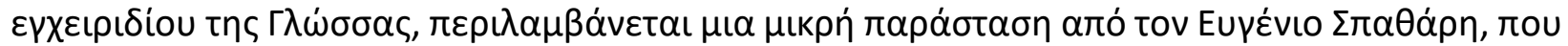

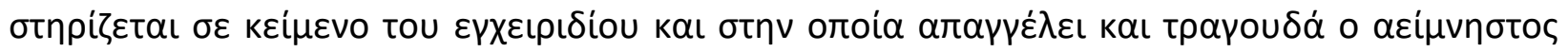

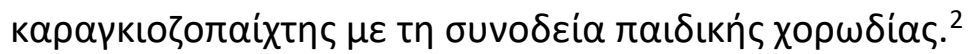

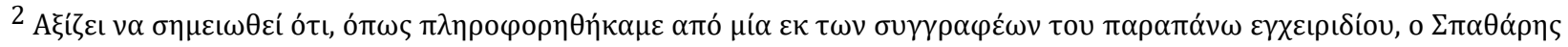

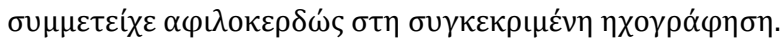


MULTILINGUAL ACADEMIC JOURNAL OF EDUCATION AND SOCIAL SCIENCES

Vol. 5 No. 1, 2017, E-ISSN: 2308-0876 @ 2017 KWP

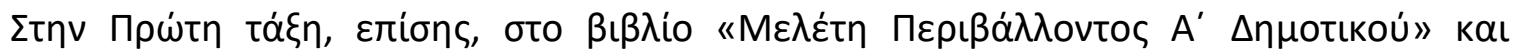

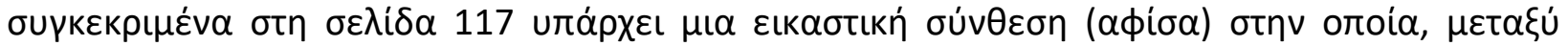

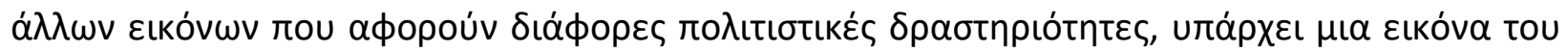

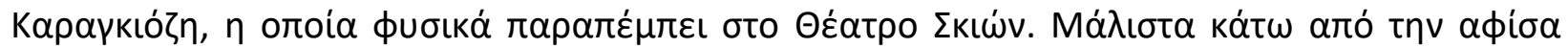

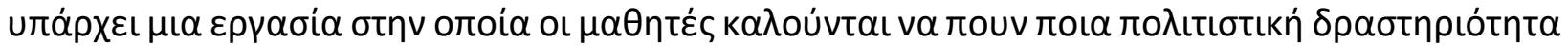

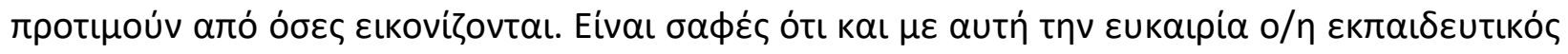

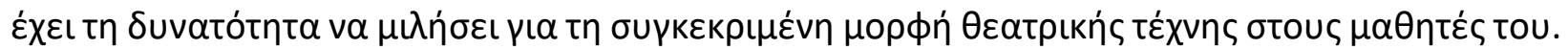

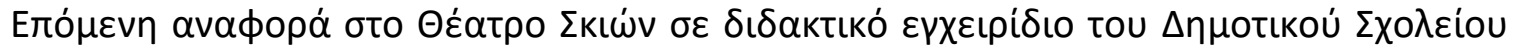

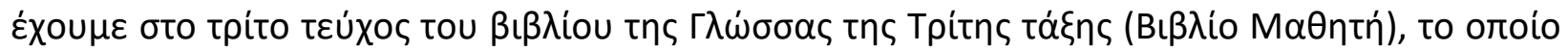

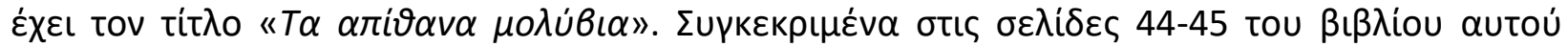

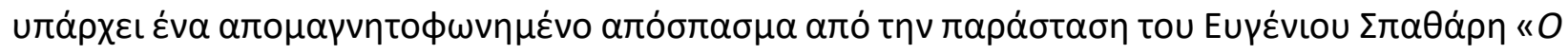

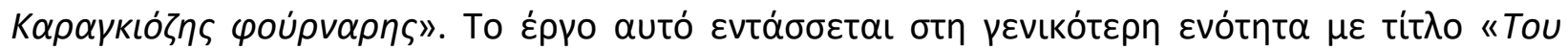

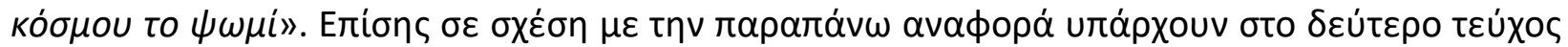

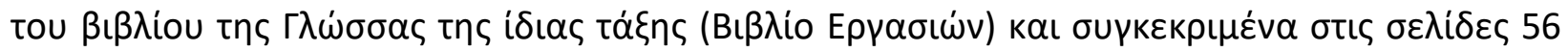

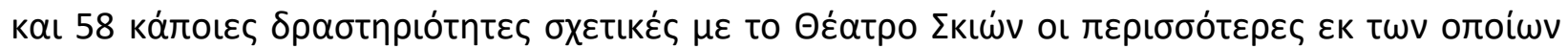

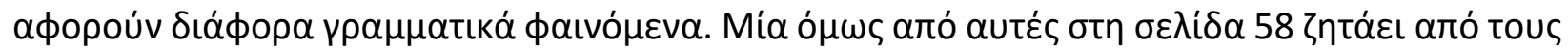

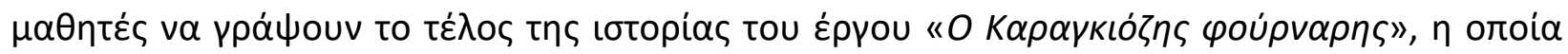

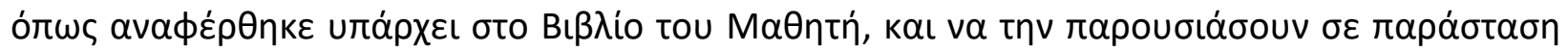

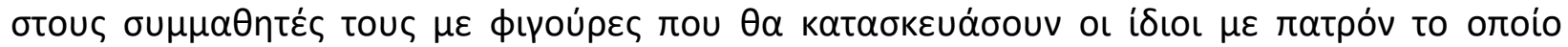

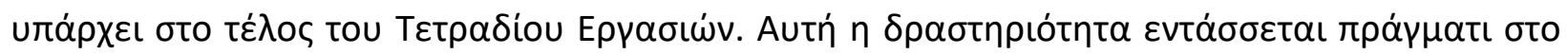

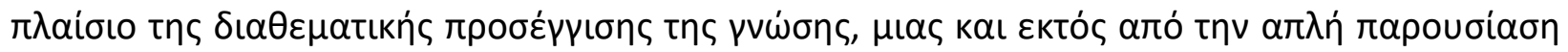

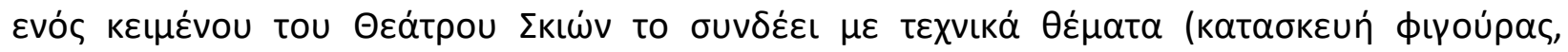

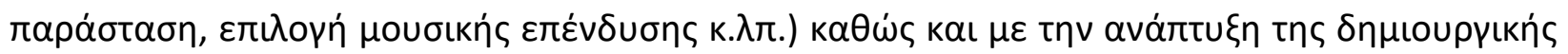

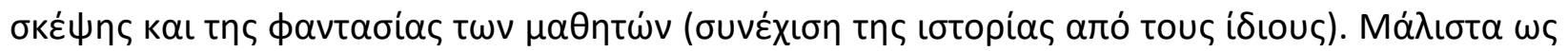

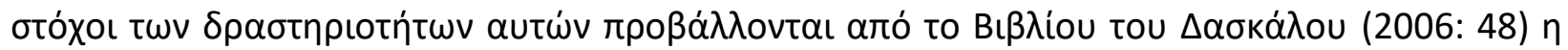

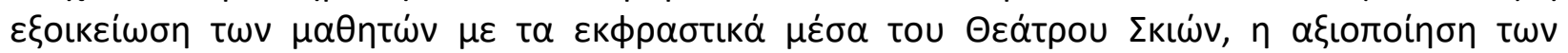

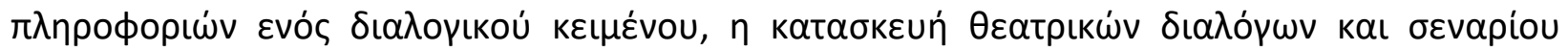

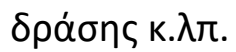

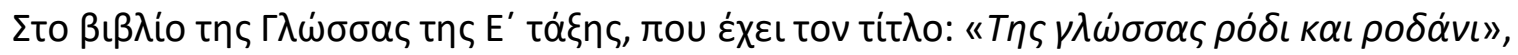

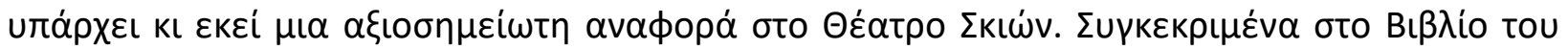

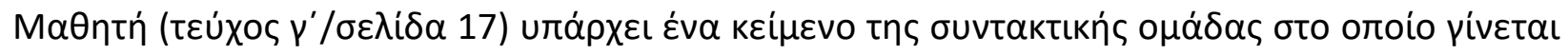

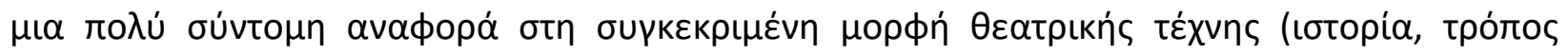

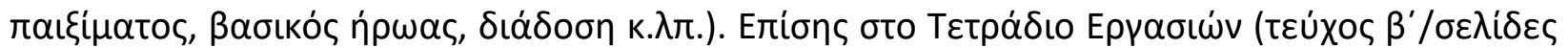

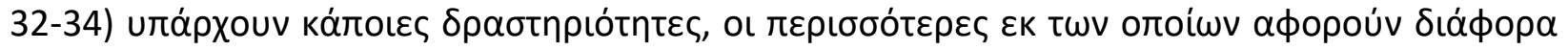

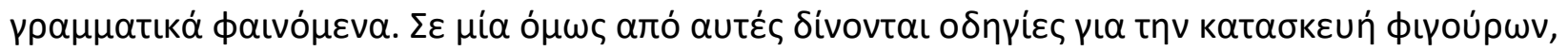

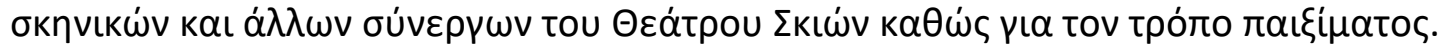

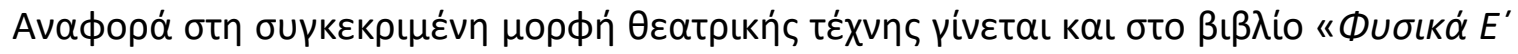

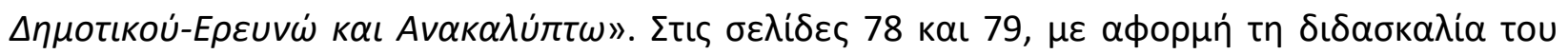

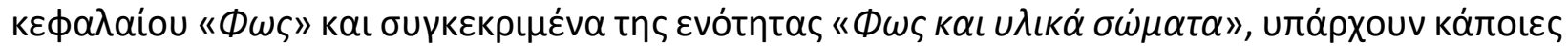

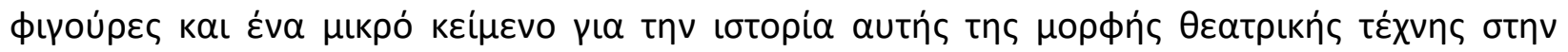

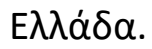

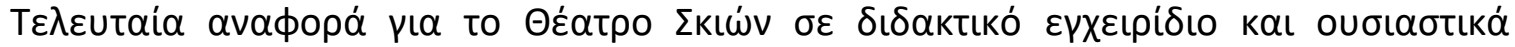

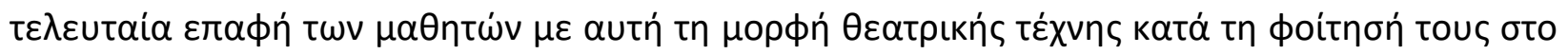

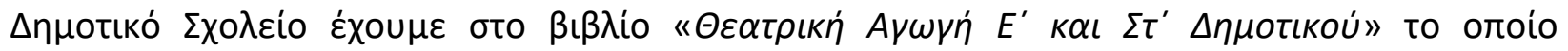


MULTILINGUAL ACADEMIC JOURNAL OF EDUCATION AND SOCIAL SCIENCES

Vol. 5 No. 1, 2017, E-ISSN: 2308-0876 @ 2017 KWP

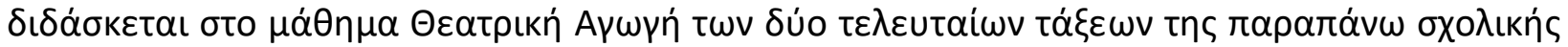

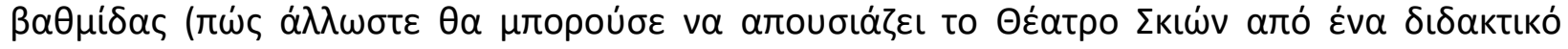

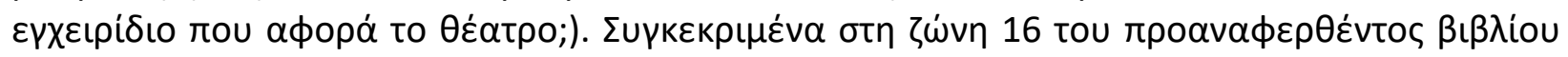

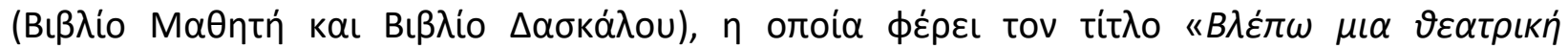

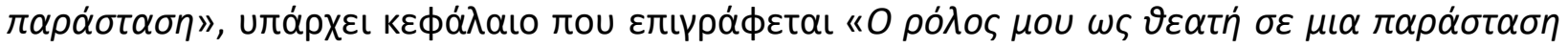

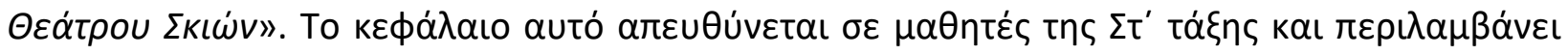

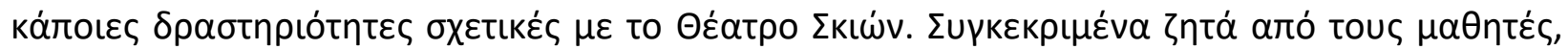

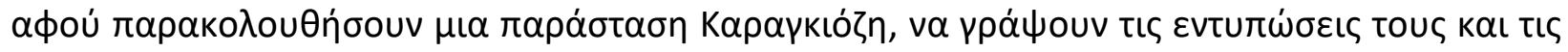

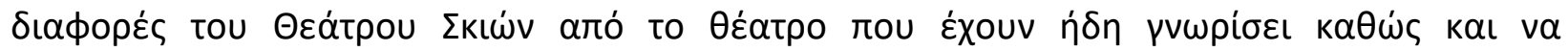

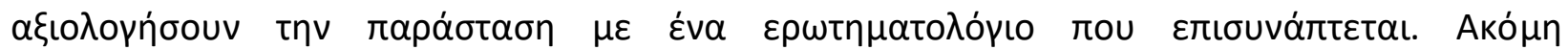

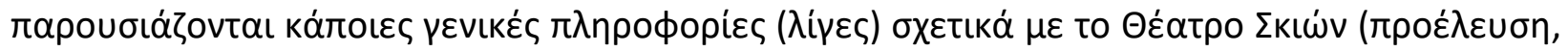

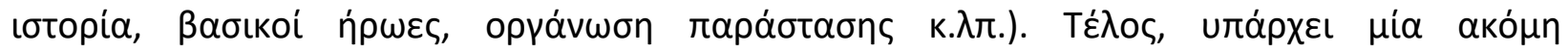

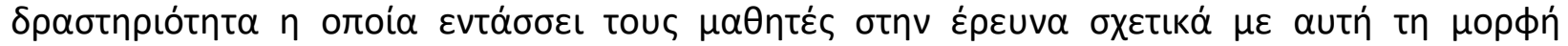

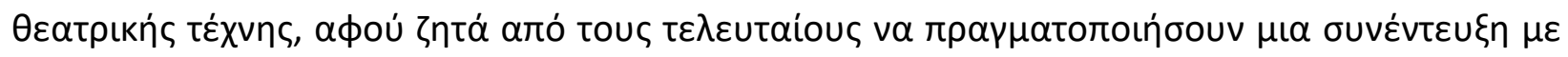

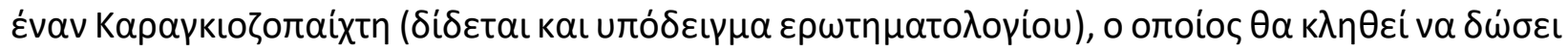

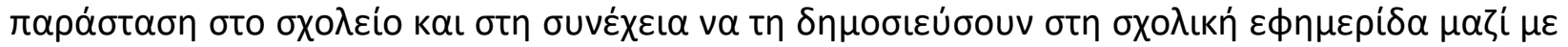

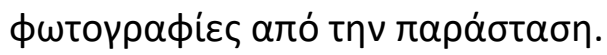

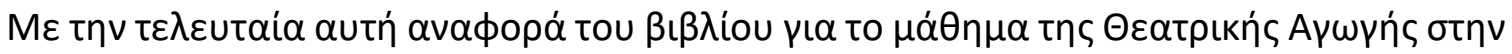

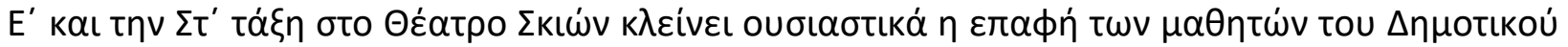

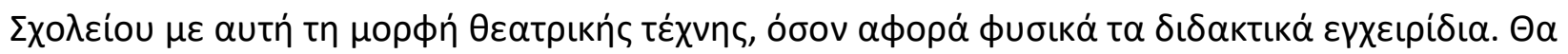

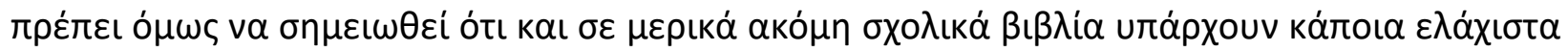

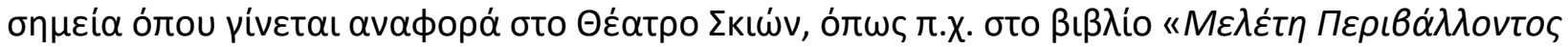

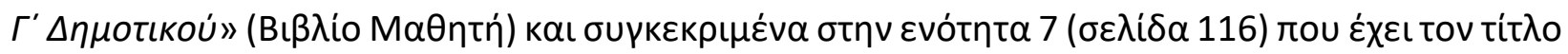

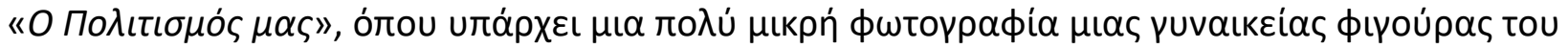

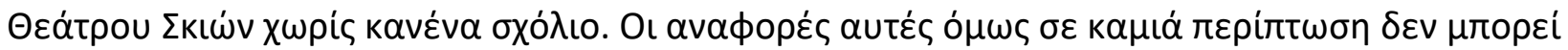

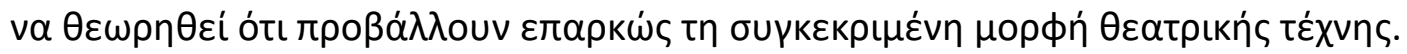

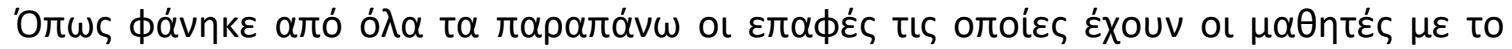

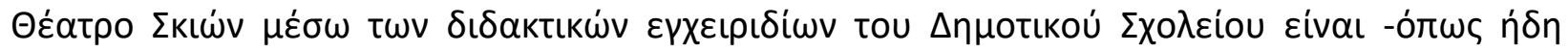

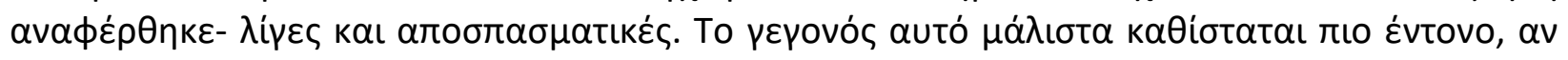

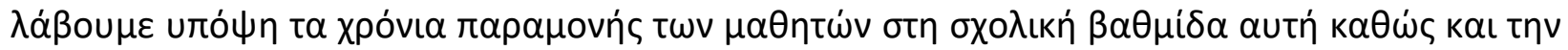

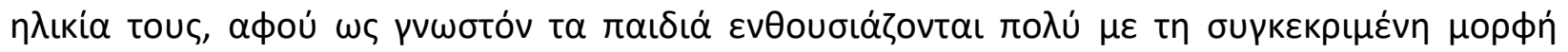

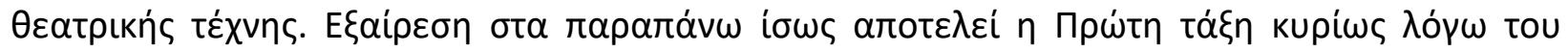

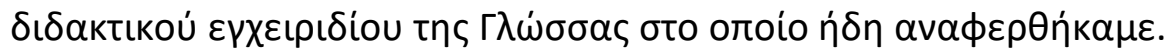

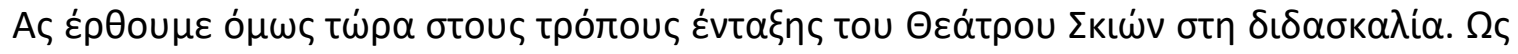

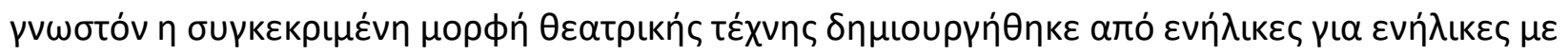

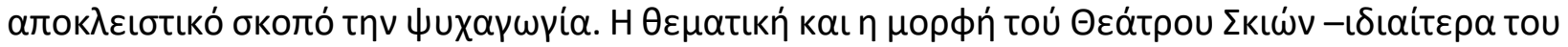

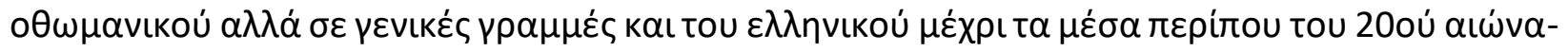

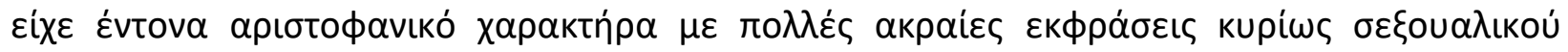

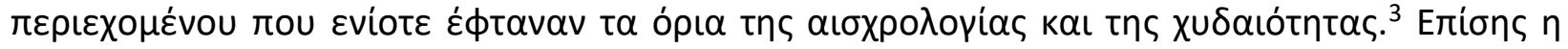

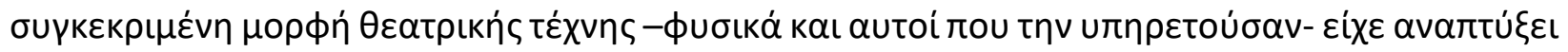

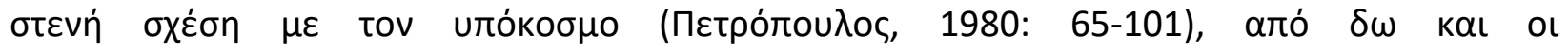

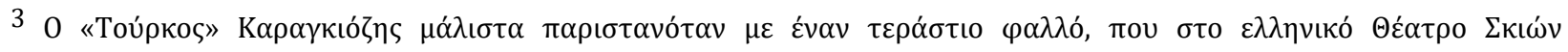

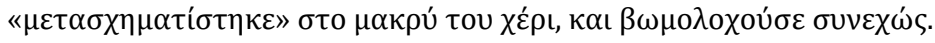




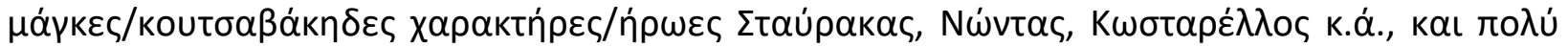

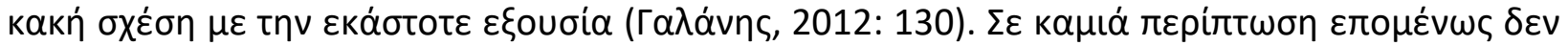

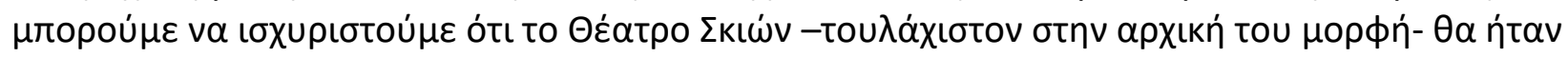

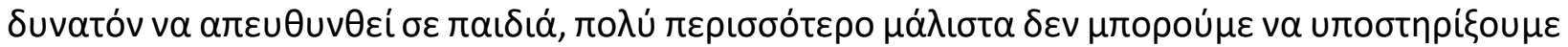

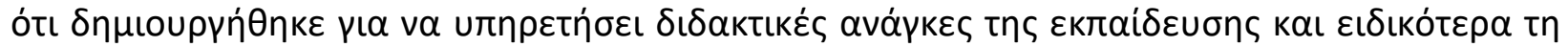

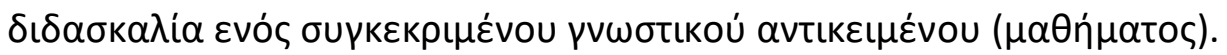

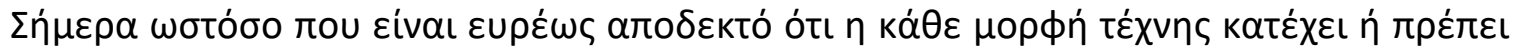

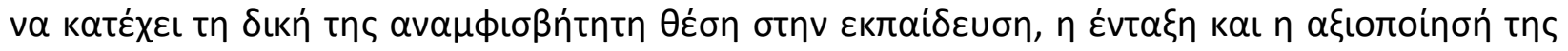

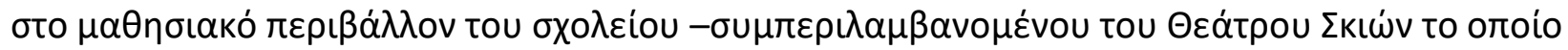

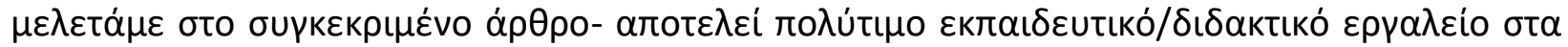

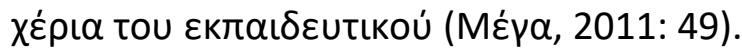

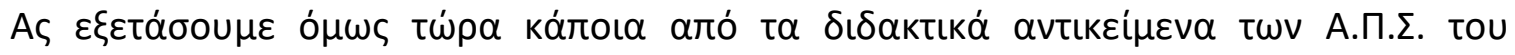

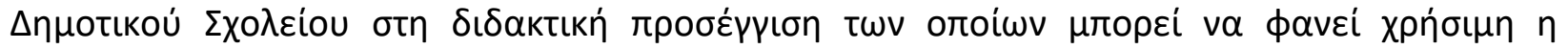

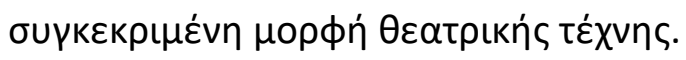

\section{$\Gamma \lambda \dot{\omega} \sigma \sigma \alpha$}

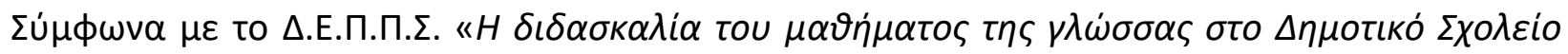

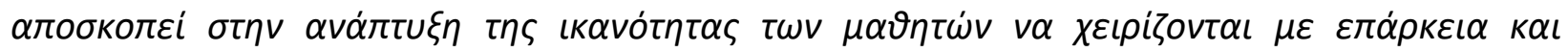

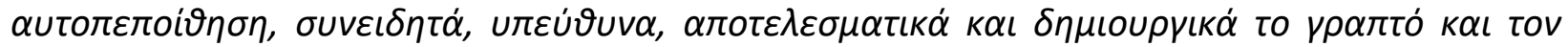

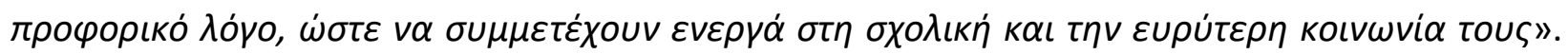

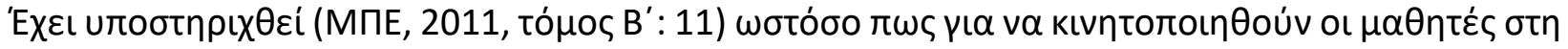

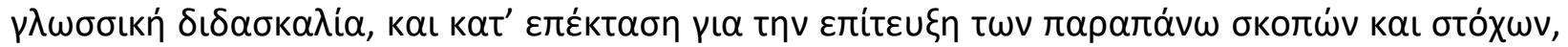

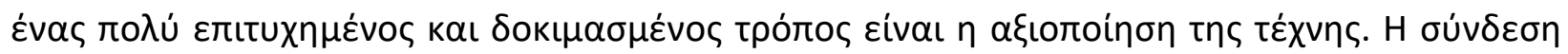

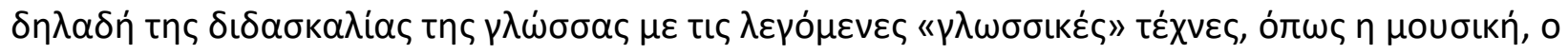

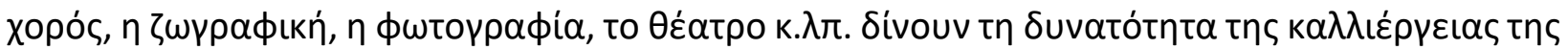

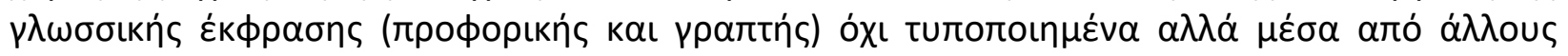

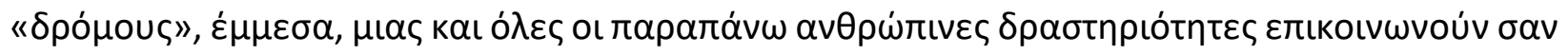

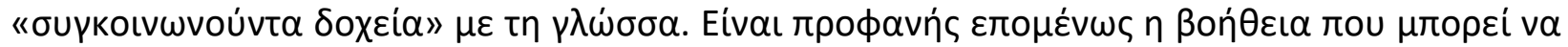

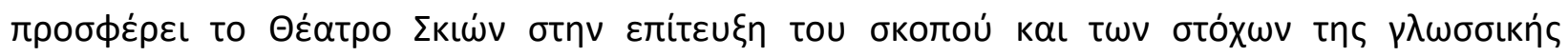

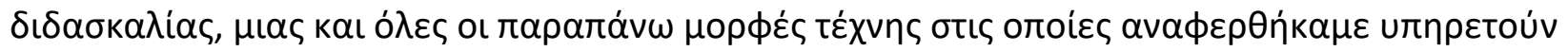

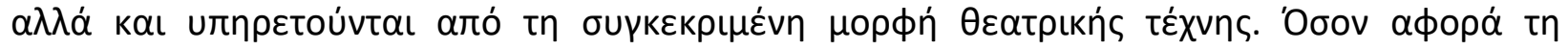

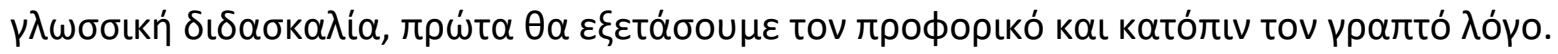

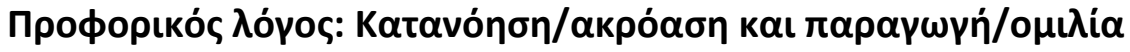

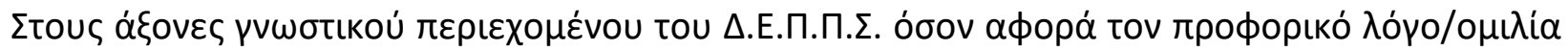

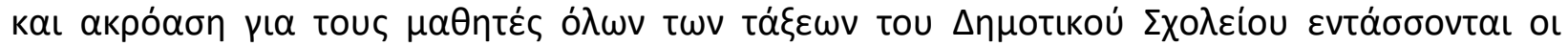

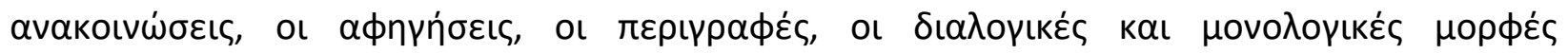

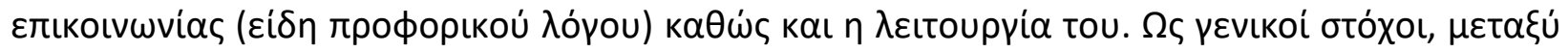

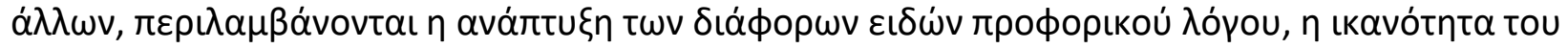

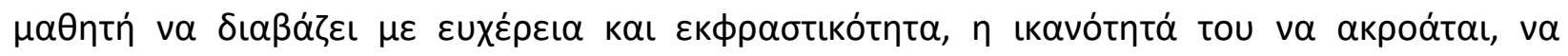

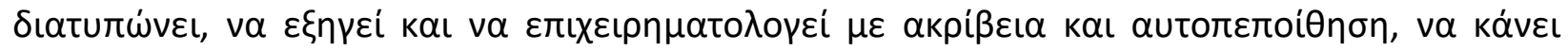

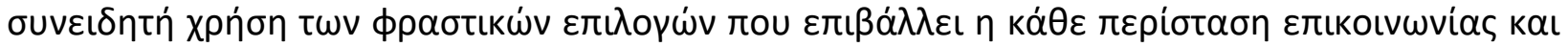

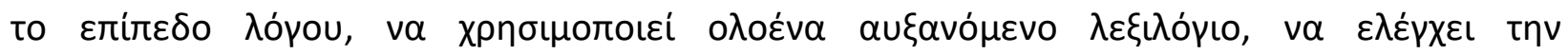

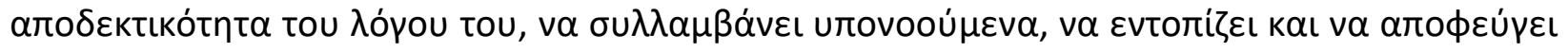


MULTILINGUAL ACADEMIC JOURNAL OF EDUCATION AND SOCIAL SCIENCES

Vol. 5 No. 1, 2017, E-ISSN: 2308-0876 @ 2017 KWP

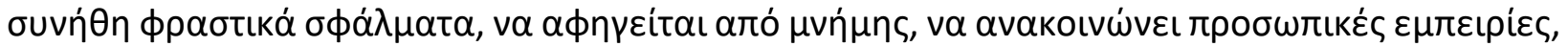

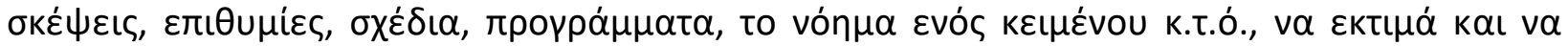

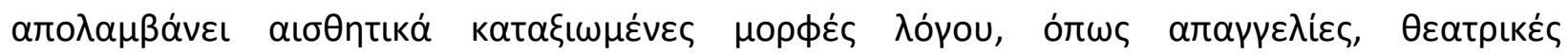

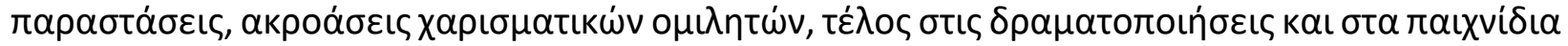

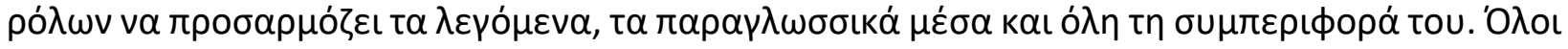

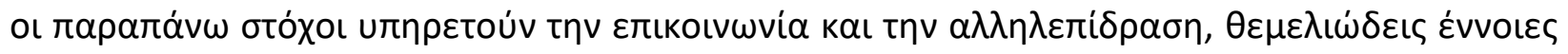

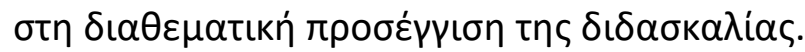

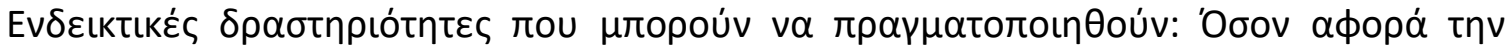

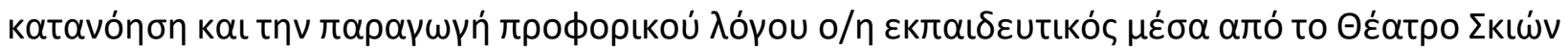

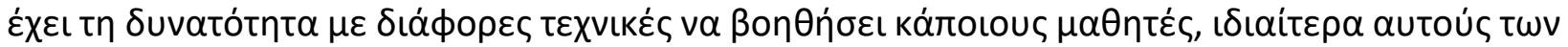

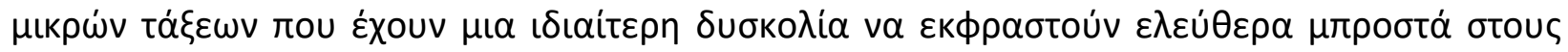

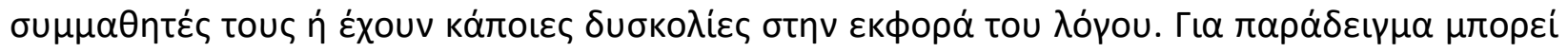

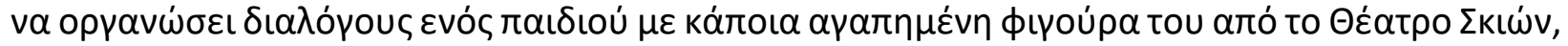

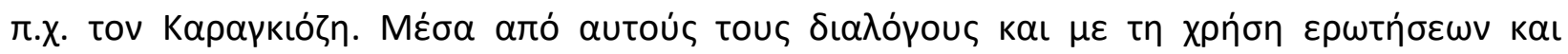

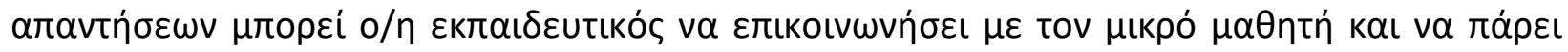

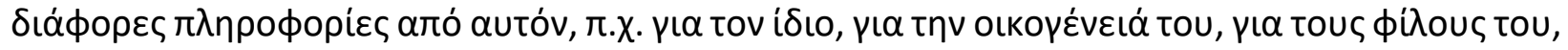

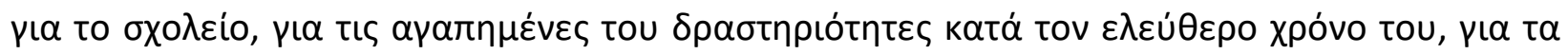

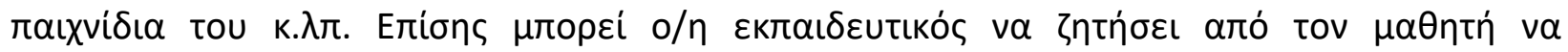

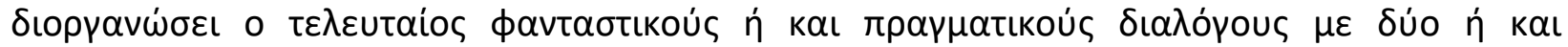

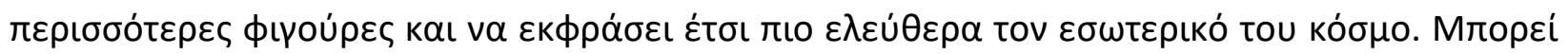

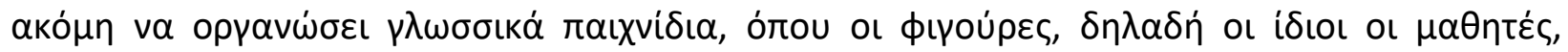

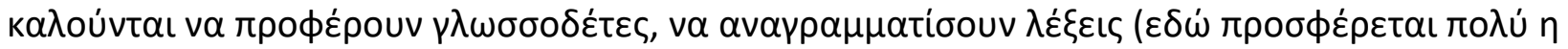

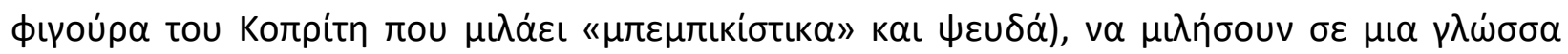

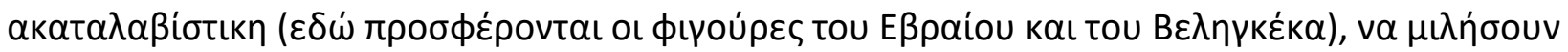

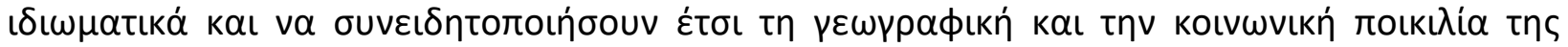

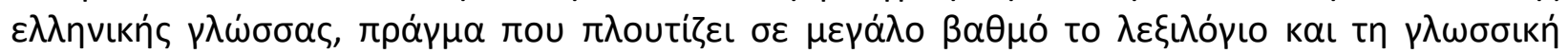

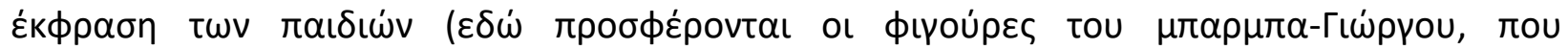

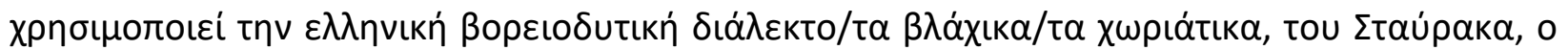

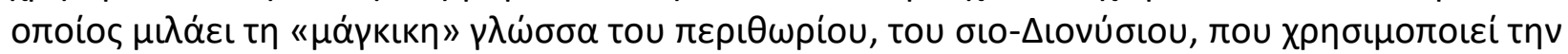

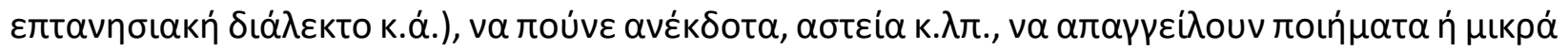

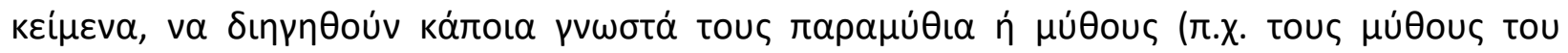

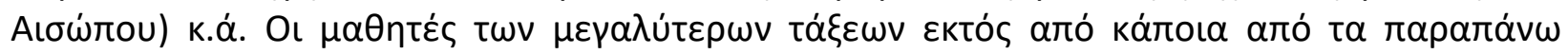

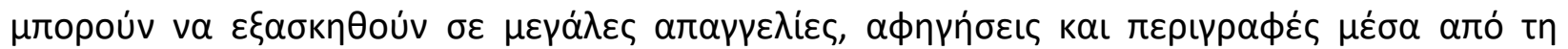

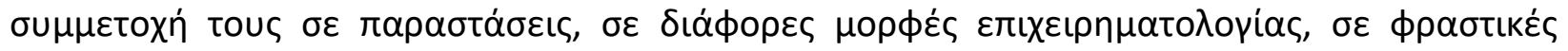

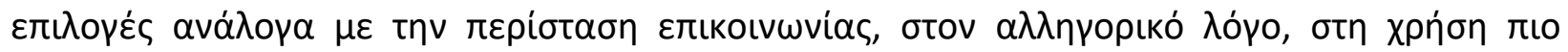

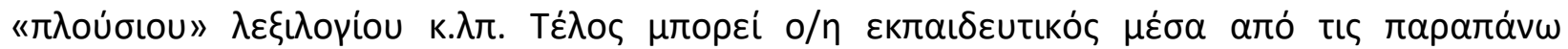

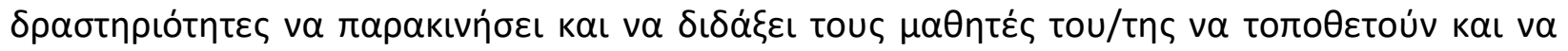

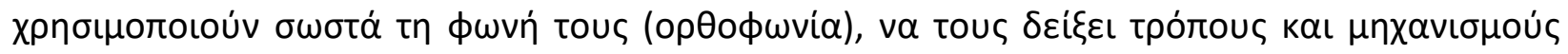

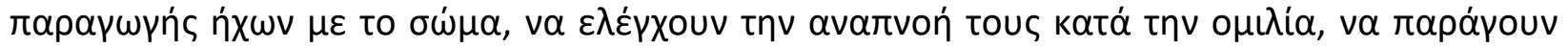

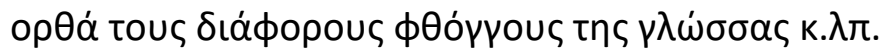

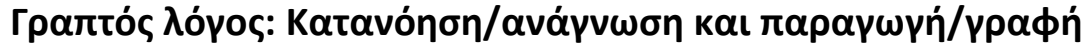

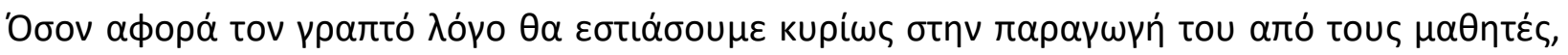

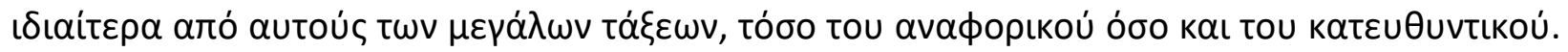


MULTILINGUAL ACADEMIC JOURNAL OF EDUCATION AND SOCIAL SCIENCES

Vol. 5 No. 1, 2017, E-ISSN: 2308-0876 @ 2017 KWP

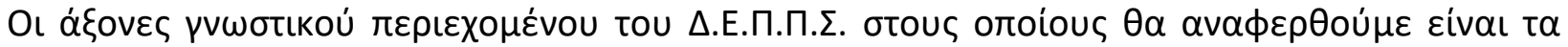

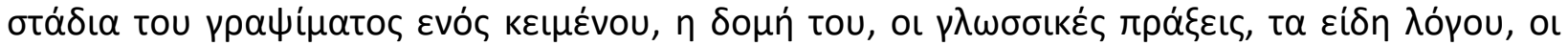

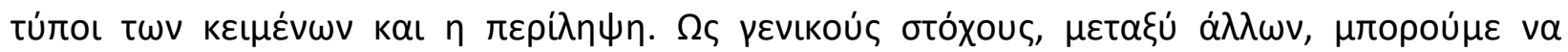

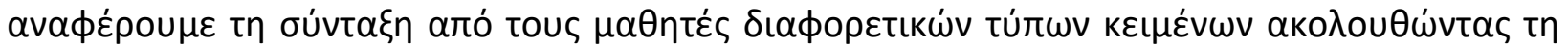

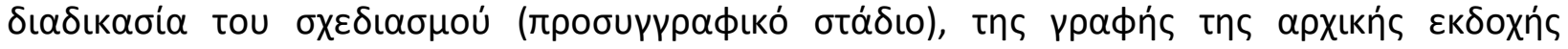

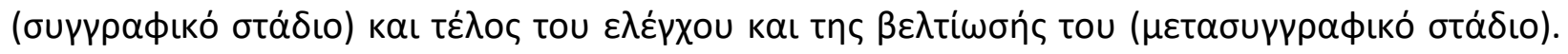

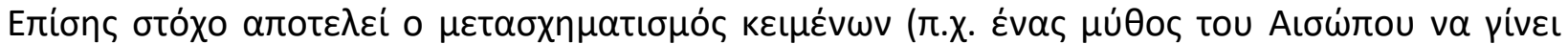

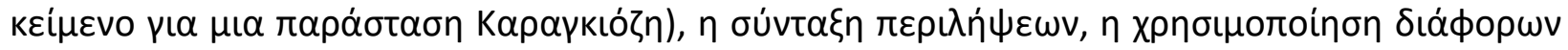

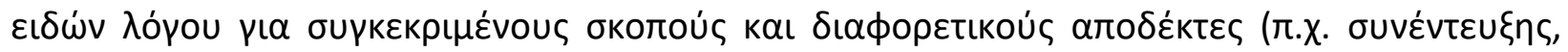

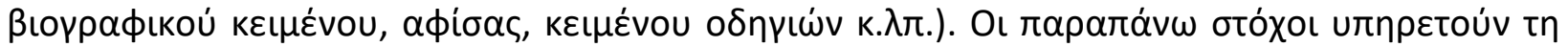

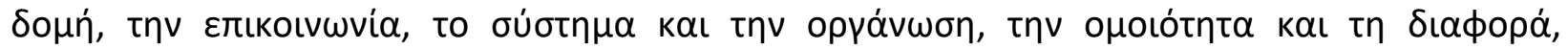

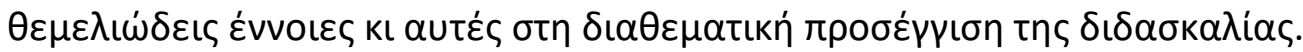

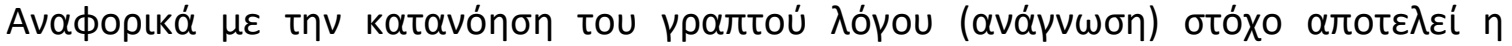

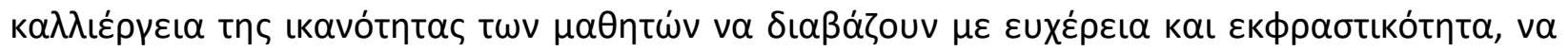

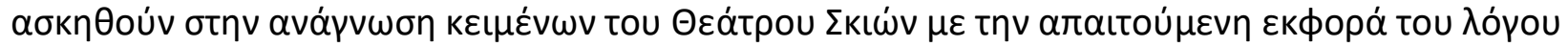

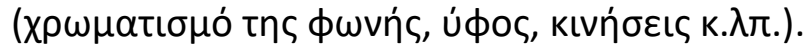

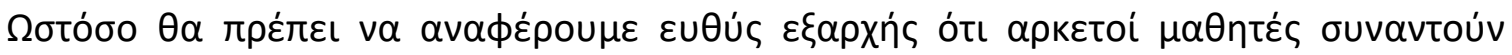

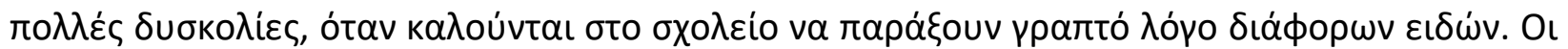

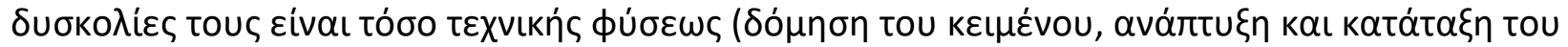

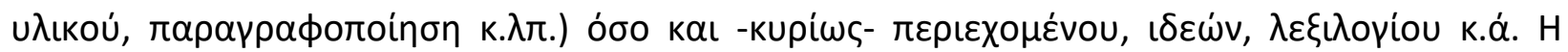

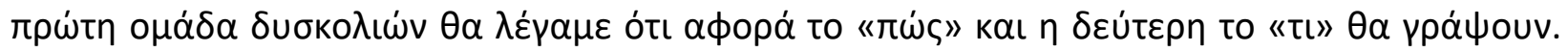

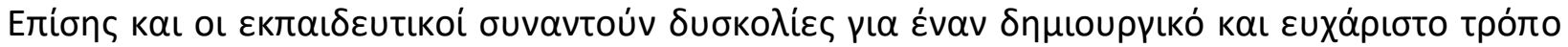

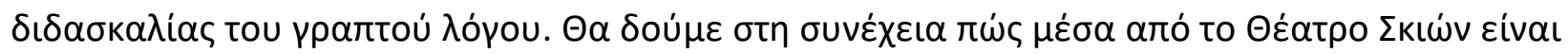

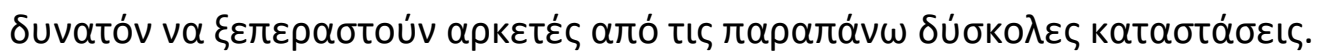

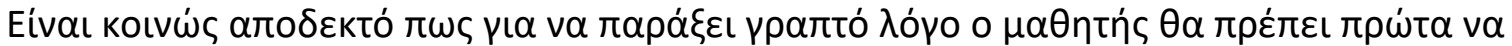

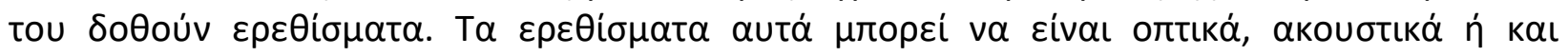

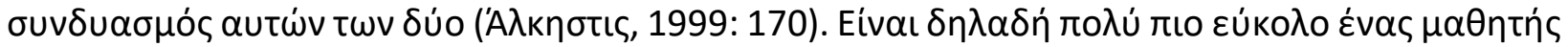

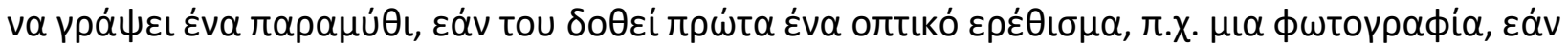

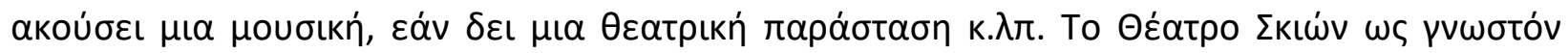

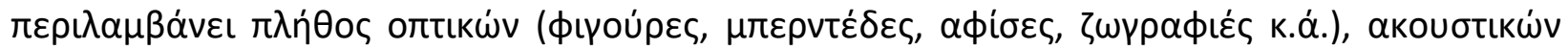

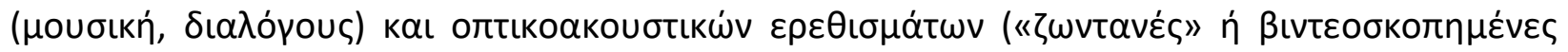

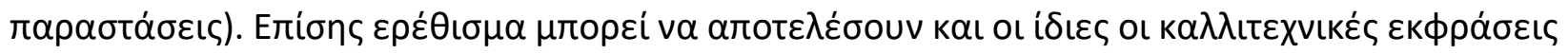

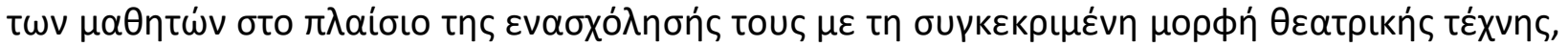
ó

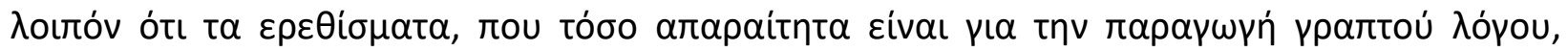

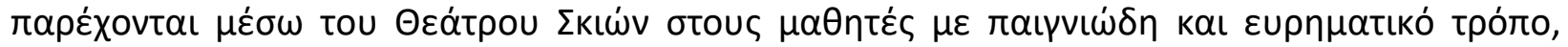

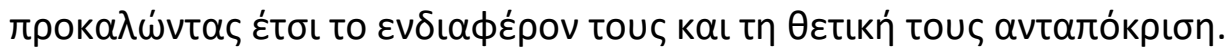

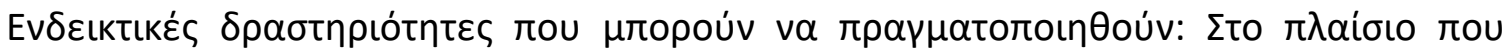

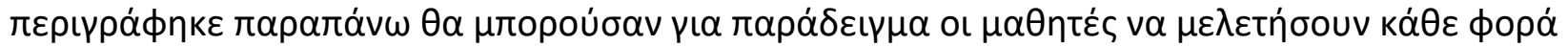

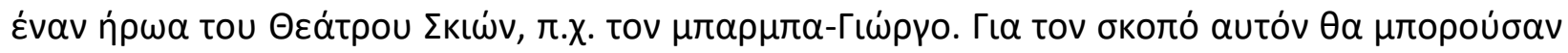

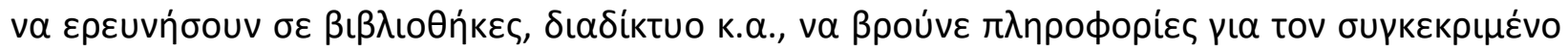

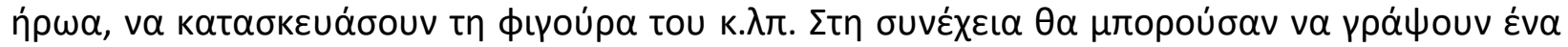

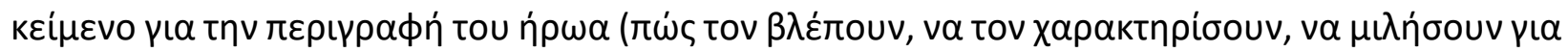

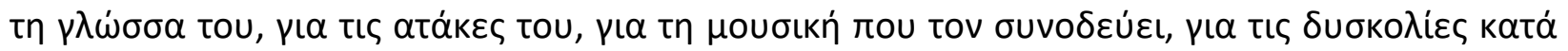


MULTILINGUAL ACADEMIC JOURNAL OF EDUCATION AND SOCIAL SCIENCES

Vol. 5 No. 1, 2017, E-ISSN: 2308-0876 @ 2017 KWP

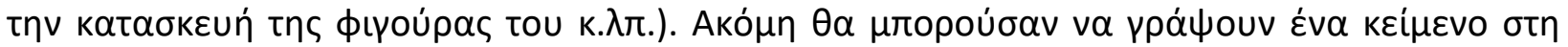

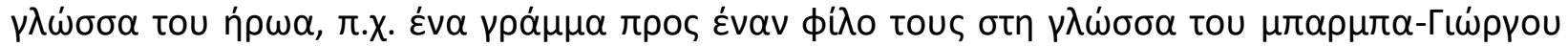

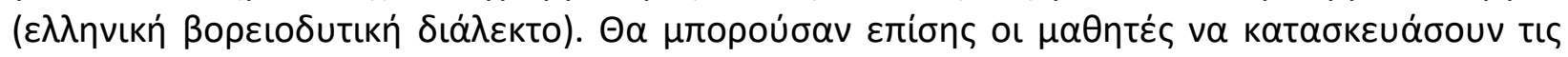

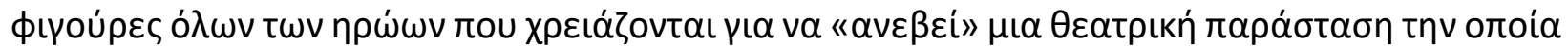

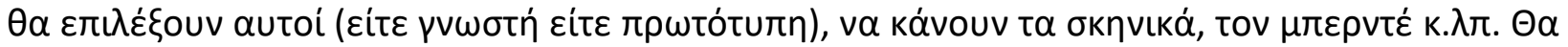

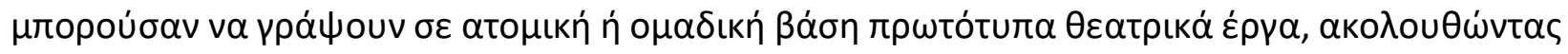

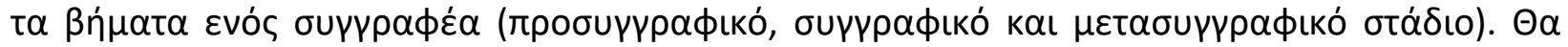

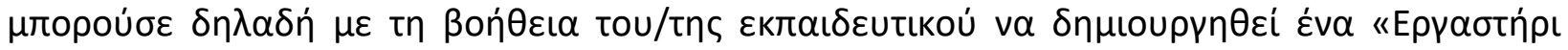

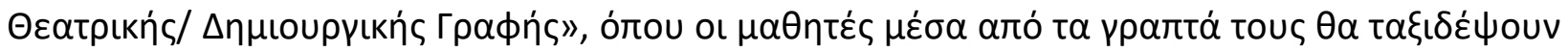

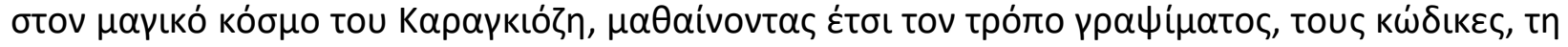

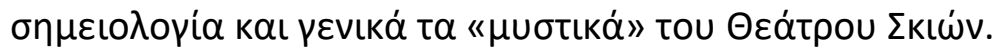

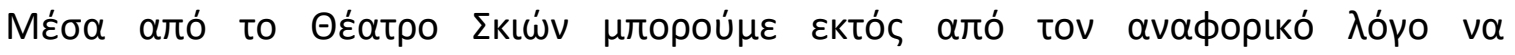

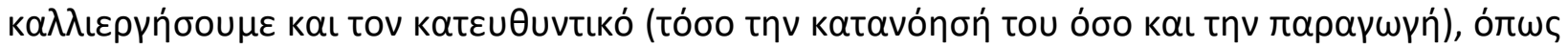

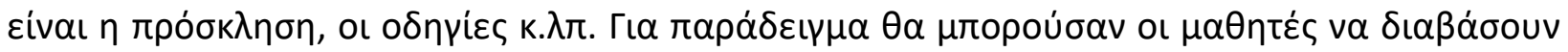

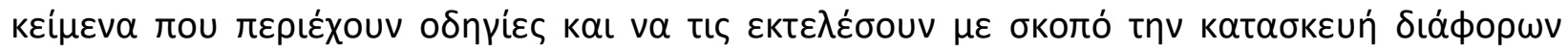

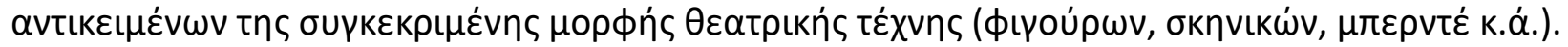

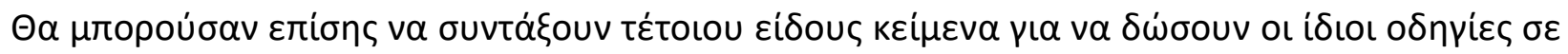

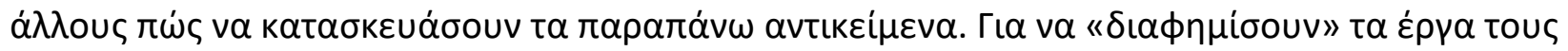
$\theta \alpha \mu \pi$ ro

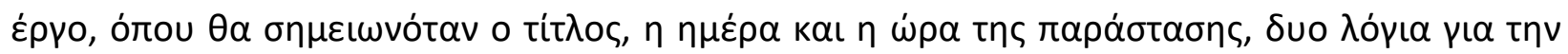

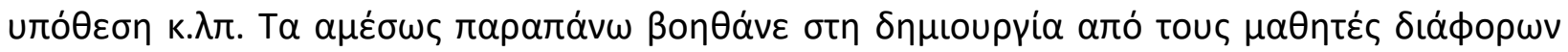

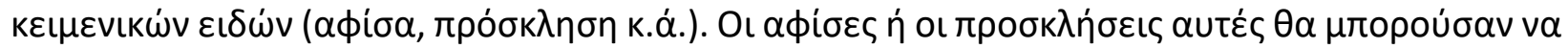

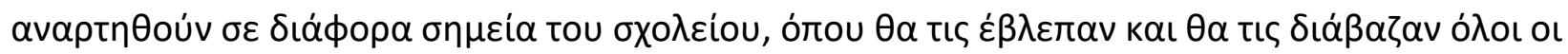

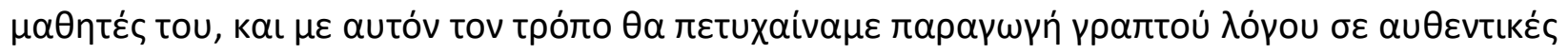

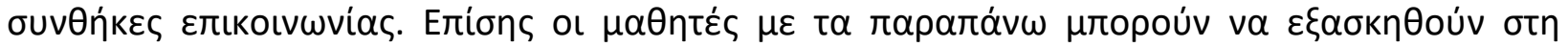

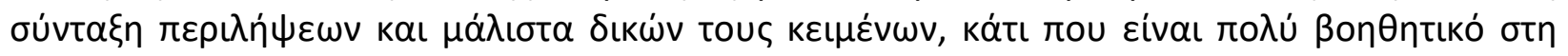

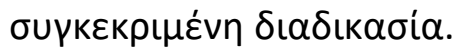

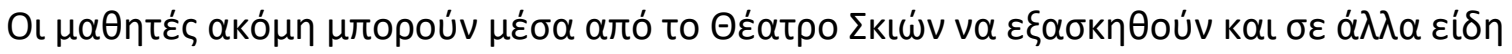

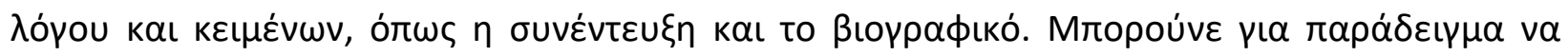

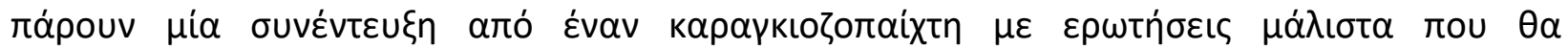

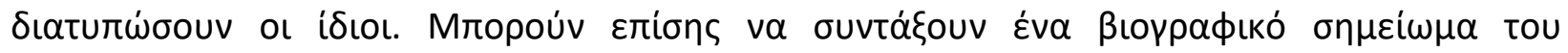

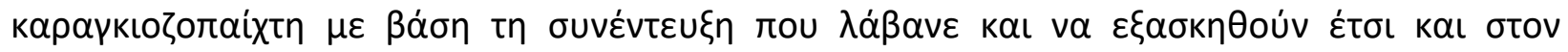

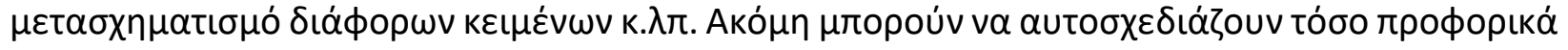

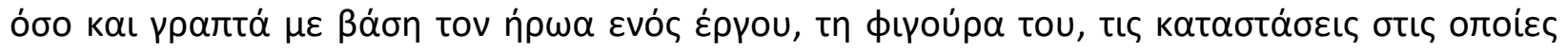

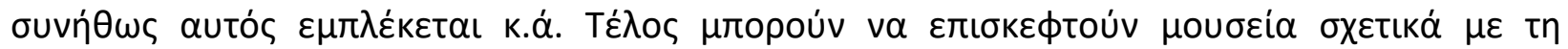

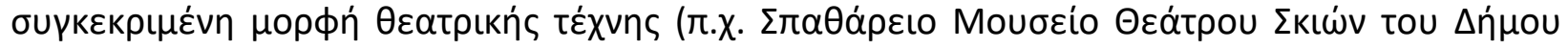

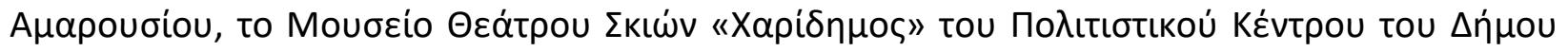

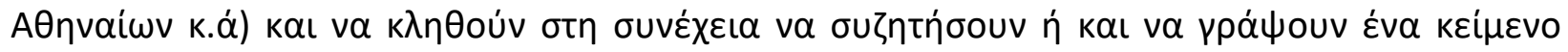

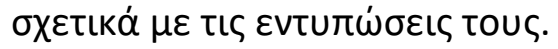

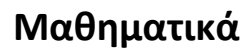

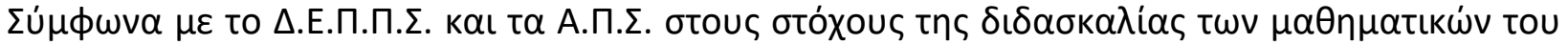

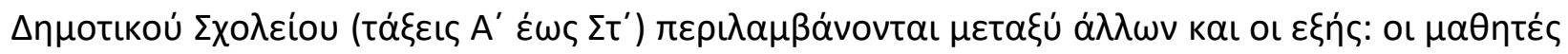

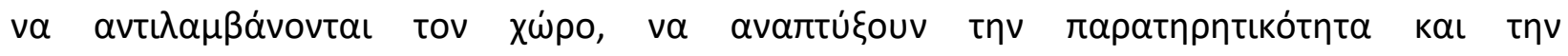


MULTILINGUAL ACADEMIC JOURNAL OF EDUCATION AND SOCIAL SCIENCES

Vol. 5 No. 1, 2017, E-ISSN: 2308-0876 @ 2017 KWP

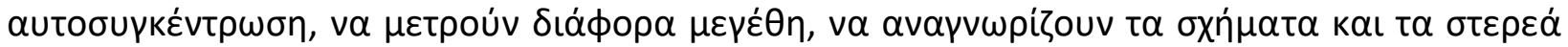

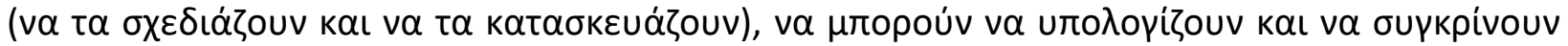

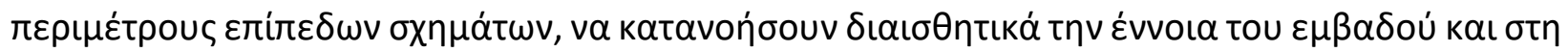

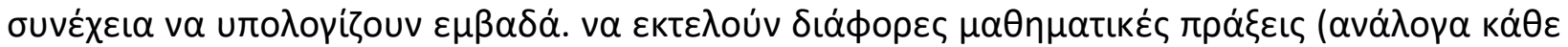

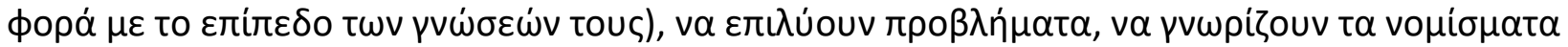

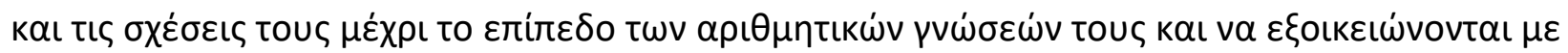

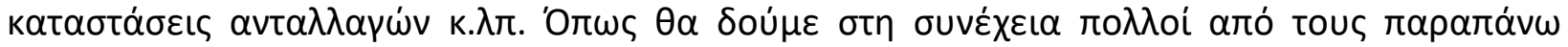

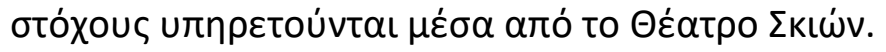

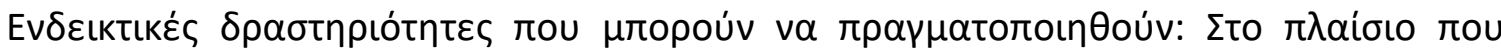

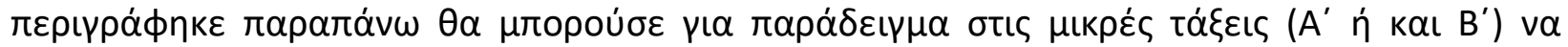

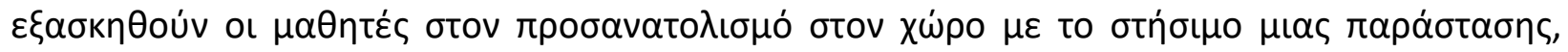

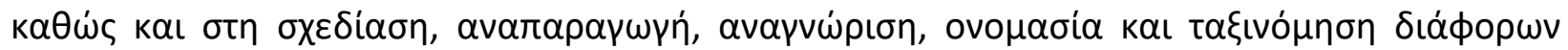

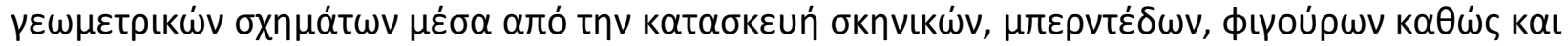

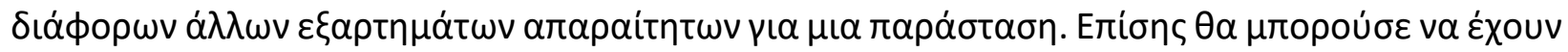

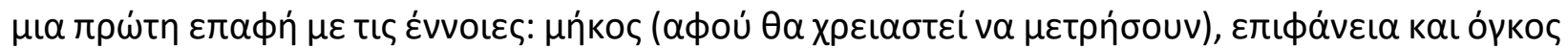

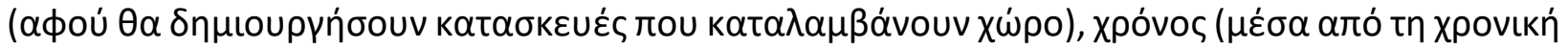

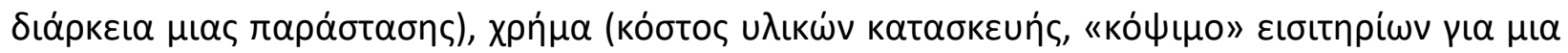

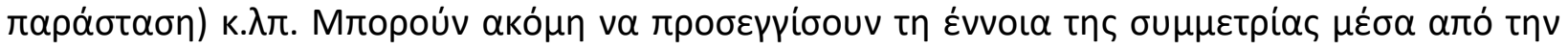

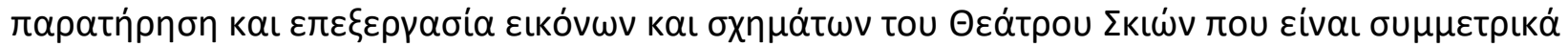

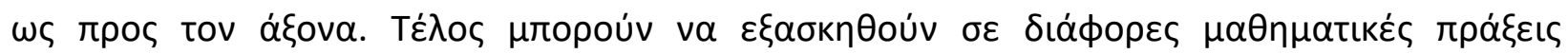

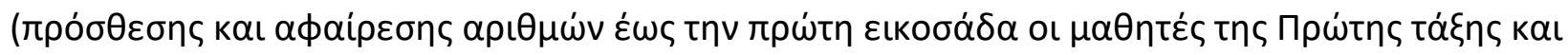

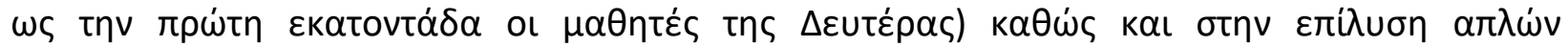

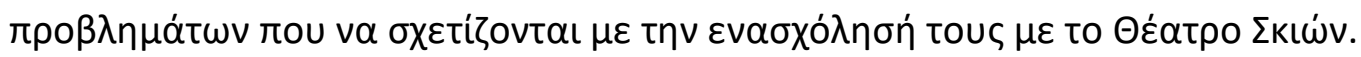

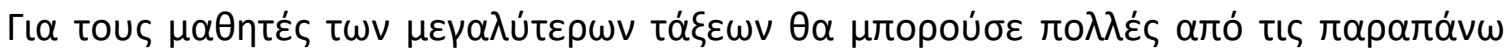

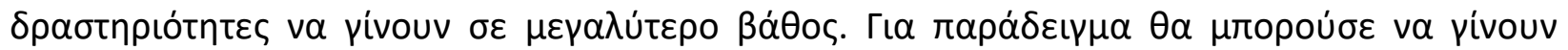

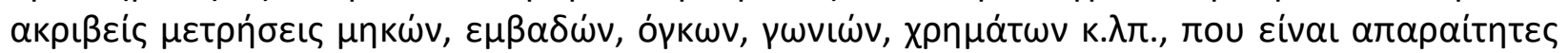

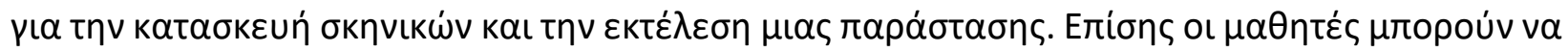

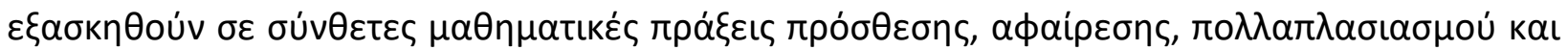

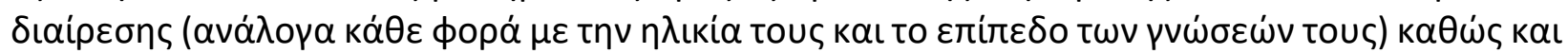

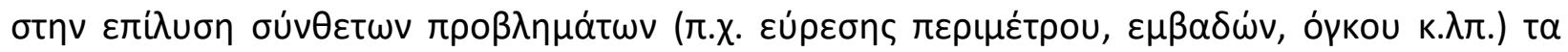

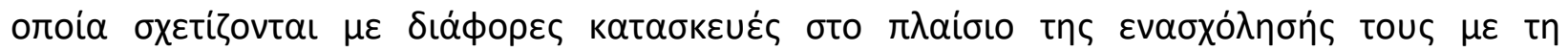

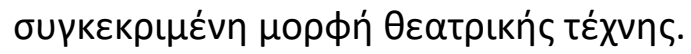

\section{lotopía}

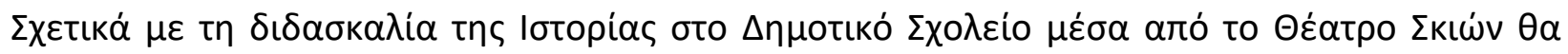

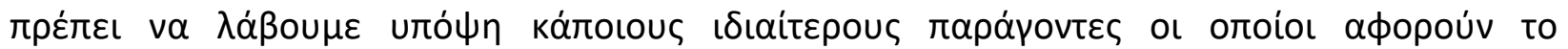

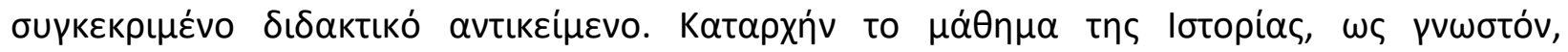

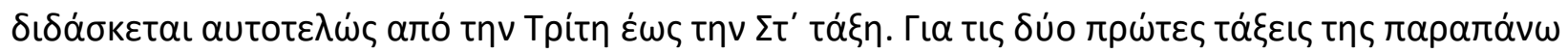

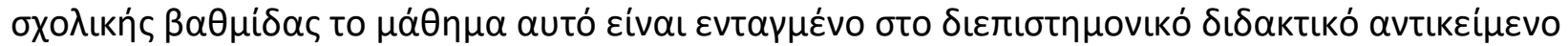

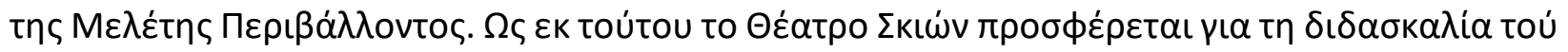

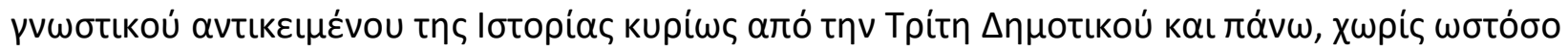

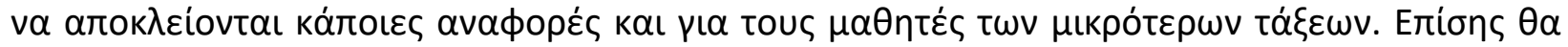

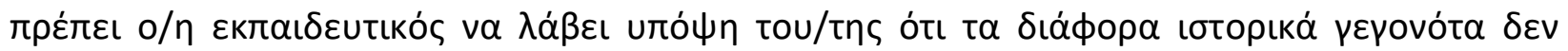

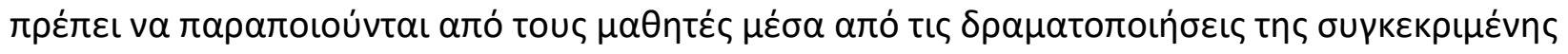


MULTILINGUAL ACADEMIC JOURNAL OF EDUCATION AND SOCIAL SCIENCES

Vol. 5 No. 1, 2017, E-ISSN: 2308-0876 @ 2017 KWP

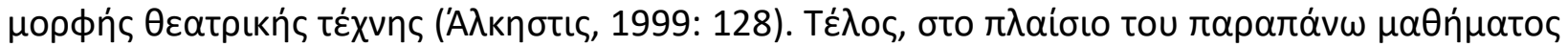

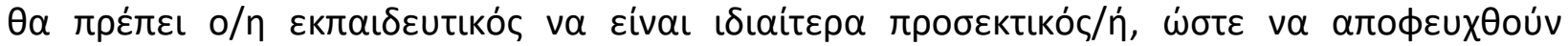

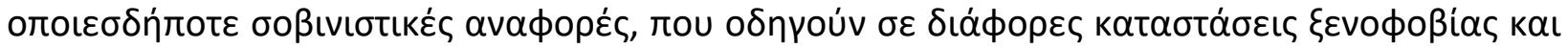

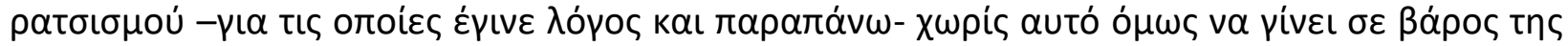

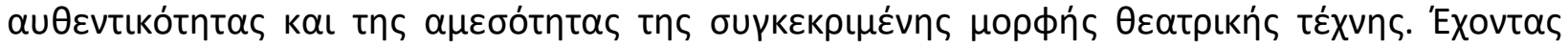

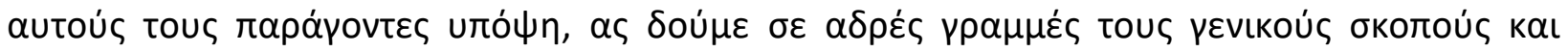

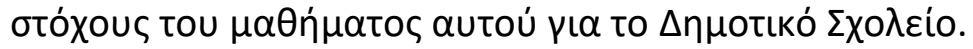

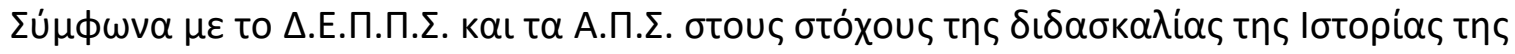

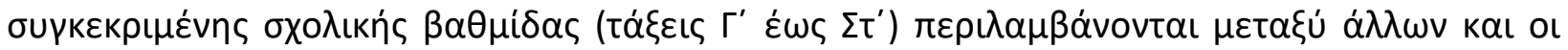

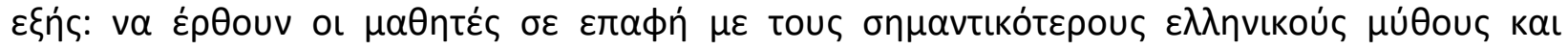

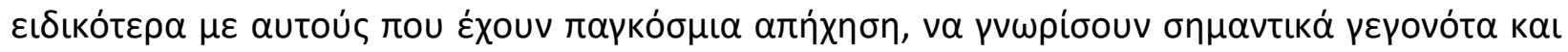

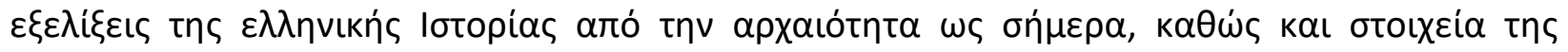

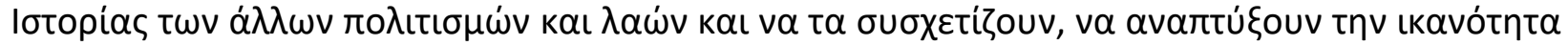

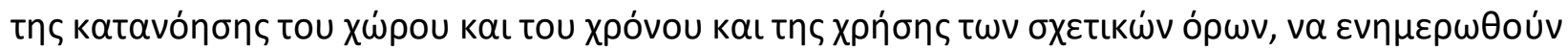

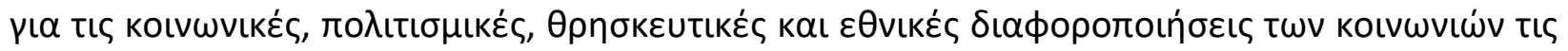

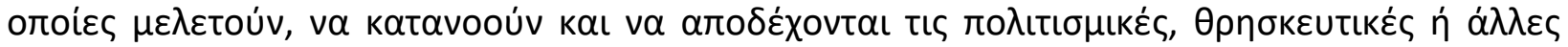

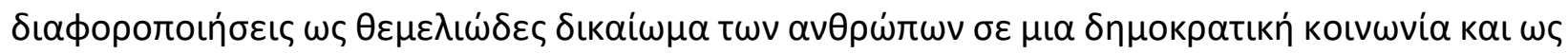

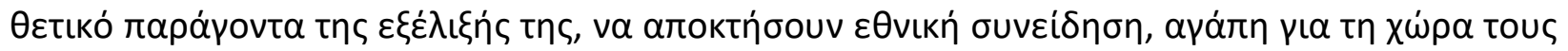

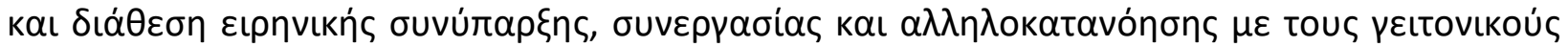

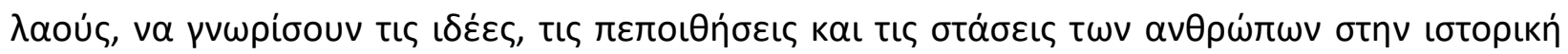

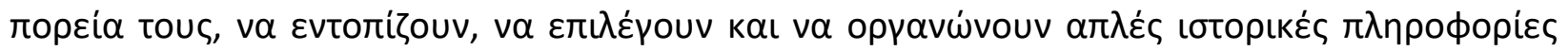

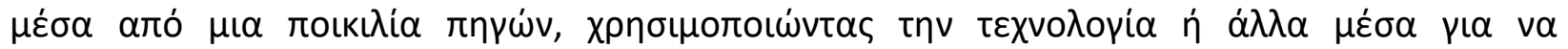

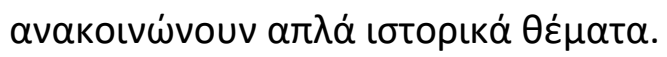

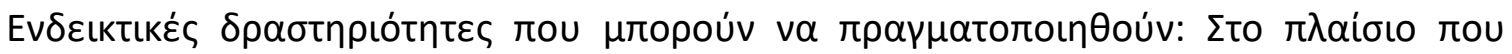

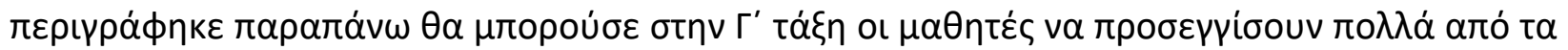

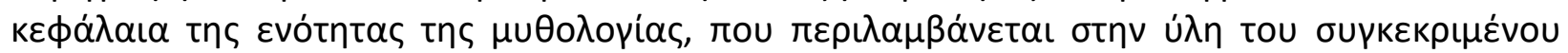

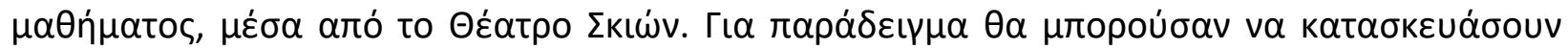

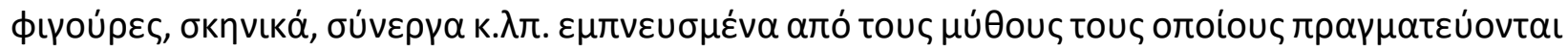

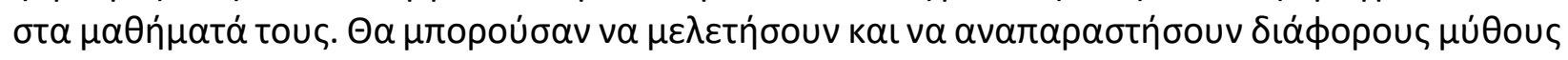

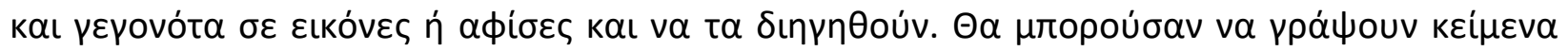

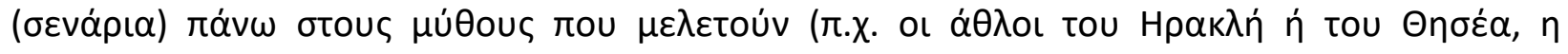

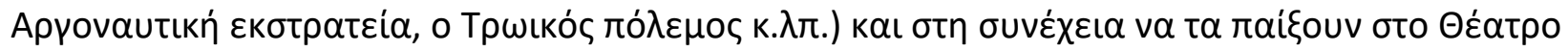

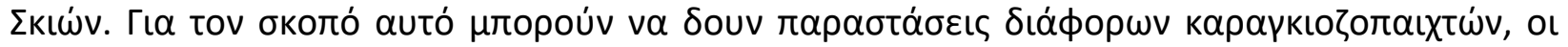

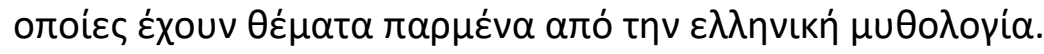

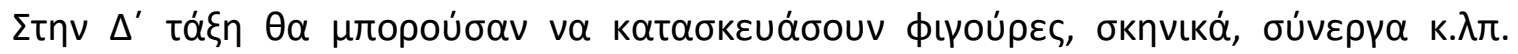

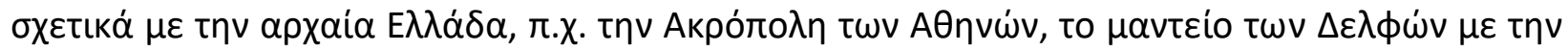

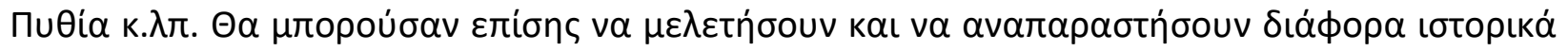

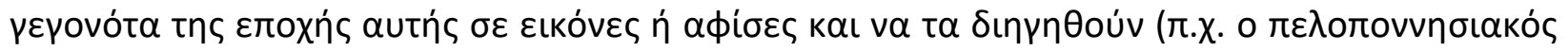

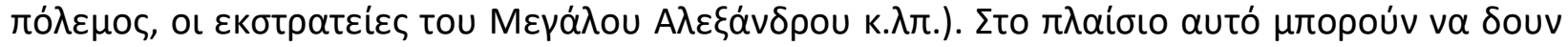

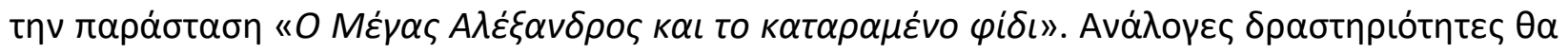

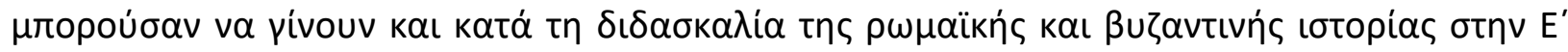

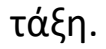

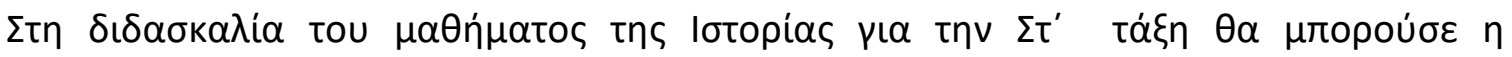

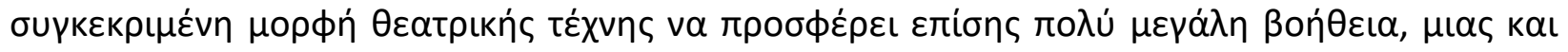


MULTILINGUAL ACADEMIC JOURNAL OF EDUCATION AND SOCIAL SCIENCES

Vol. 5 No. 1, 2017, E-ISSN: 2308-0876 @ 2017 KWP

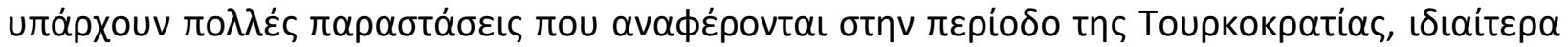

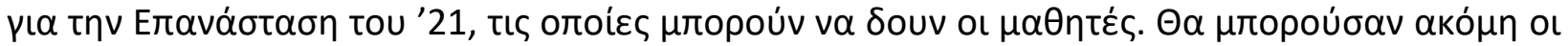

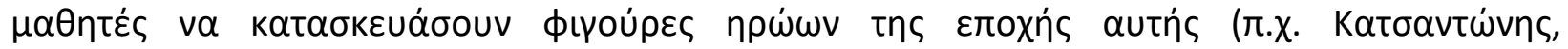

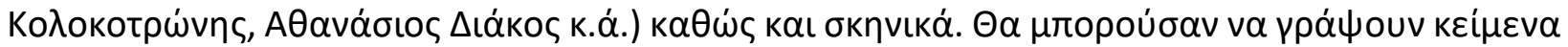

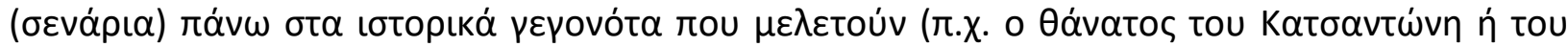

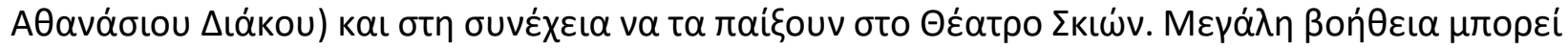

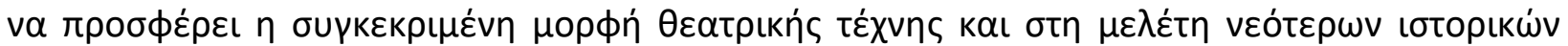

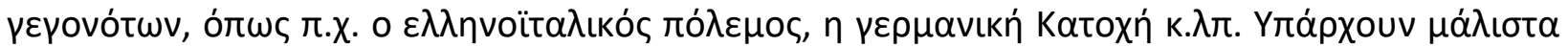

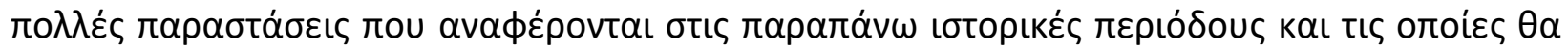

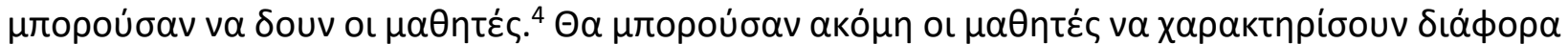

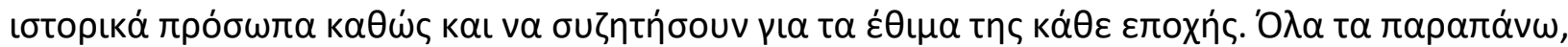

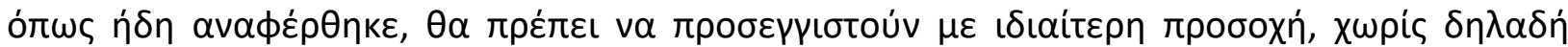

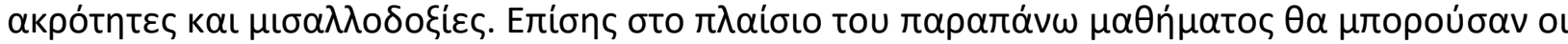

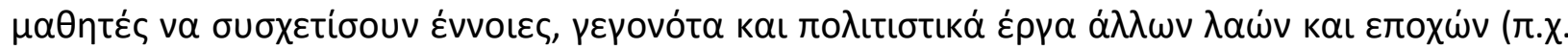

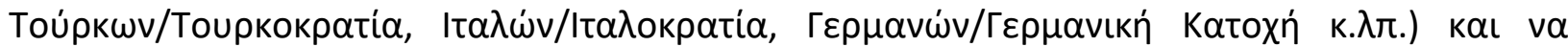

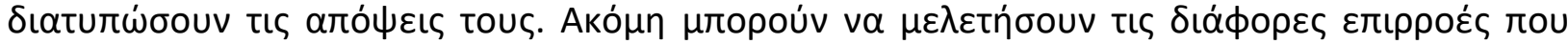

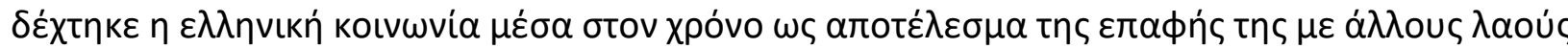

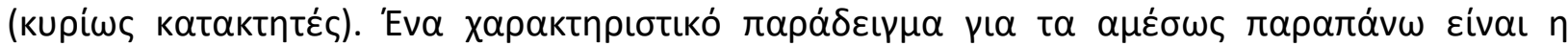

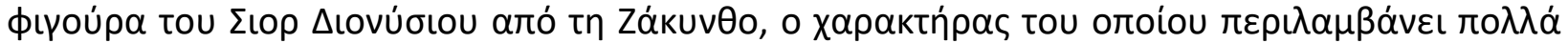

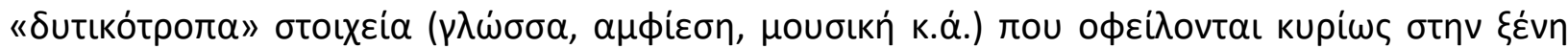

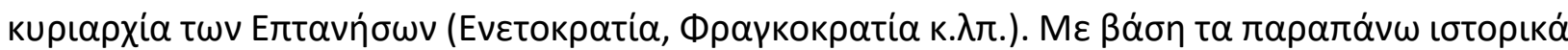

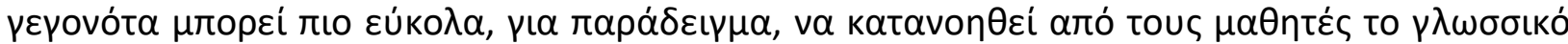

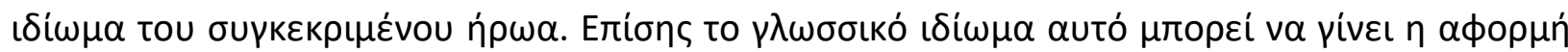

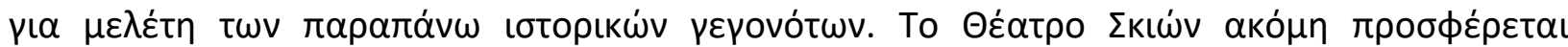

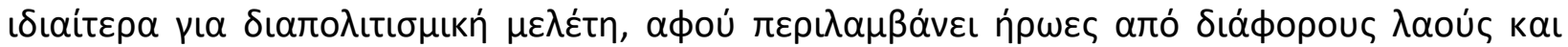

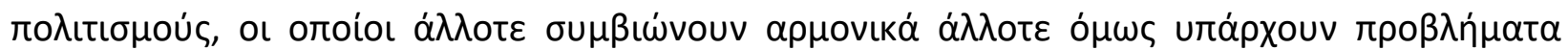

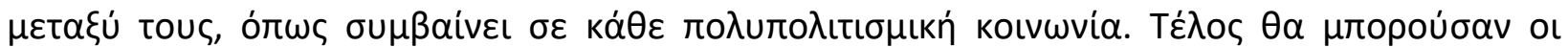

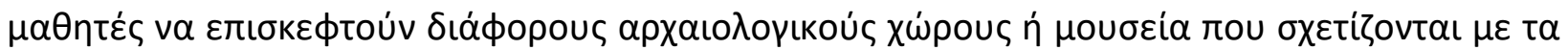

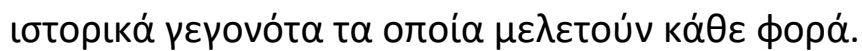

\section{$\Gamma \varepsilon \omega p \rho \alpha \phi i \alpha$}

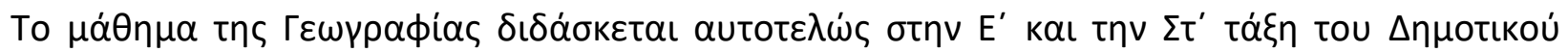

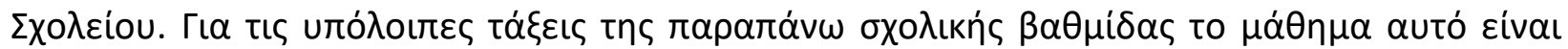

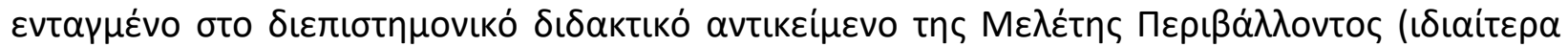

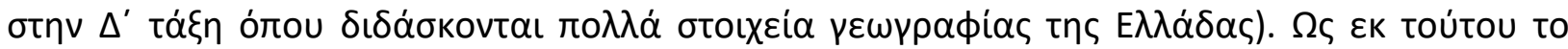

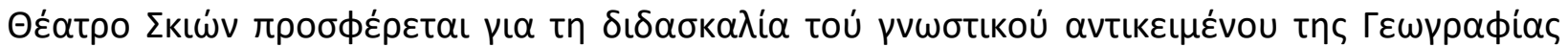

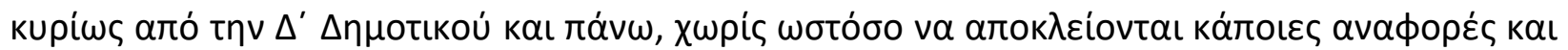

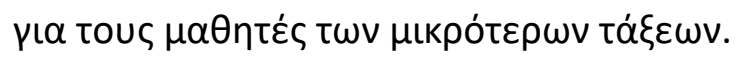

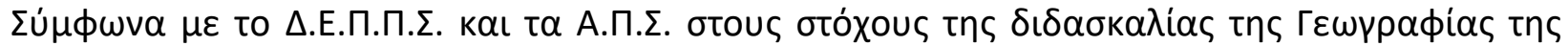

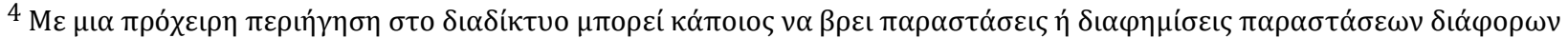

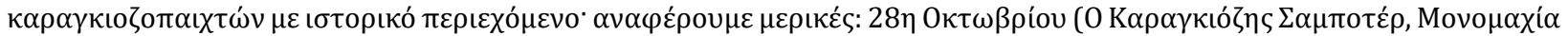

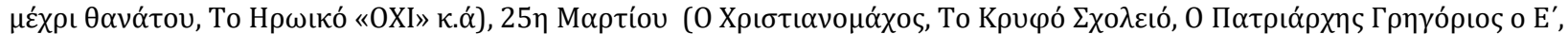

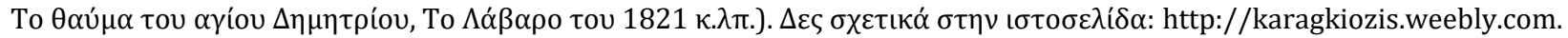


MULTILINGUAL ACADEMIC JOURNAL OF EDUCATION AND SOCIAL SCIENCES

Vol. 5 No. 1, 2017, E-ISSN: 2308-0876 @ 2017 KWP

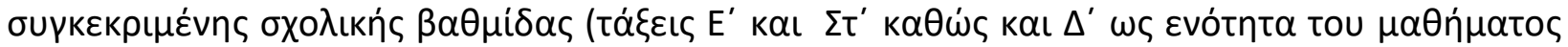

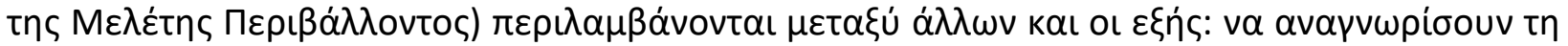

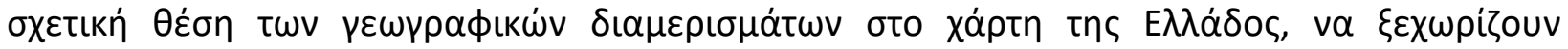

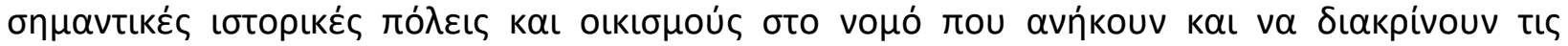

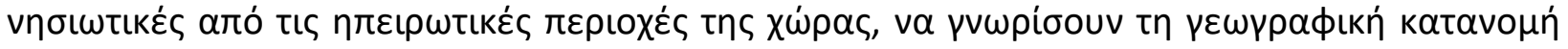

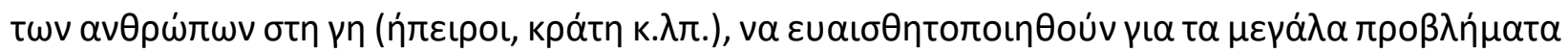

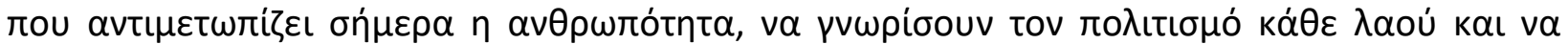

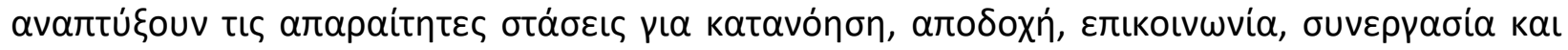

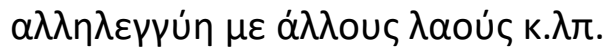

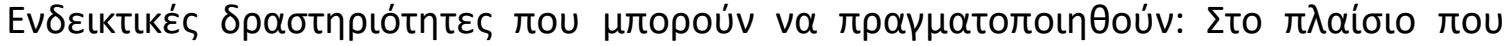

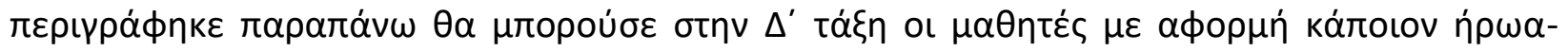

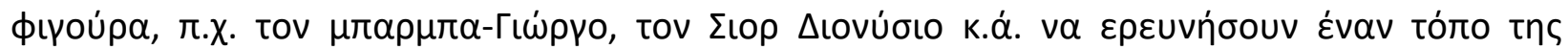

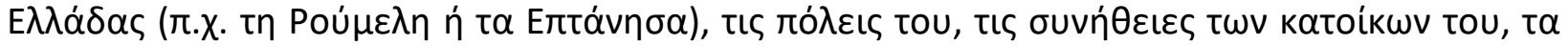

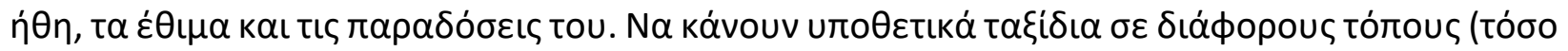

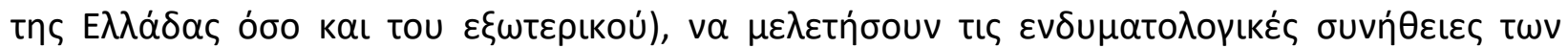

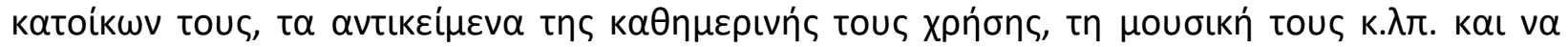

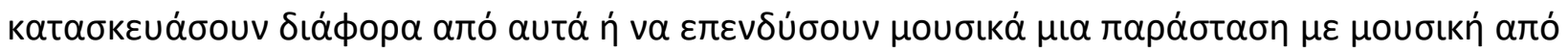

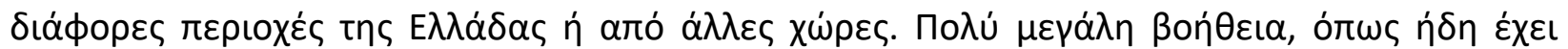

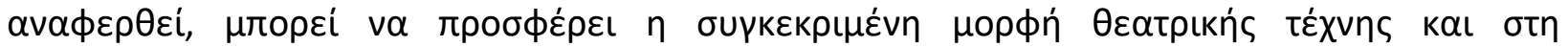

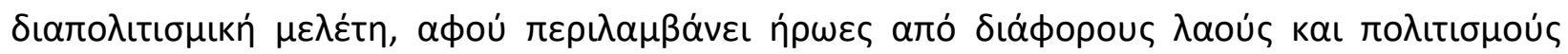

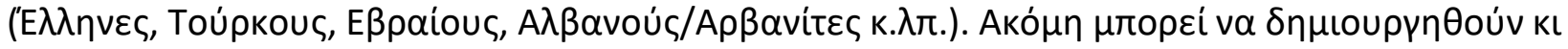

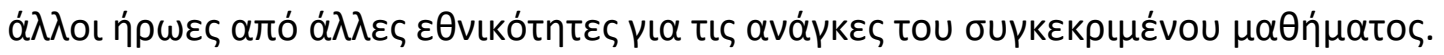

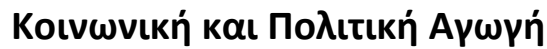

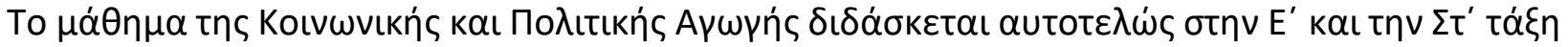

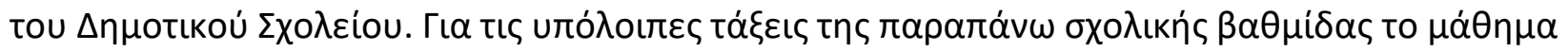

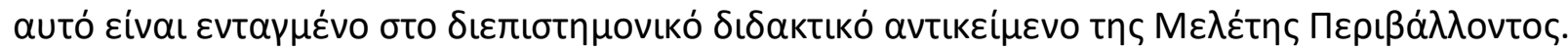

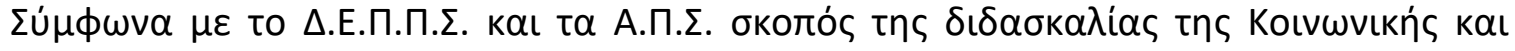

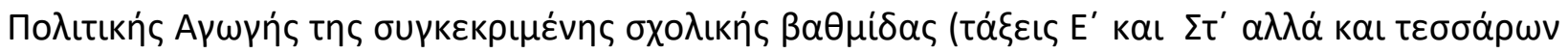

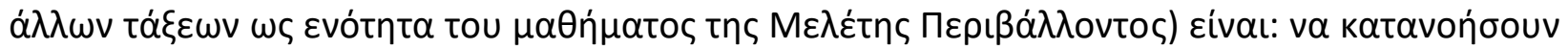

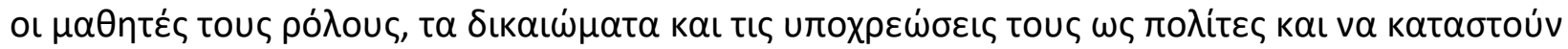

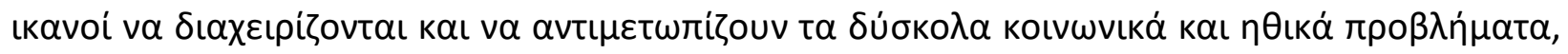

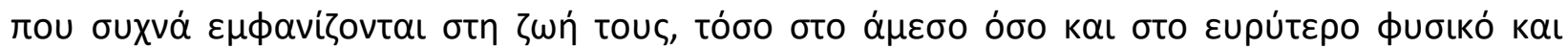

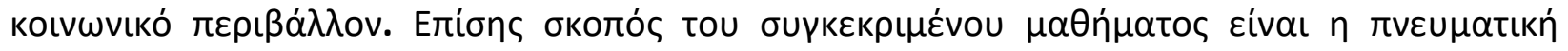

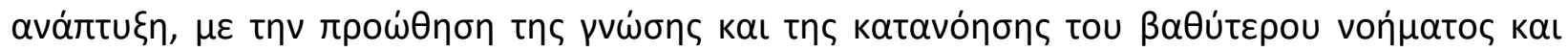

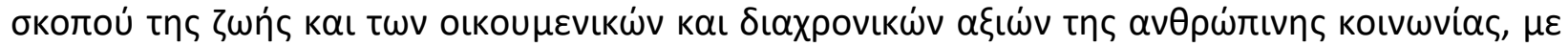

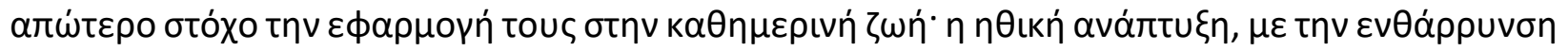

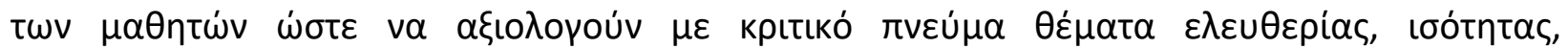

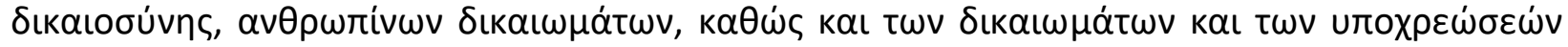

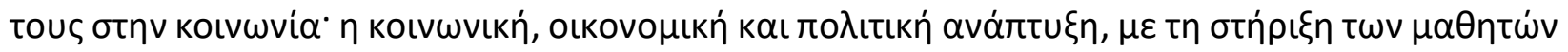

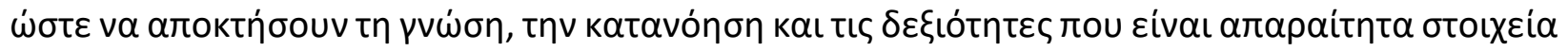

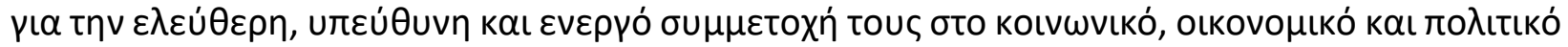

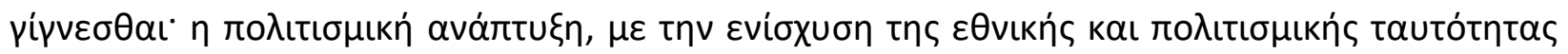

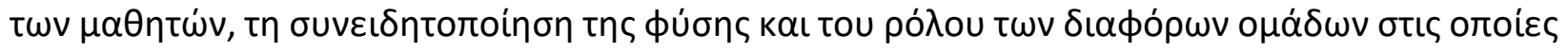


MULTILINGUAL ACADEMIC JOURNAL OF EDUCATION AND SOCIAL SCIENCES

Vol. 5 No. 1, 2017, E-ISSN: 2308-0876 @ 2017 KWP

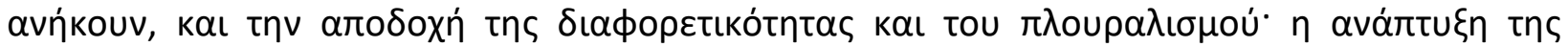

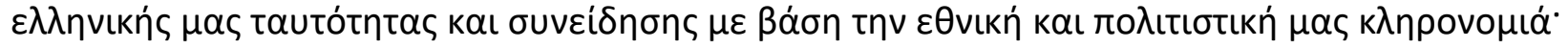

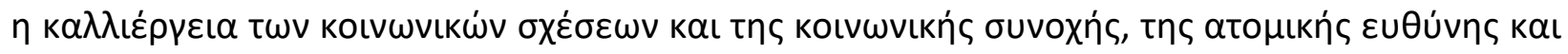

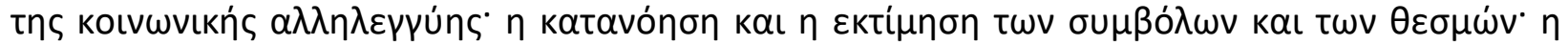

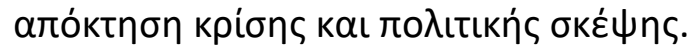

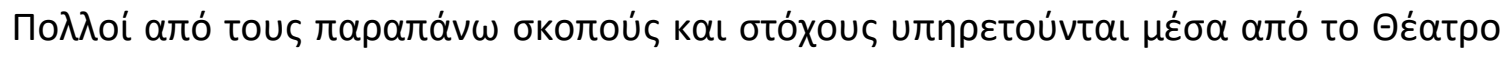

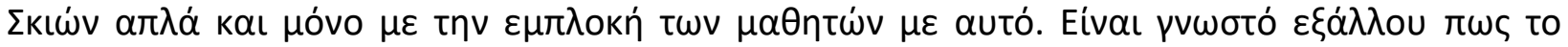

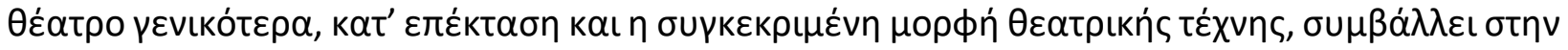

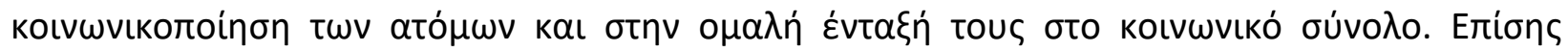

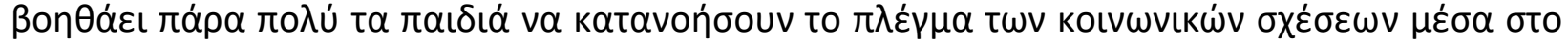

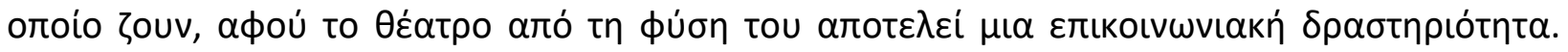

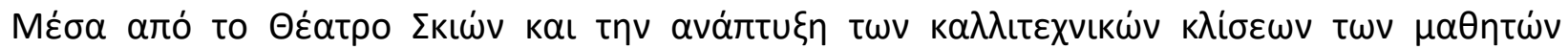

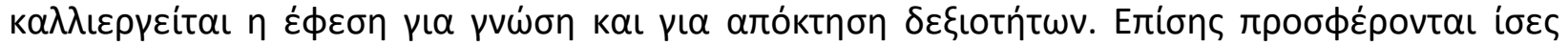

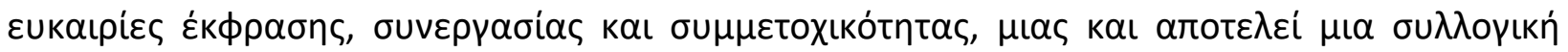

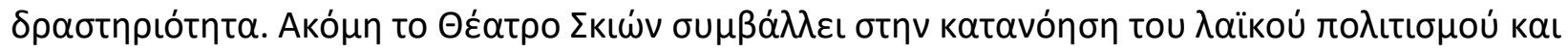

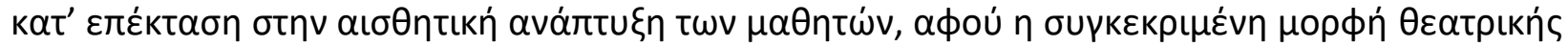

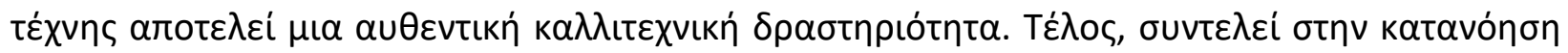

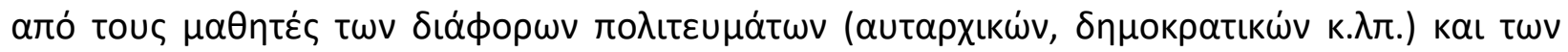

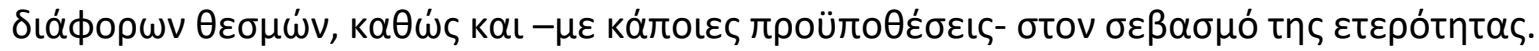

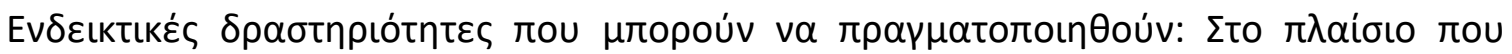

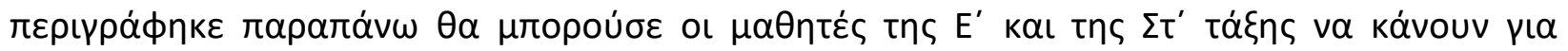

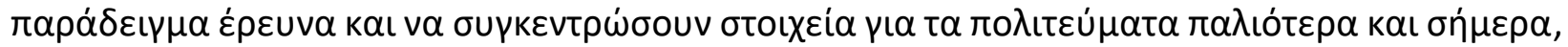

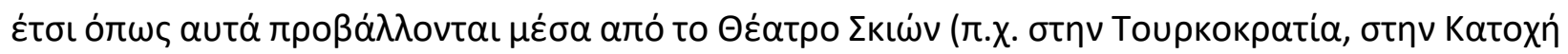

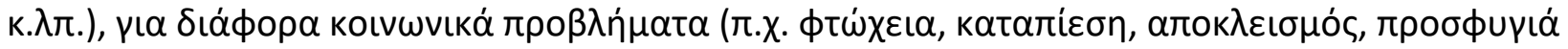

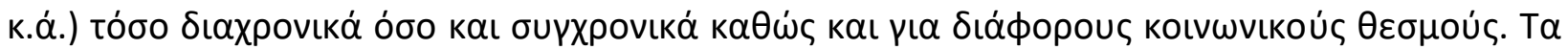

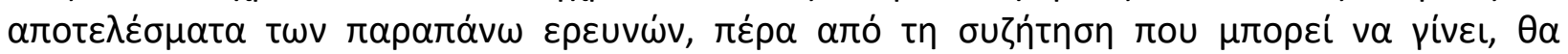

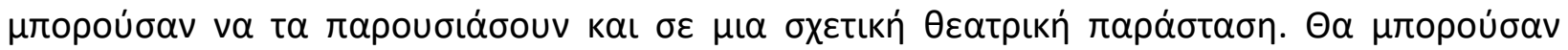

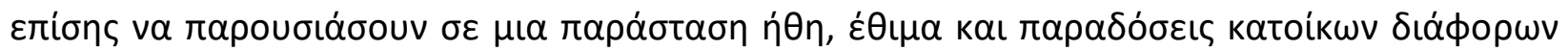

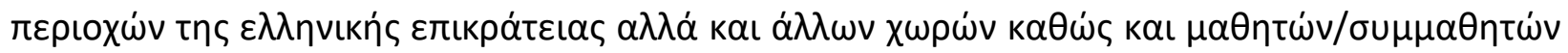

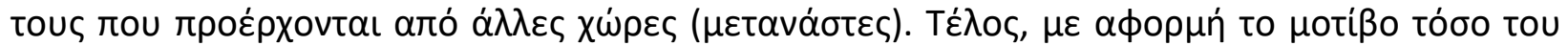

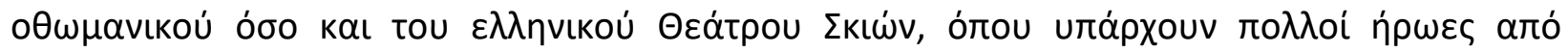

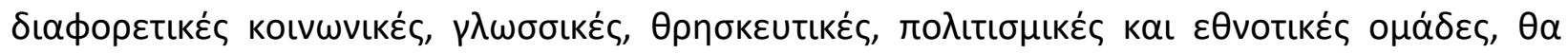

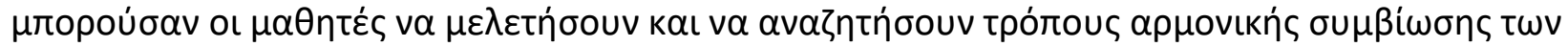

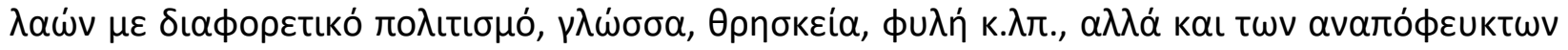

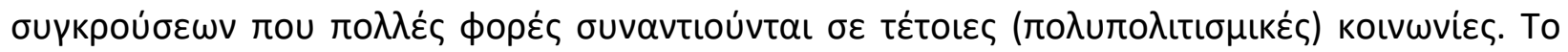

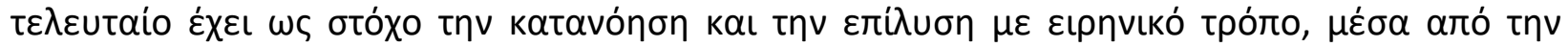

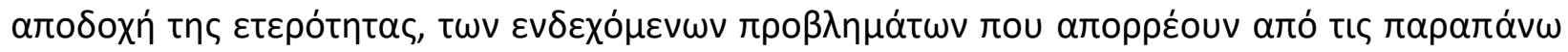

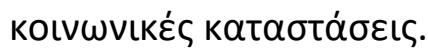

\section{Фибкка́}

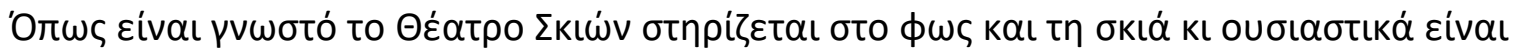

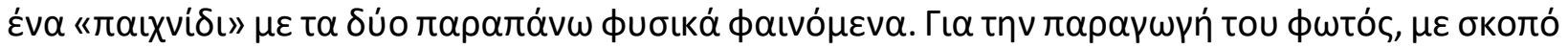

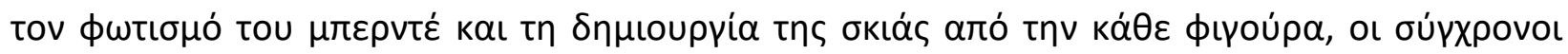

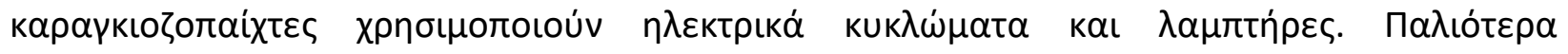


MULTILINGUAL ACADEMIC JOURNAL OF EDUCATION AND SOCIAL SCIENCES

Vol. 5 No. 1, 2017, E-ISSN: 2308-0876 @ 2017 KWP

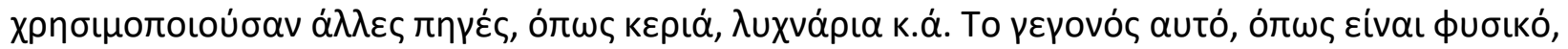

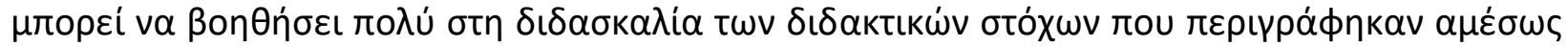

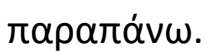

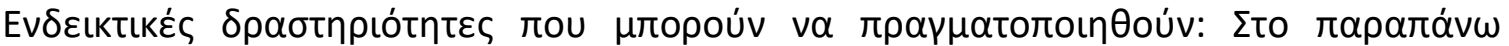

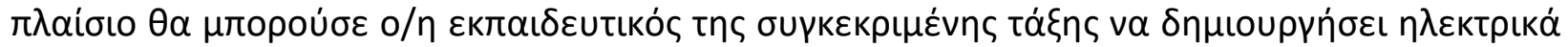

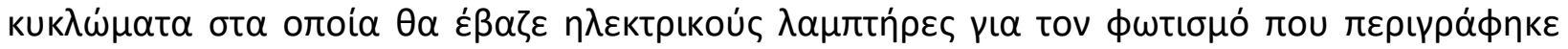

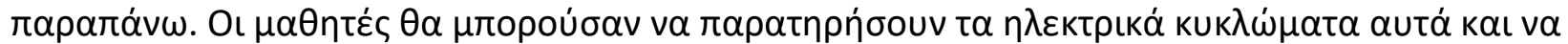

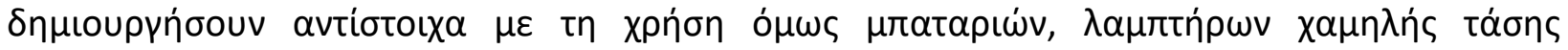

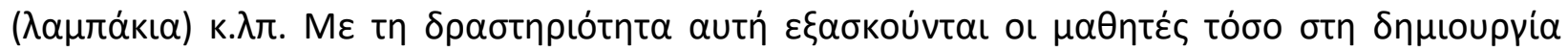

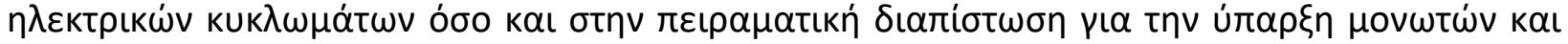

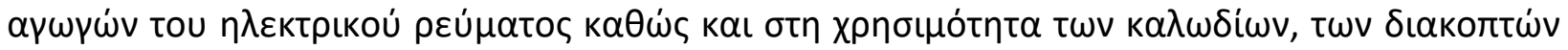

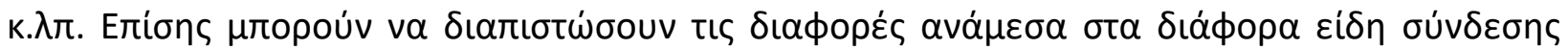

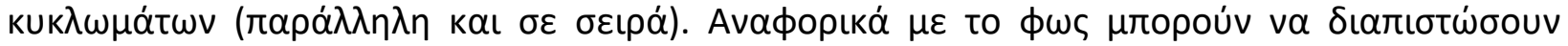

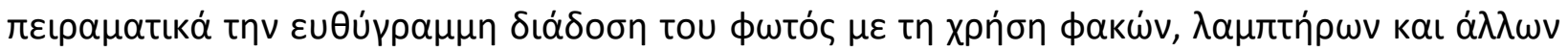

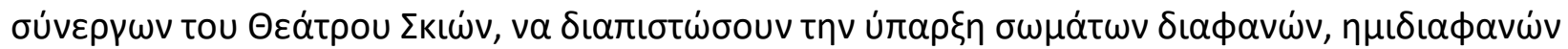

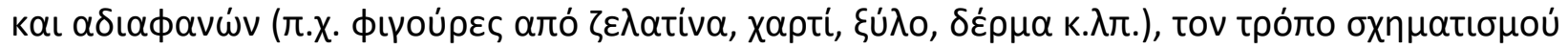

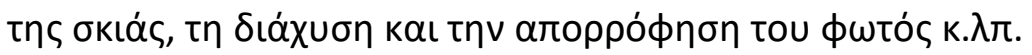

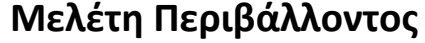

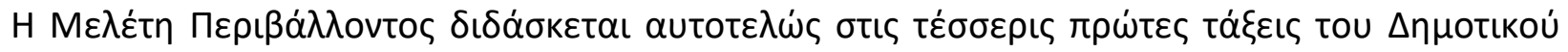

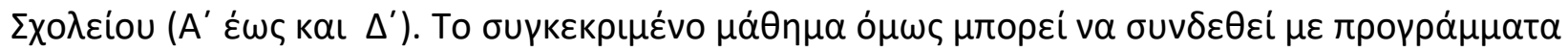

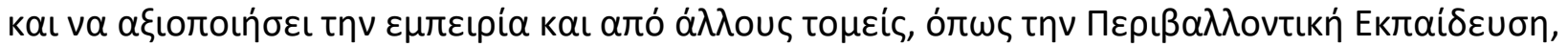

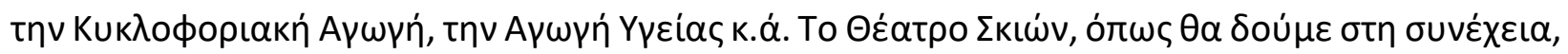

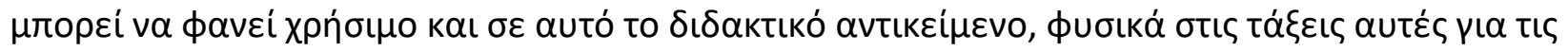

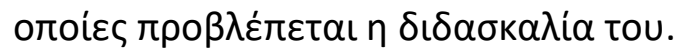

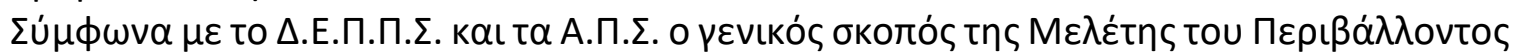

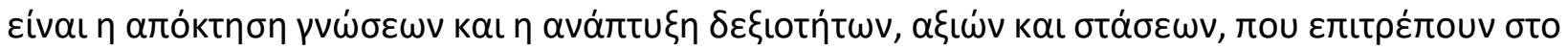

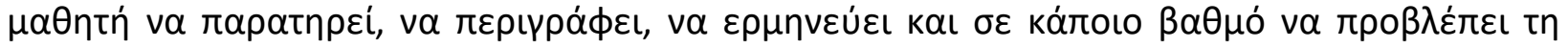

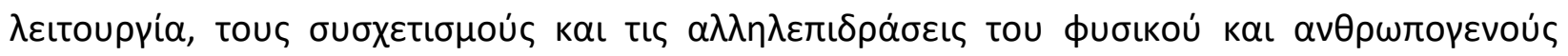

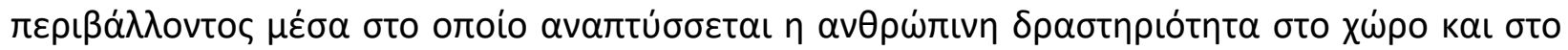

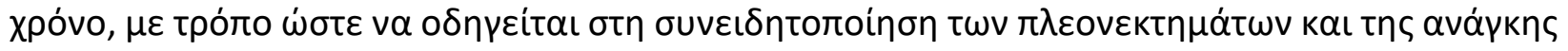

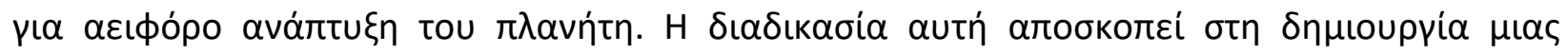

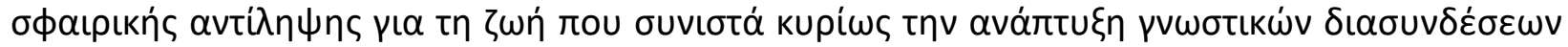

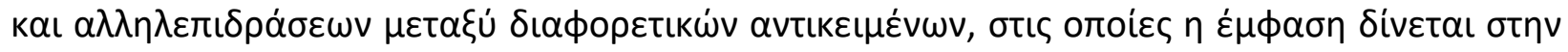

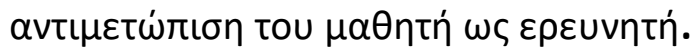

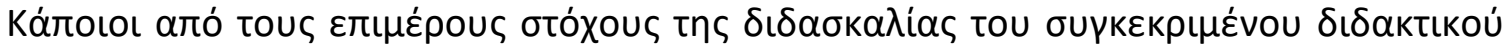

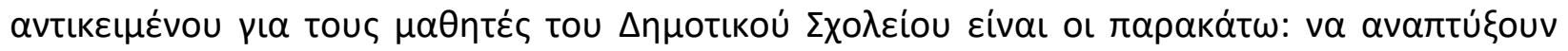

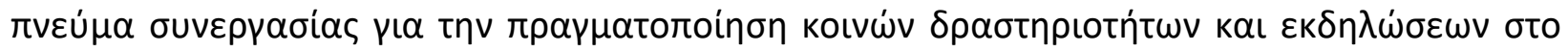

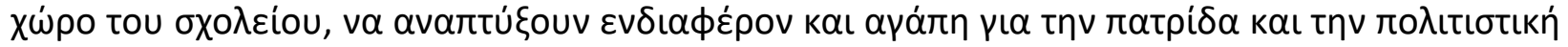

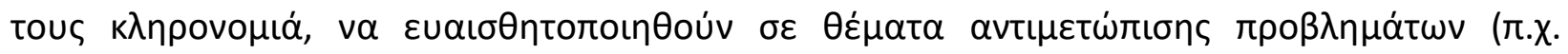

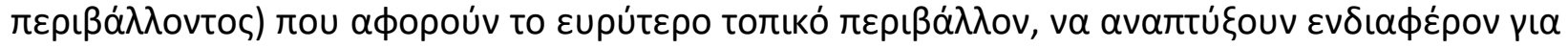

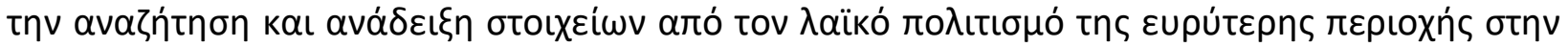

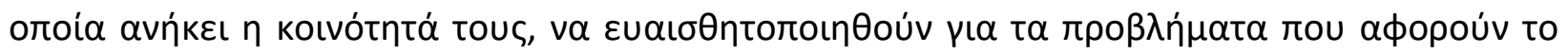

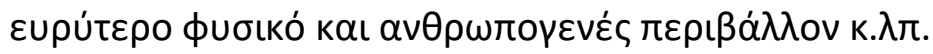


MULTILINGUAL ACADEMIC JOURNAL OF EDUCATION AND SOCIAL SCIENCES

Vol. 5 No. 1, 2017, E-ISSN: 2308-0876 @ 2017 KWP

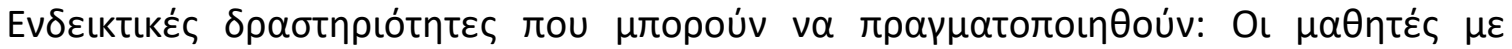

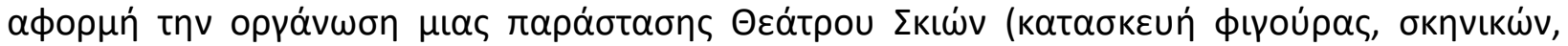

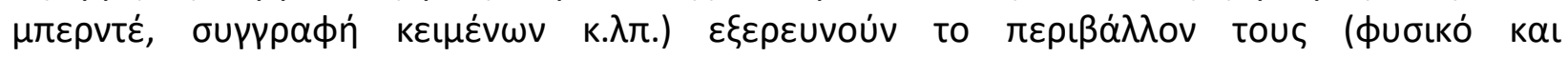

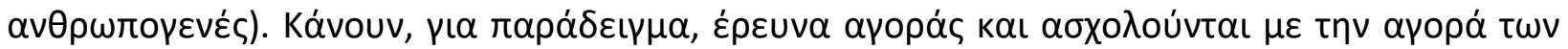

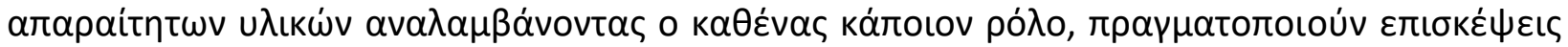

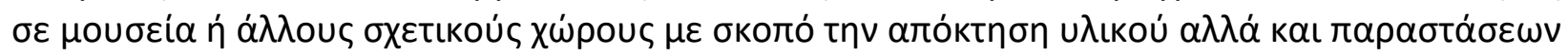

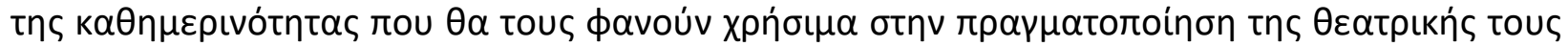

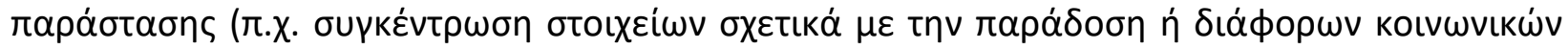

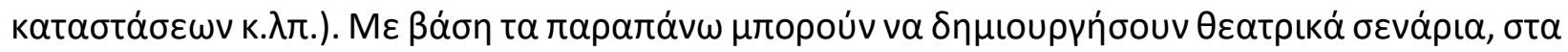

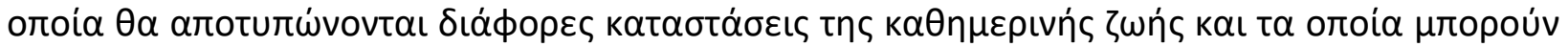

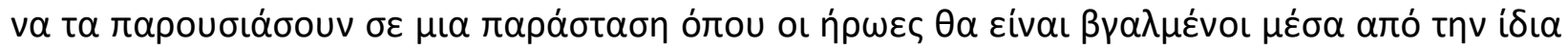

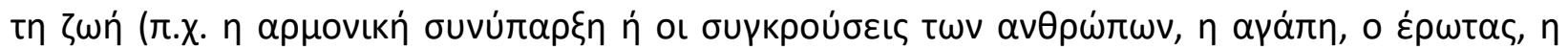

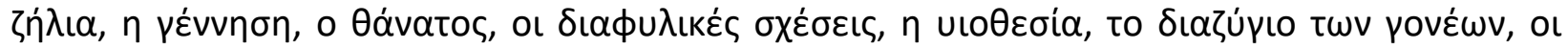

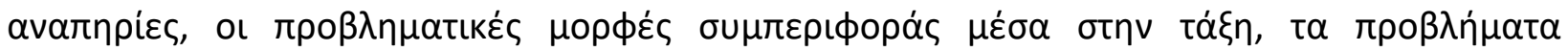

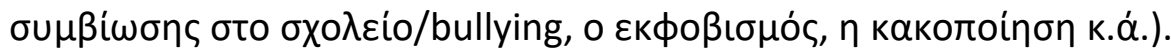

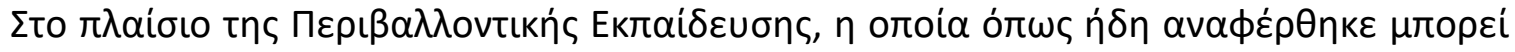

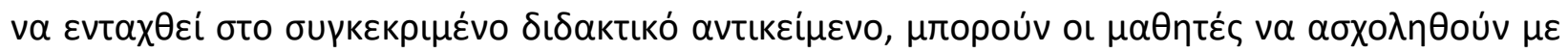

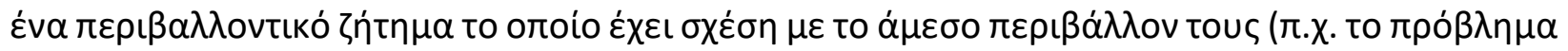

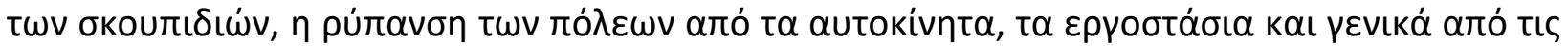

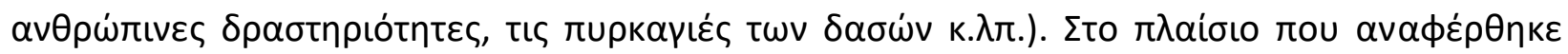

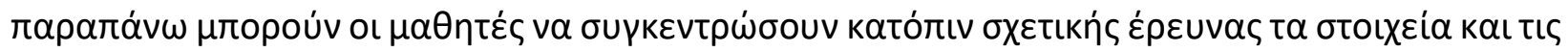

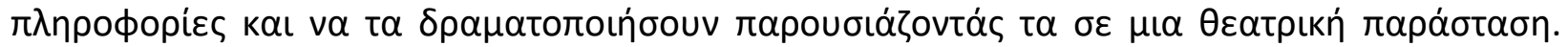

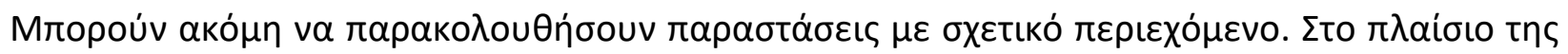

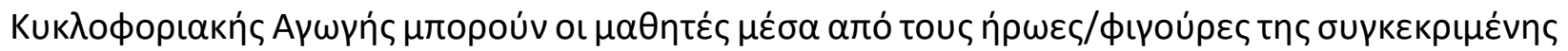

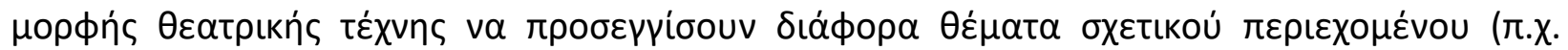

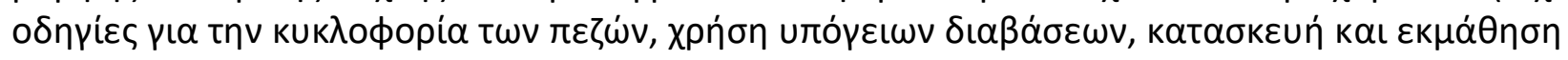

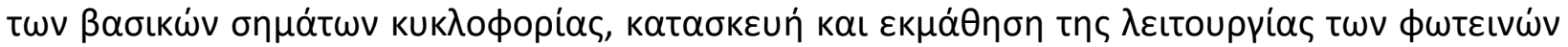

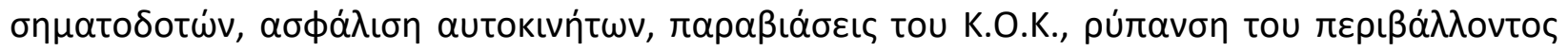

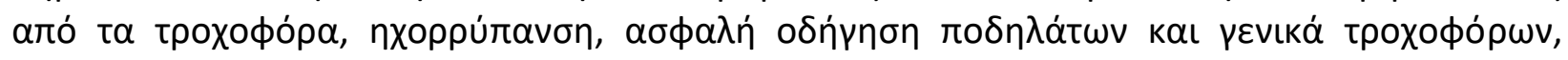

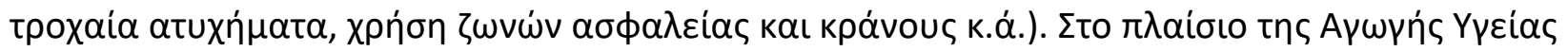

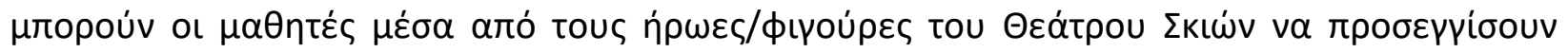

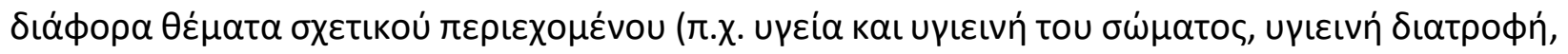

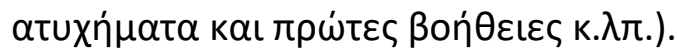

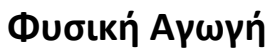

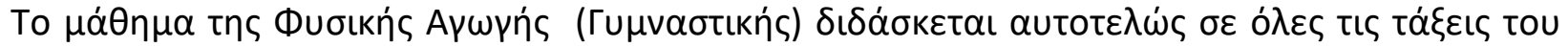

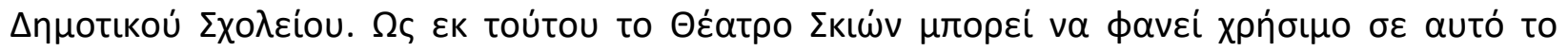

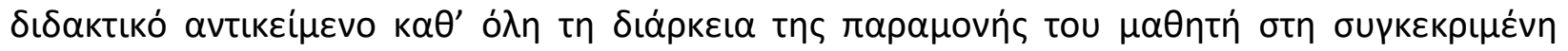
$\sigma \chi о \lambda \iota к n ́ ~ \beta \alpha \theta \mu i \delta \alpha$.

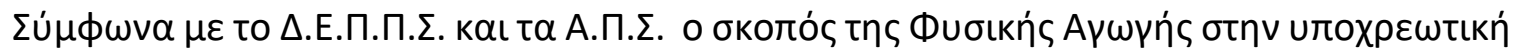

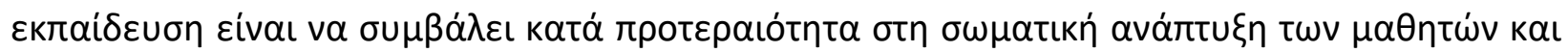

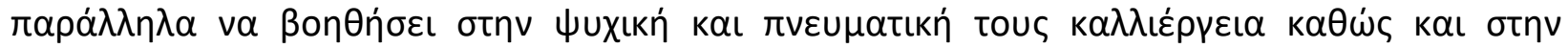

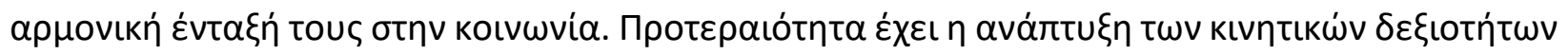

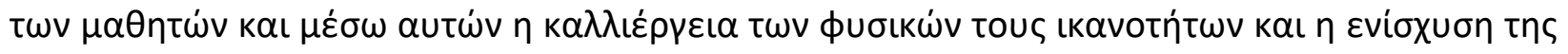


MULTILINGUAL ACADEMIC JOURNAL OF EDUCATION AND SOCIAL SCIENCES

Vol. 5 No. 1, 2017, E-ISSN: 2308-0876 @ 2017 KWP

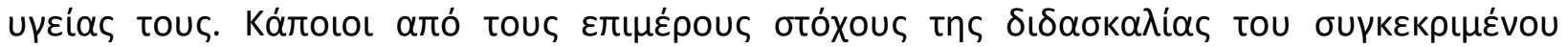

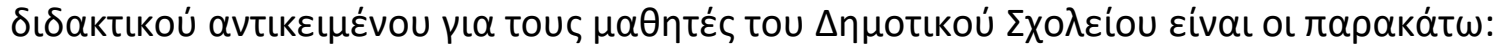

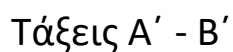

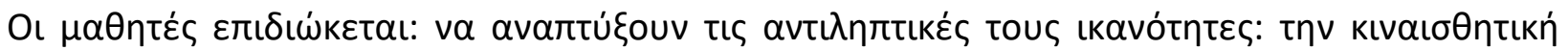

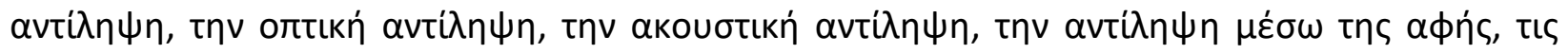

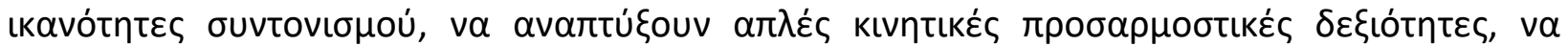

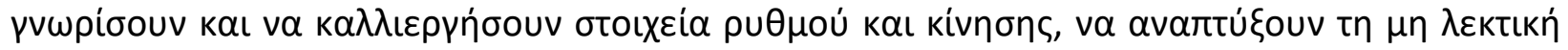

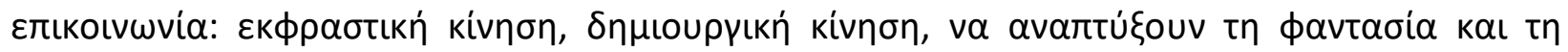

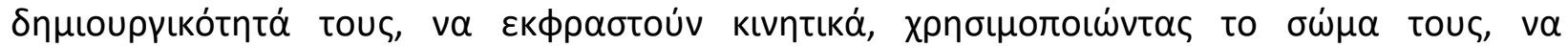

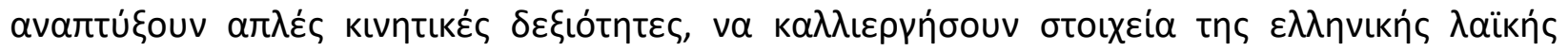

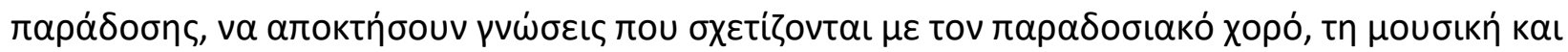

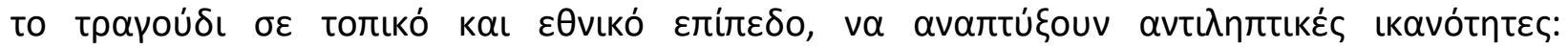

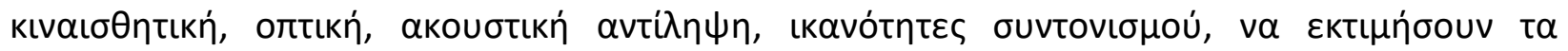

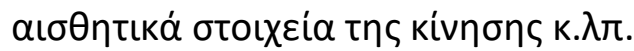

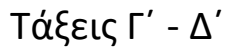

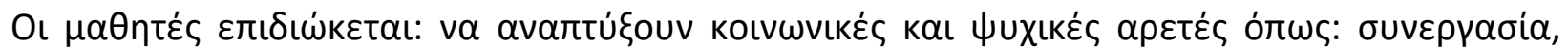

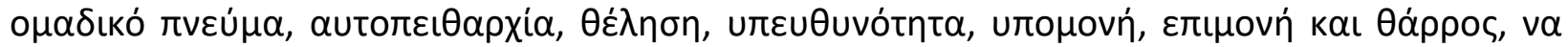

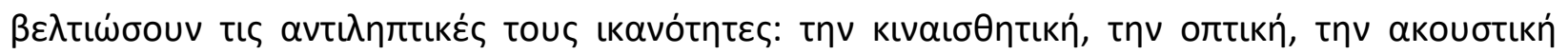

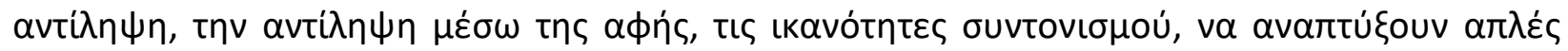

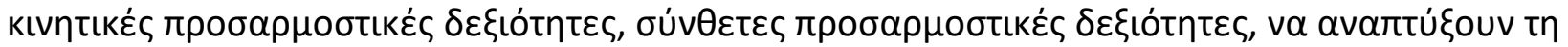

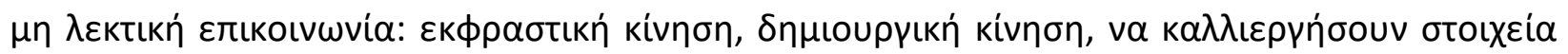

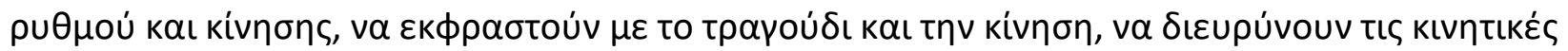

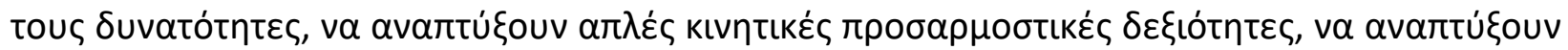

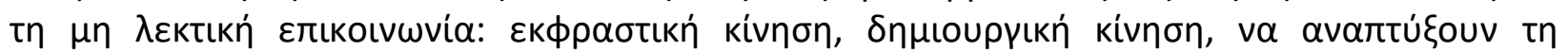

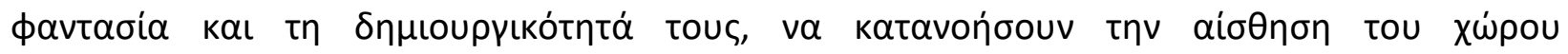

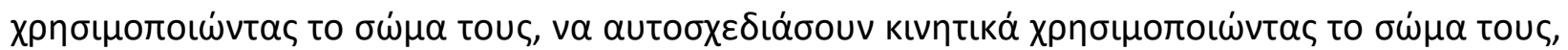

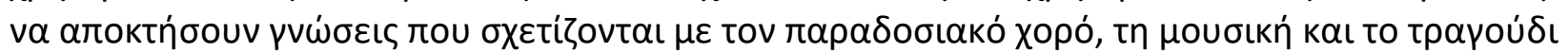

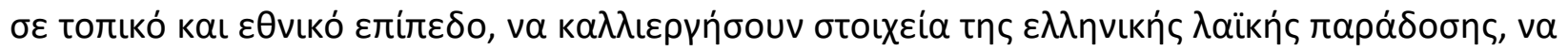

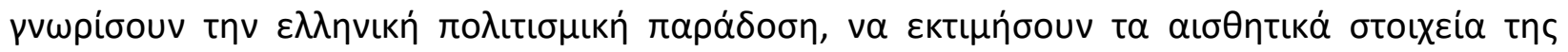

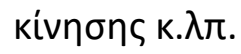

\section{Tákદıৎ $E^{\prime}-\Sigma \tau^{\prime}$}

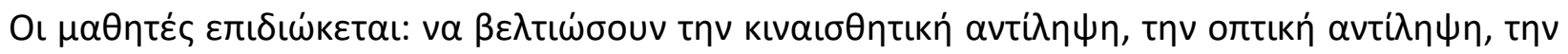

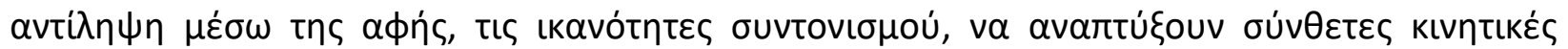

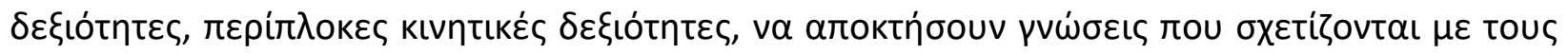

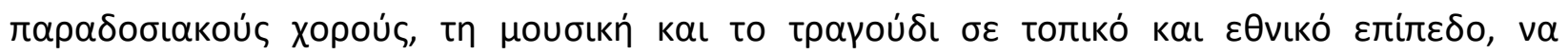

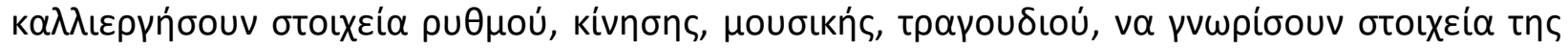

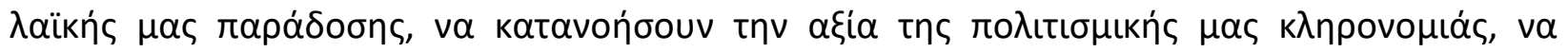

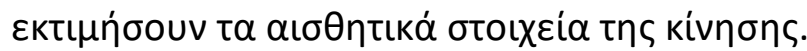

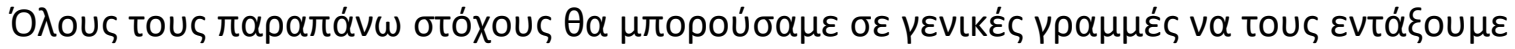

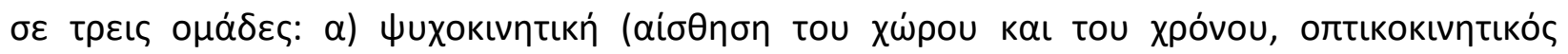

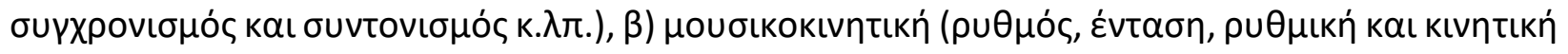


MULTILINGUAL ACADEMIC JOURNAL OF EDUCATION AND SOCIAL SCIENCES

Vol. 5 No. 1, 2017, E-ISSN: 2308-0876 @ 2017 KWP

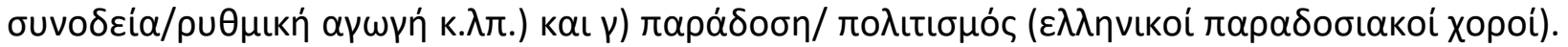

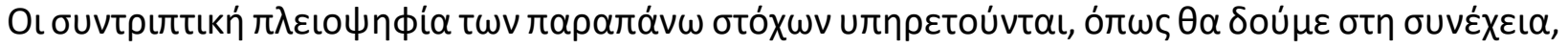

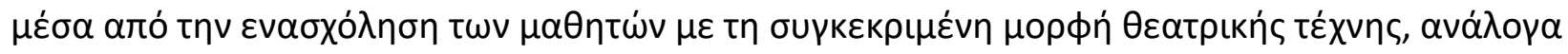

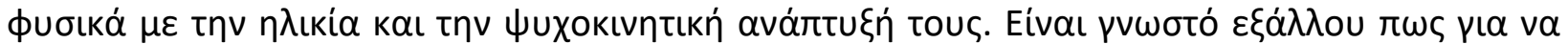

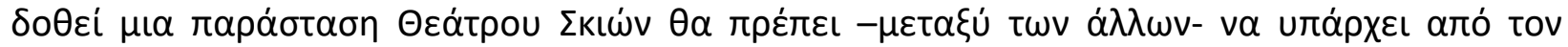

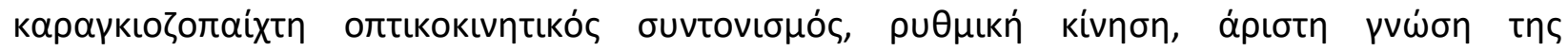

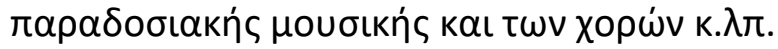

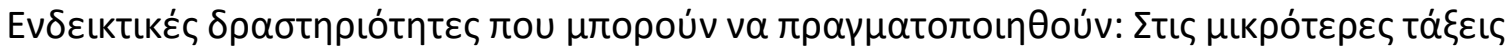

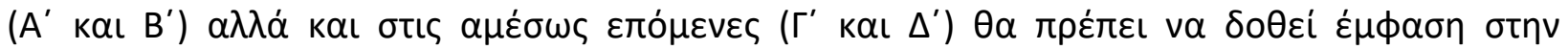

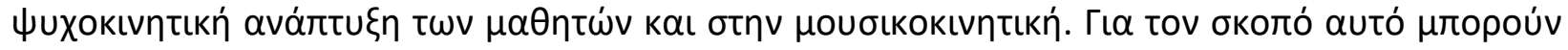

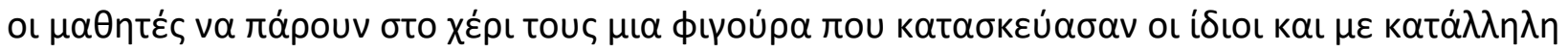

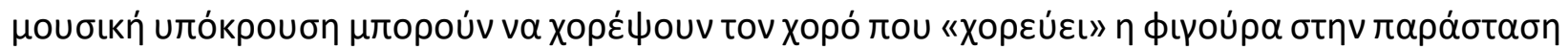

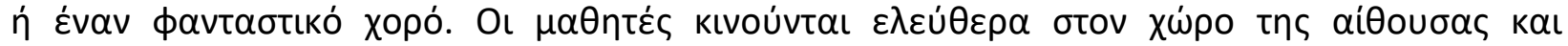

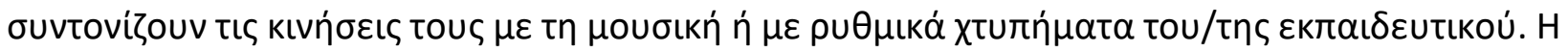

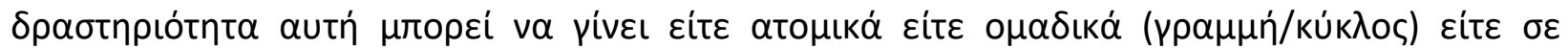

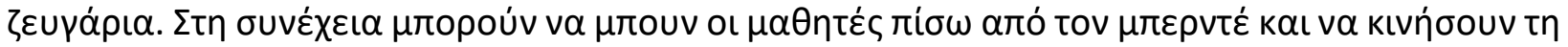

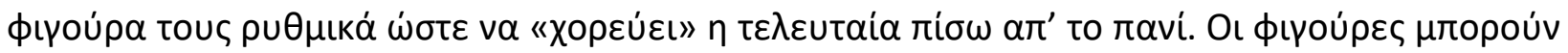

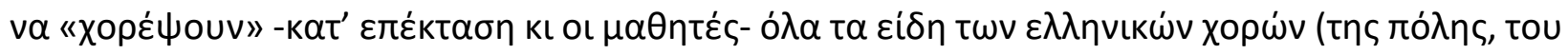

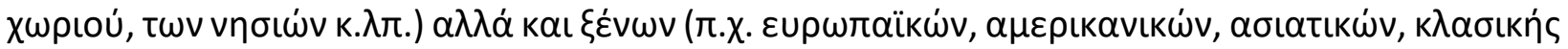

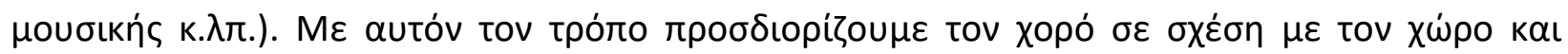

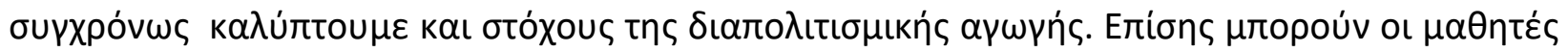

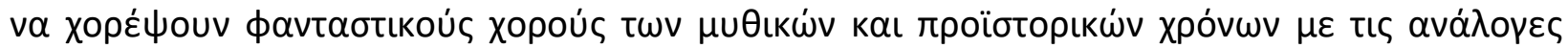

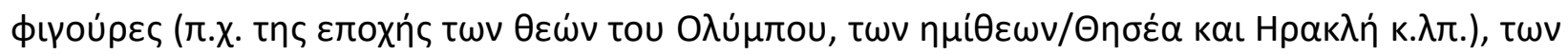

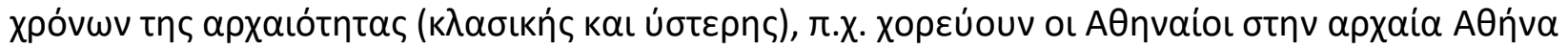

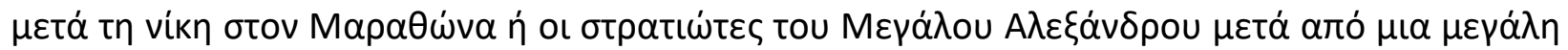

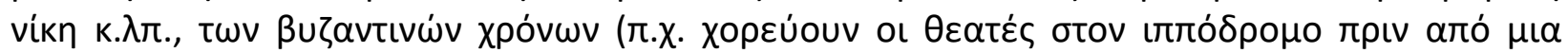

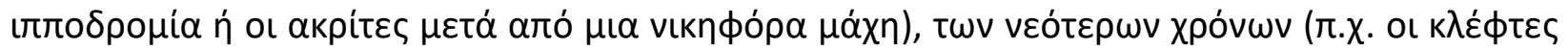

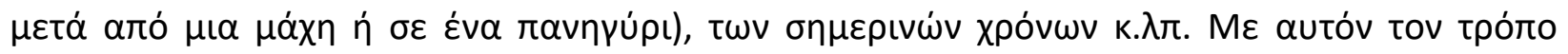

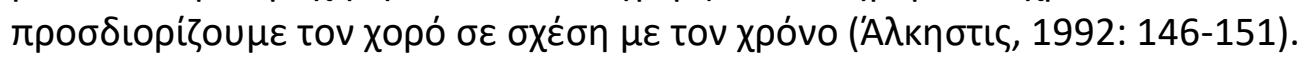

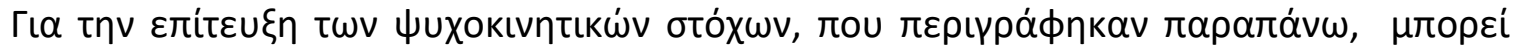

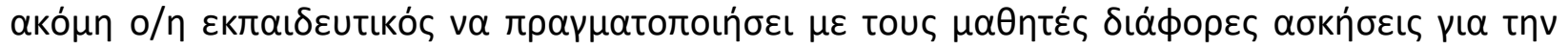

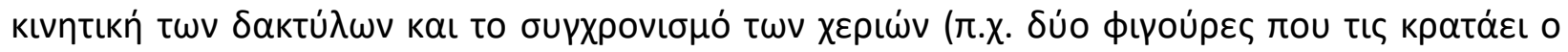

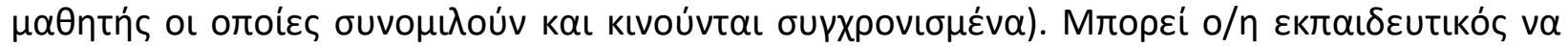

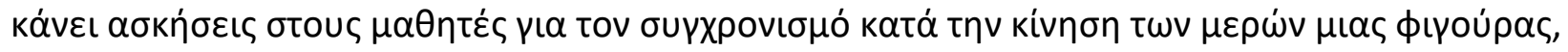

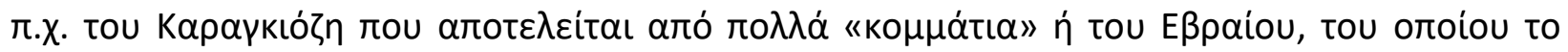

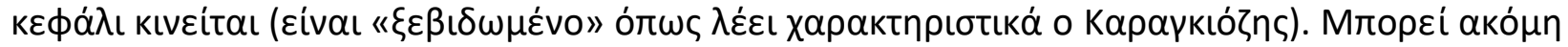

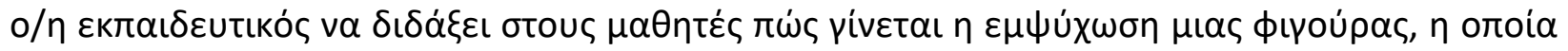

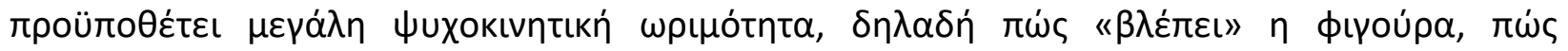

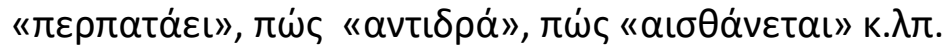

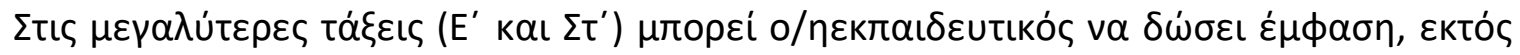

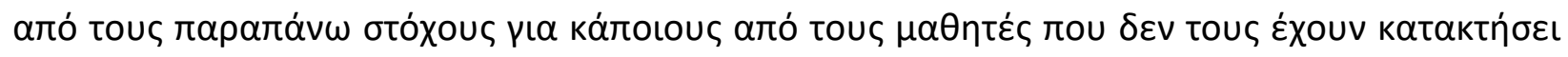

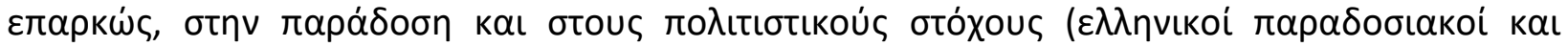

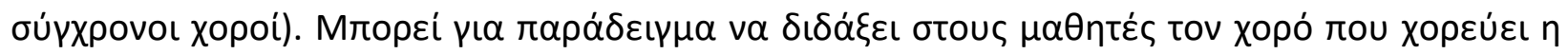

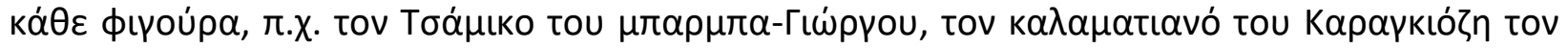


MULTILINGUAL ACADEMIC JOURNAL OF EDUCATION AND SOCIAL SCIENCES

Vol. 5 No. 1, 2017, E-ISSN: 2308-0876 @ 2017 KWP

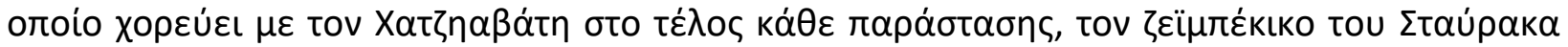

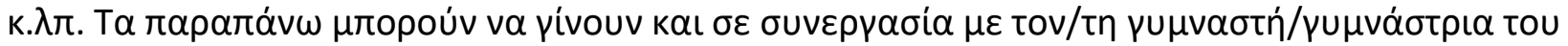

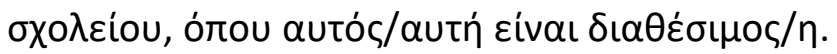

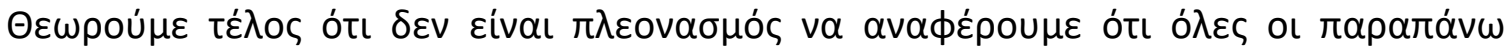

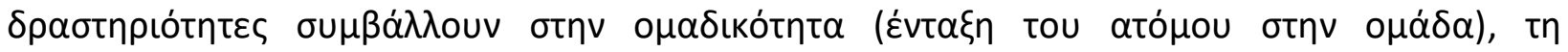

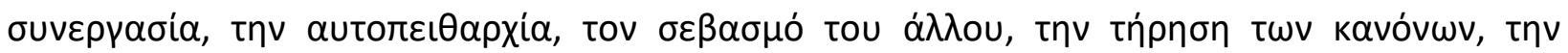

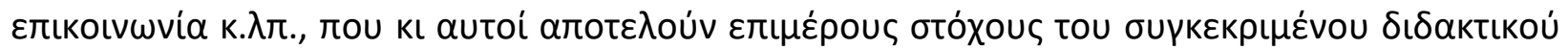

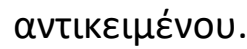

\section{Mouбเкń}

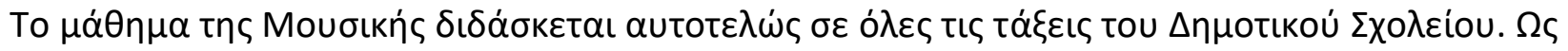

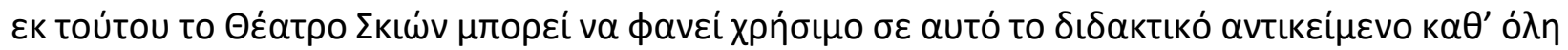

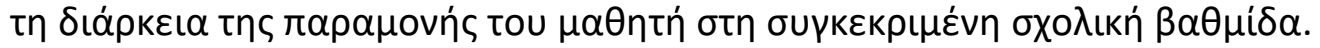

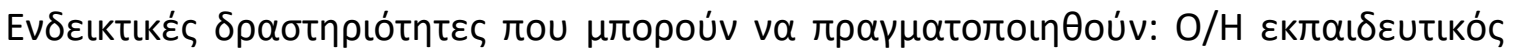

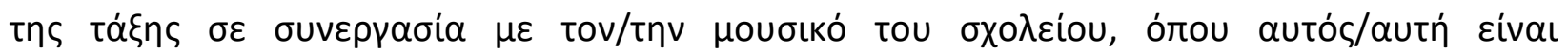

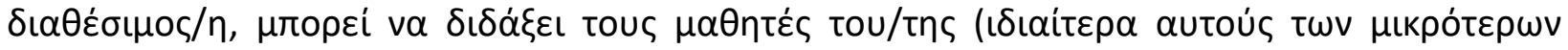

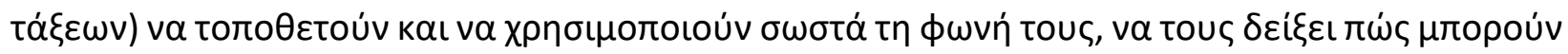

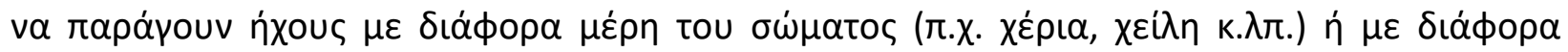

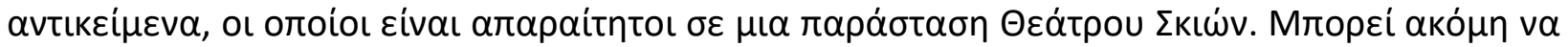

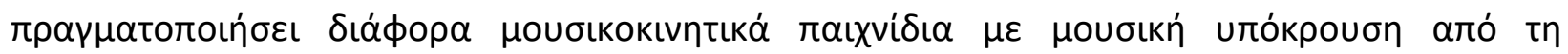

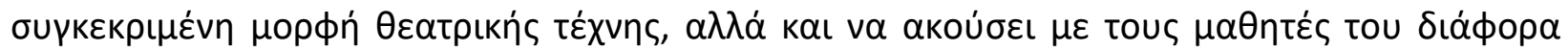

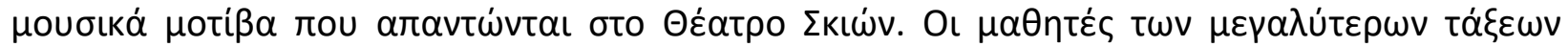

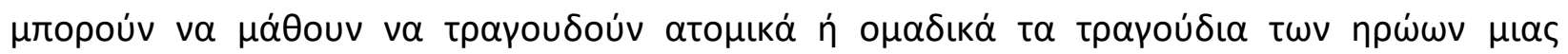

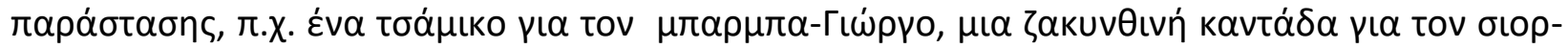

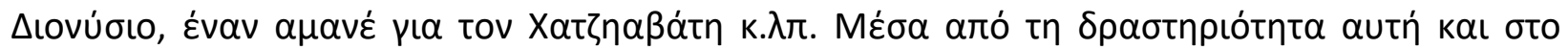

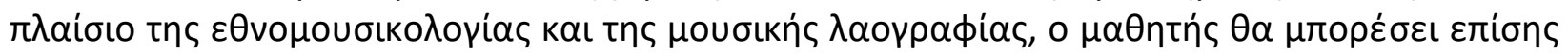

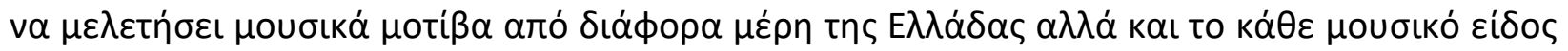

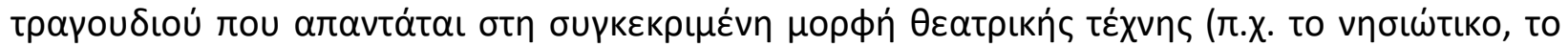

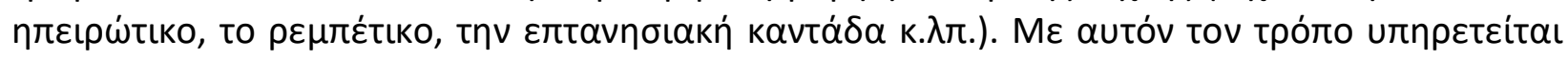

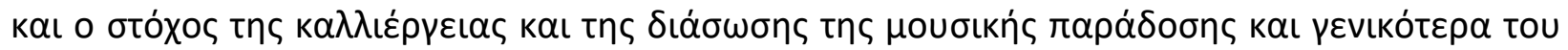

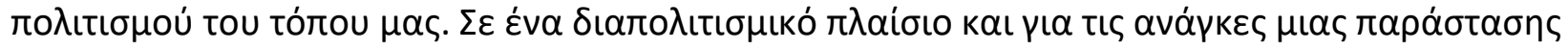

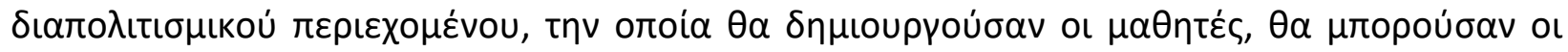

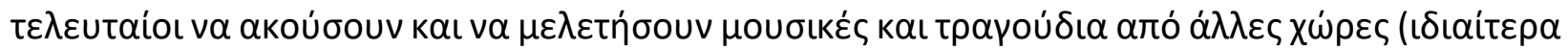

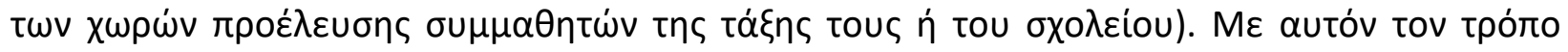

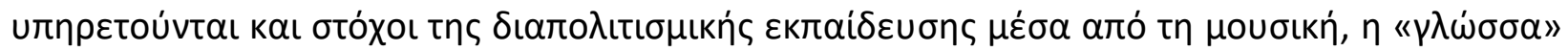

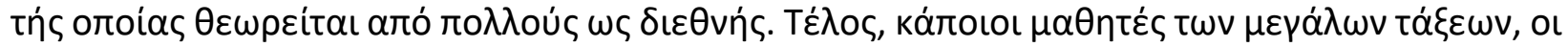

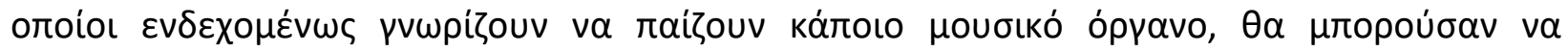

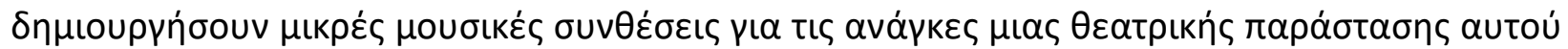

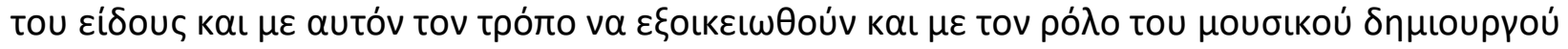

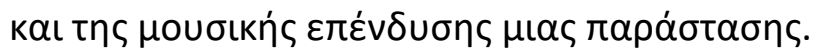

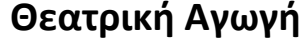

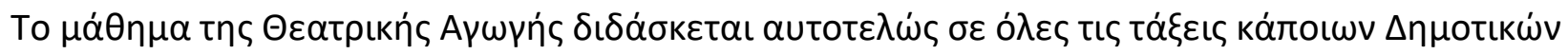

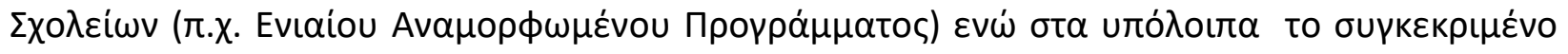


MULTILINGUAL ACADEMIC JOURNAL OF EDUCATION AND SOCIAL SCIENCES

Vol. 5 No. 1, 2017, E-ISSN: 2308-0876 @ 2017 KWP

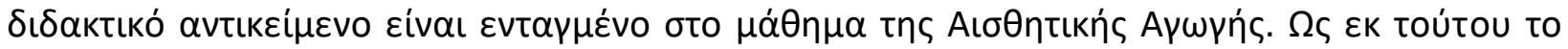

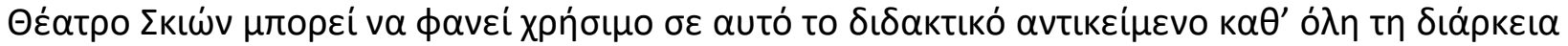

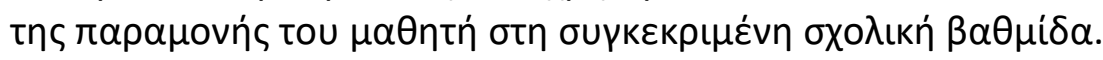

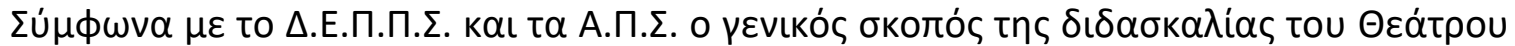

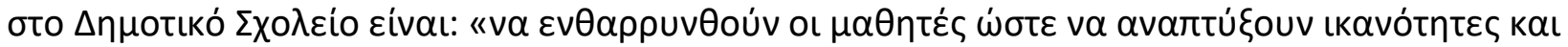

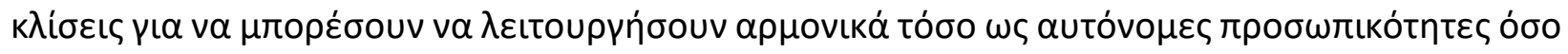

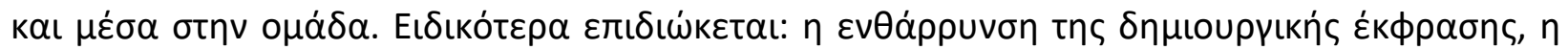

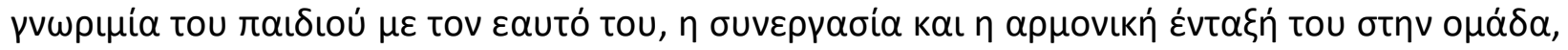

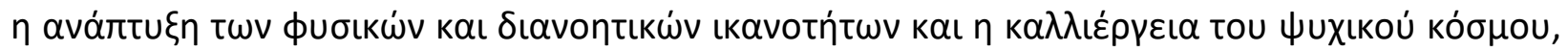

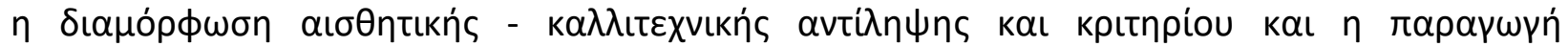

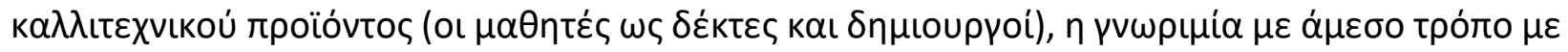

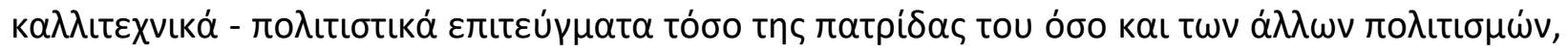

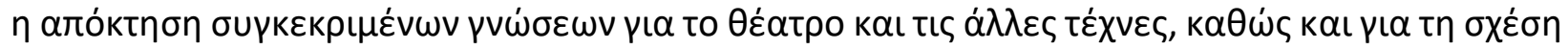

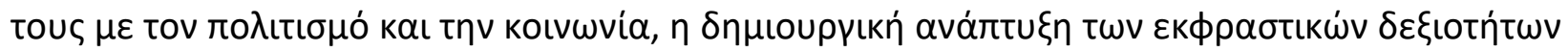

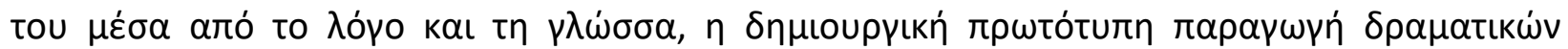

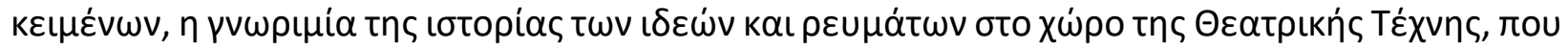

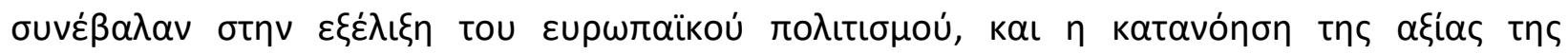

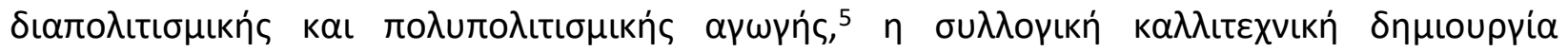

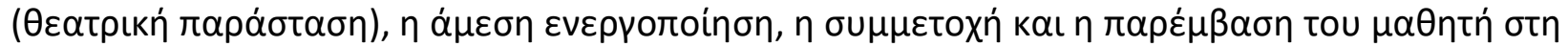

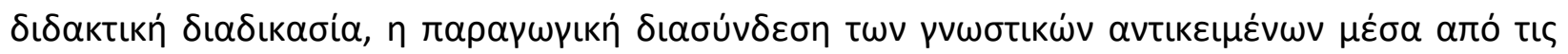

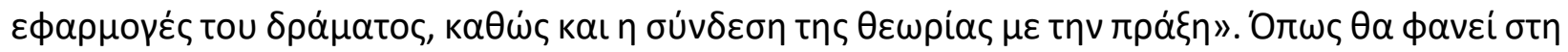

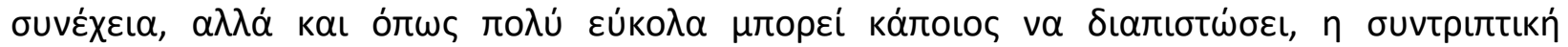

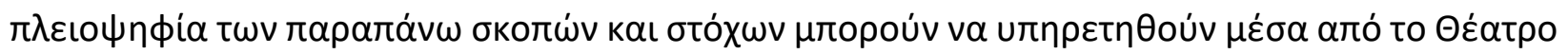

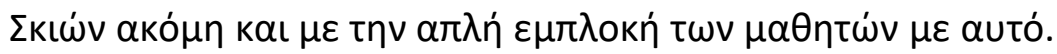

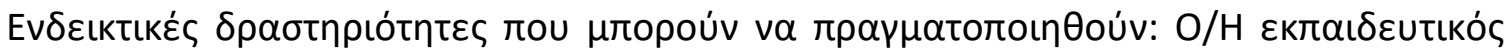

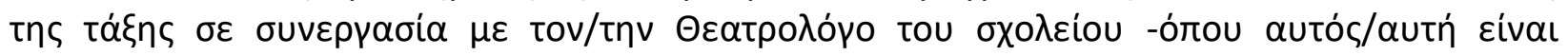

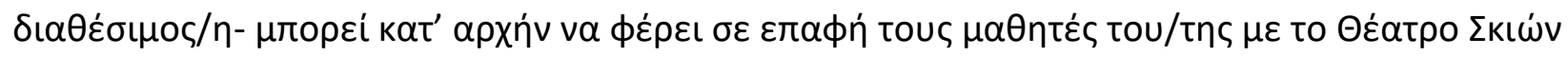

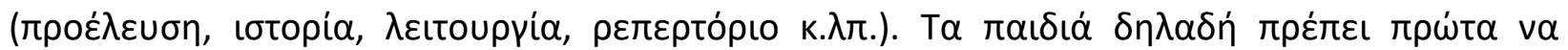

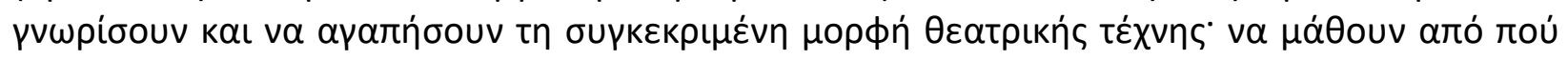

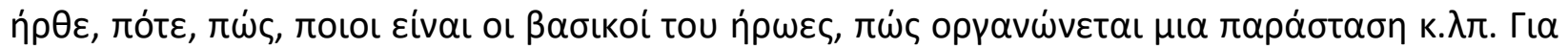

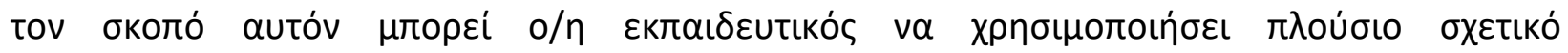

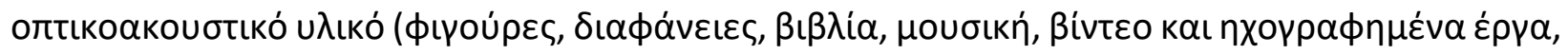

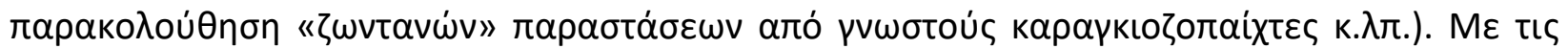

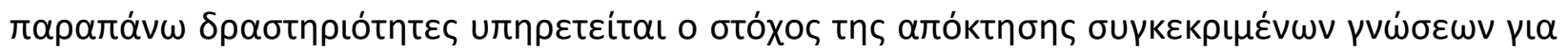

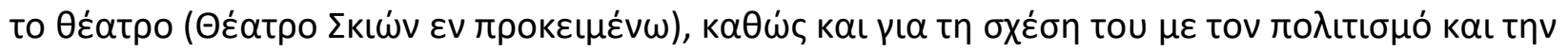
кolv $\omega v i \alpha$.

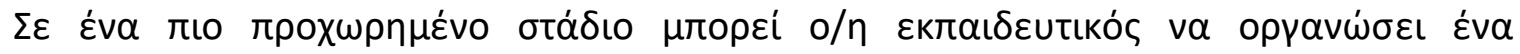

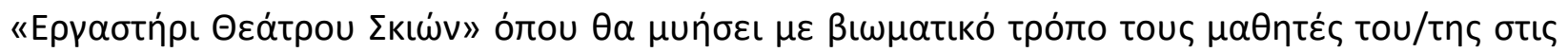

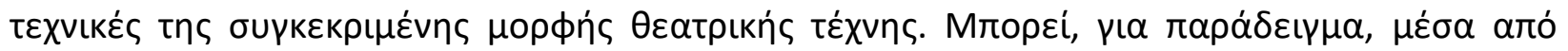

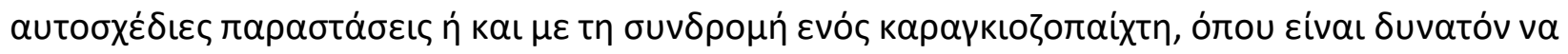

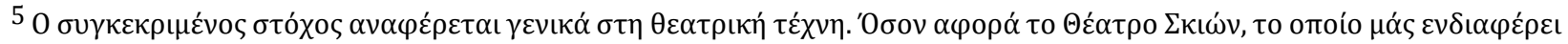

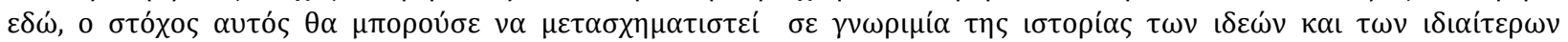

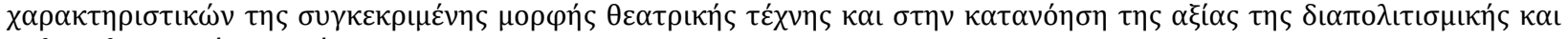

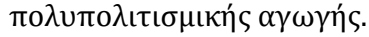


MULTILINGUAL ACADEMIC JOURNAL OF EDUCATION AND SOCIAL SCIENCES

Vol. 5 No. 1, 2017, E-ISSN: 2308-0876 @ 2017 KWP

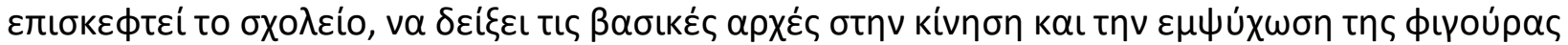

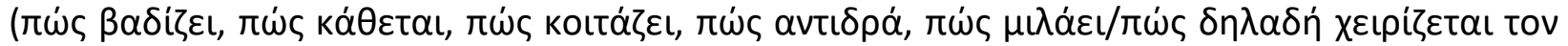

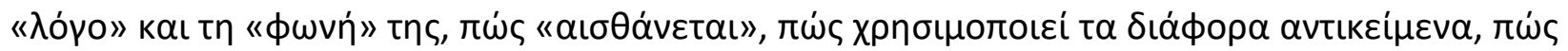

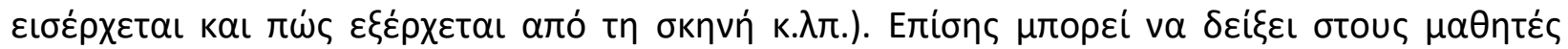

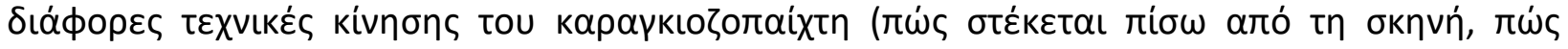

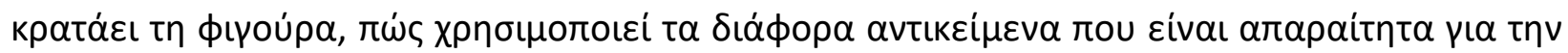

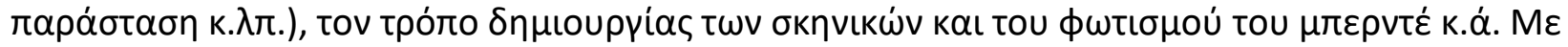

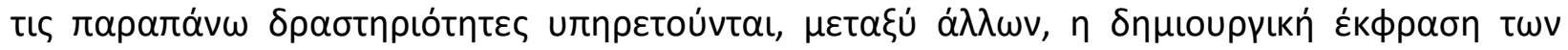

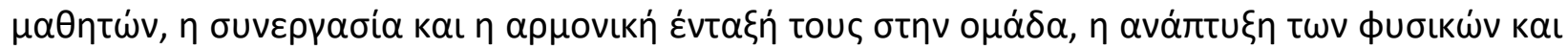

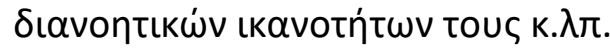

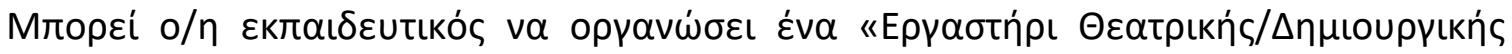

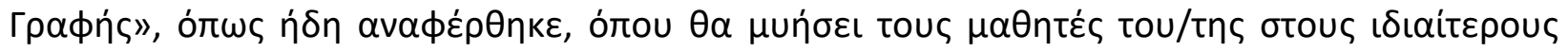

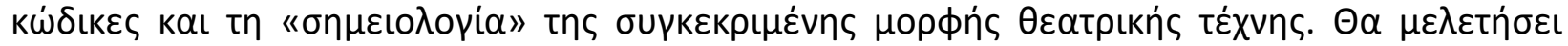

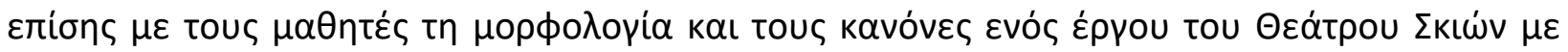

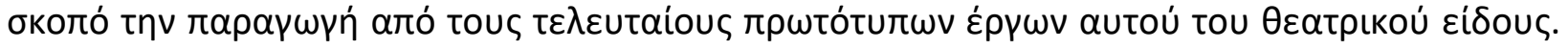

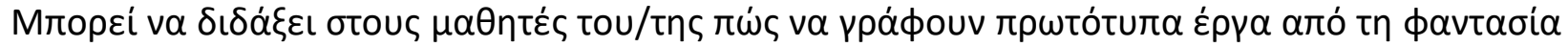

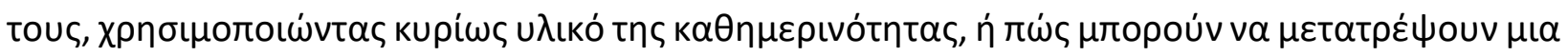

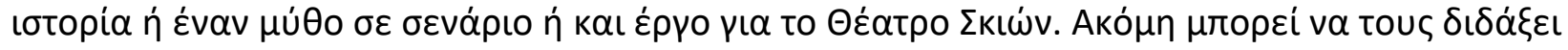

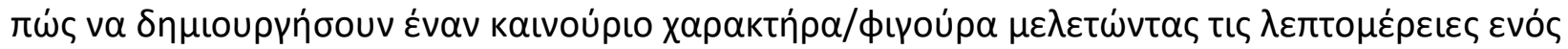

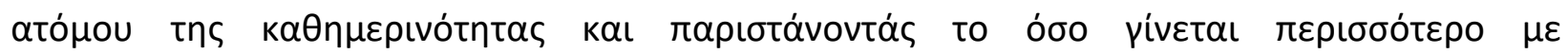

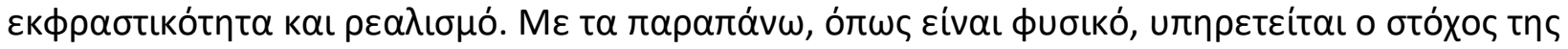

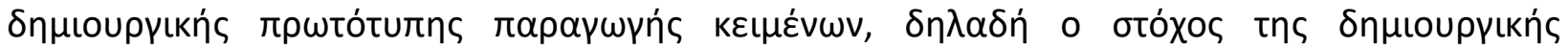

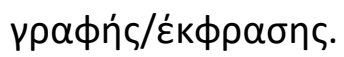

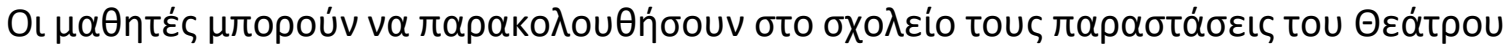

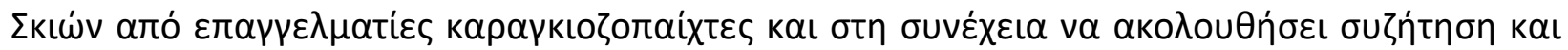

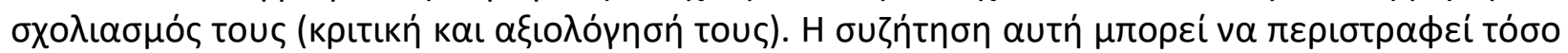

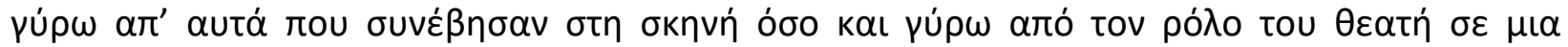

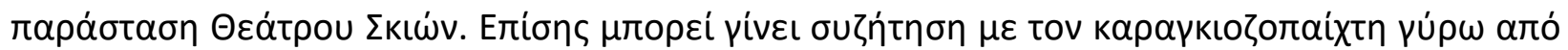

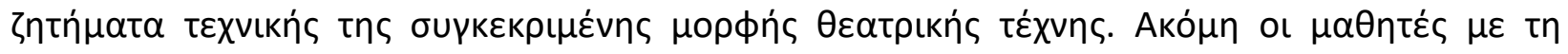

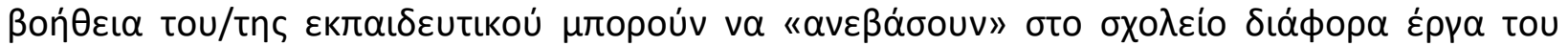

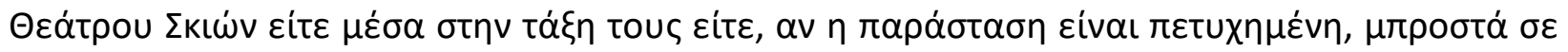

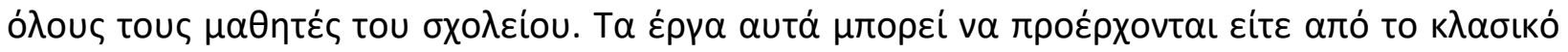

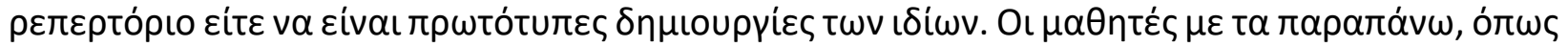

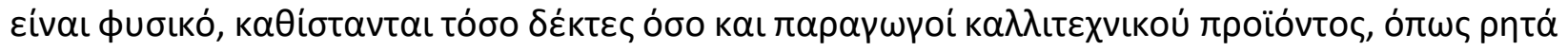

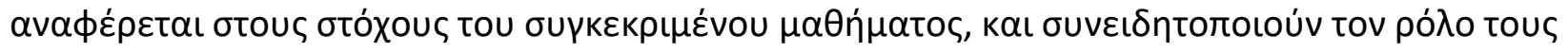

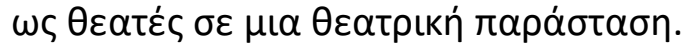

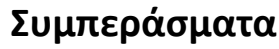

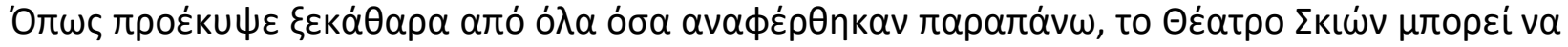

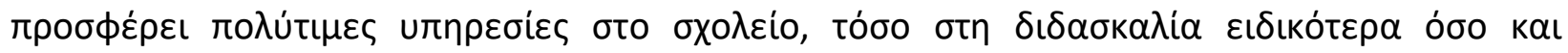

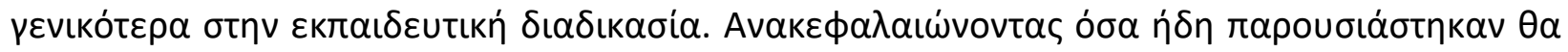

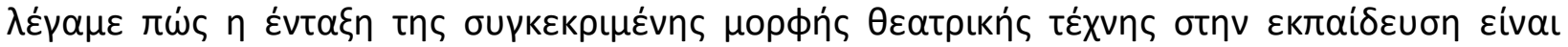

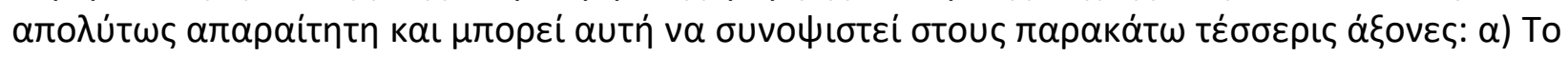

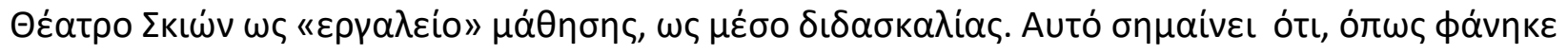


MULTILINGUAL ACADEMIC JOURNAL OF EDUCATION AND SOCIAL SCIENCES

Vol. 5 No. 1, 2017, E-ISSN: 2308-0876 @ 2017 KWP

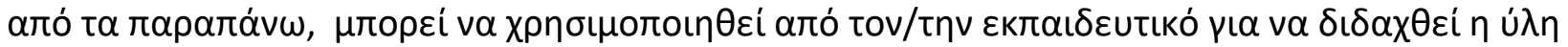

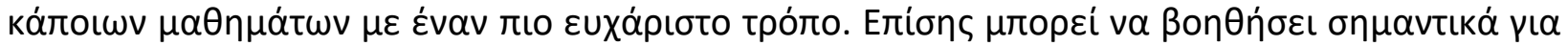

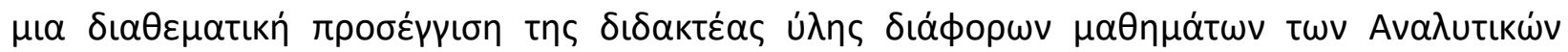

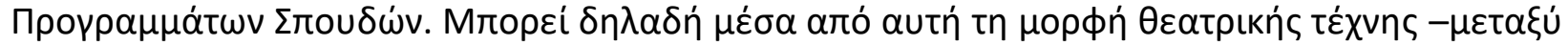

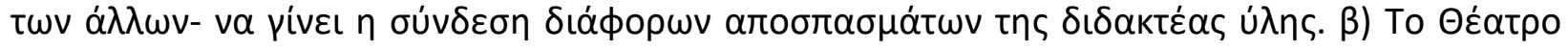

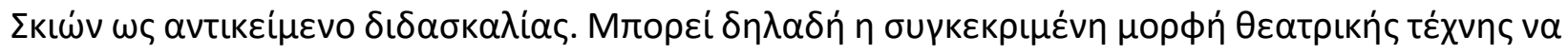

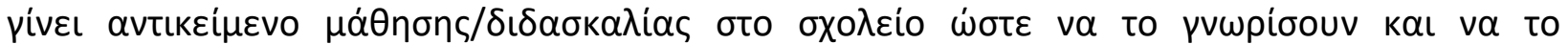

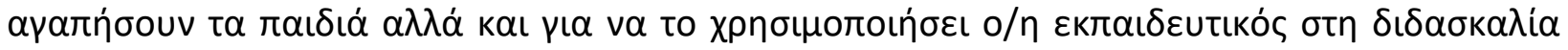

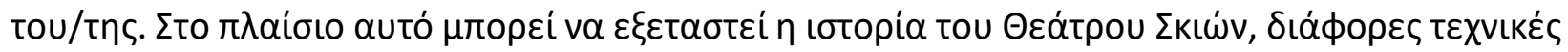

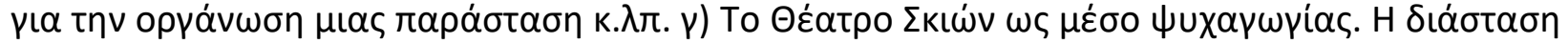

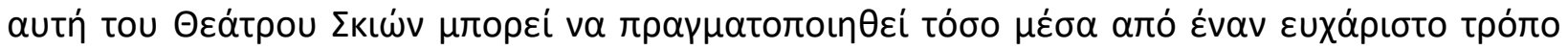

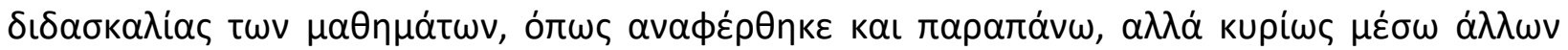

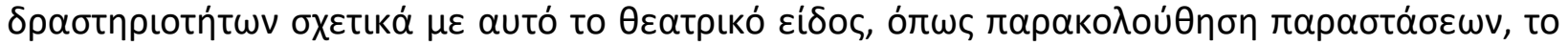

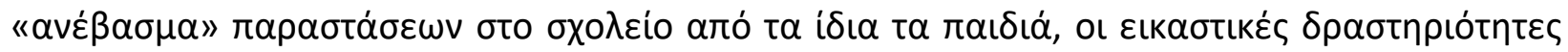

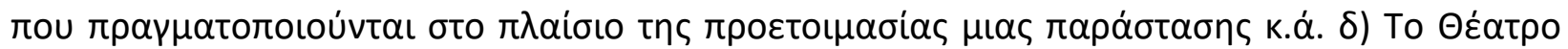

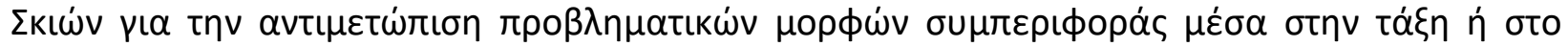

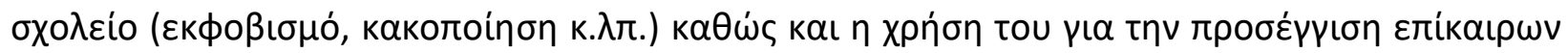

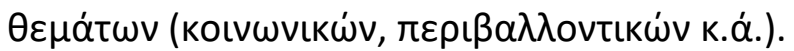

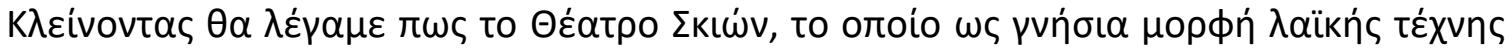

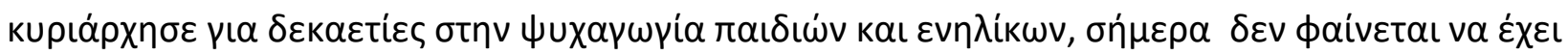

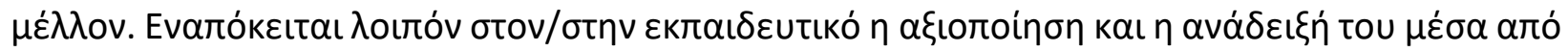

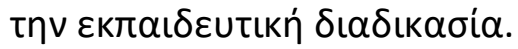

\section{References}

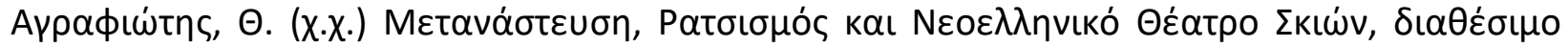

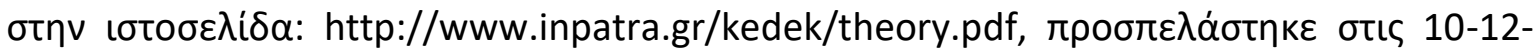
2015.

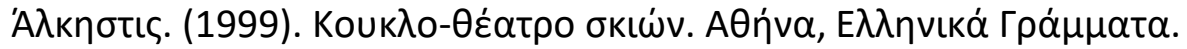

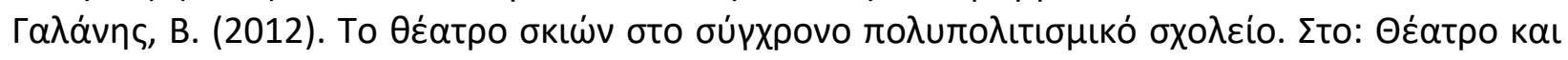

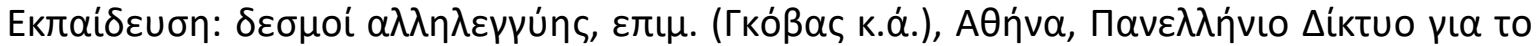

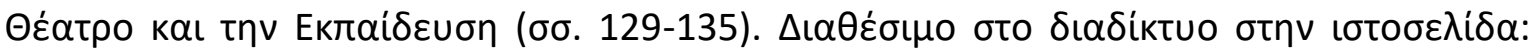
http://users.sch.gr/theatro/Praktika2012\%20Gr/C1Galanis\%20ndn\%20Gr.pdf,

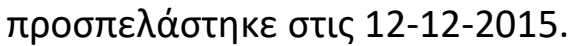

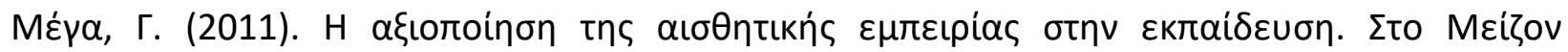

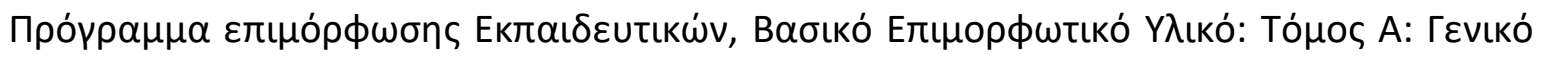

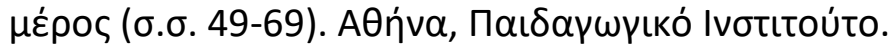

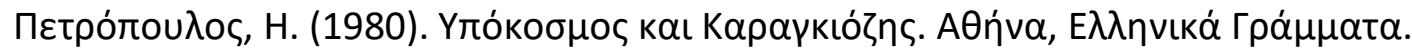

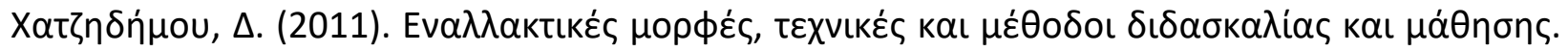

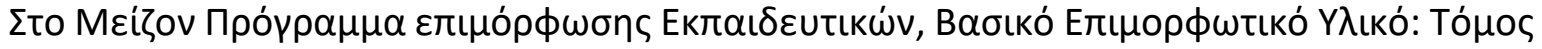

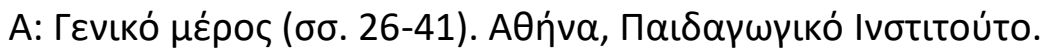

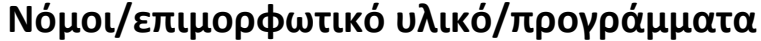

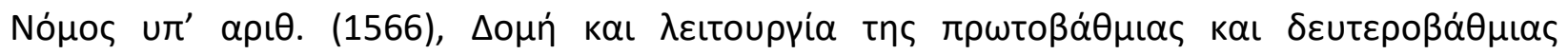

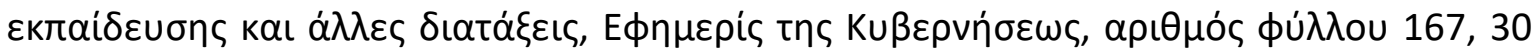


MULTILINGUAL ACADEMIC JOURNAL OF EDUCATION AND SOCIAL SCIENCES

Vol. 5 No. 1, 2017, E-ISSN: 2308-0876 @ 2017 KWP

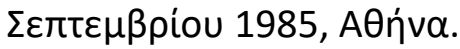

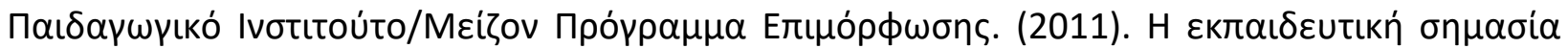

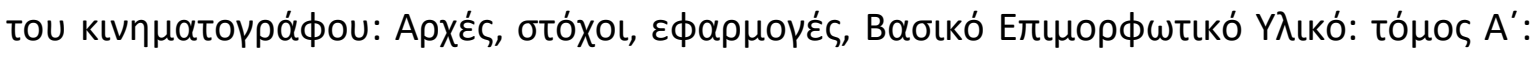

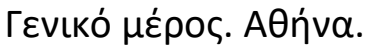

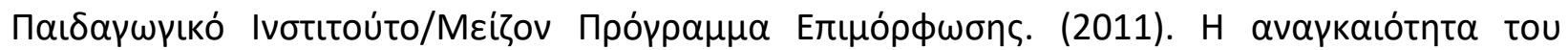

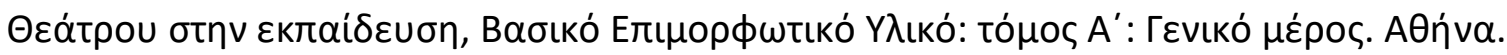

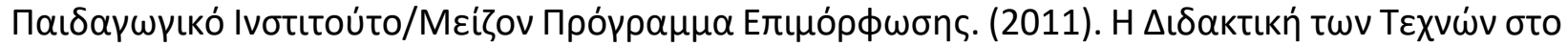

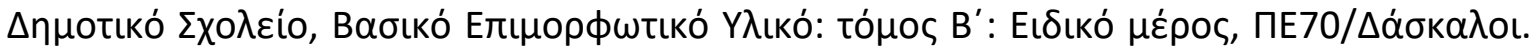
AӨńva.

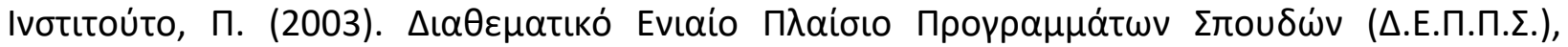

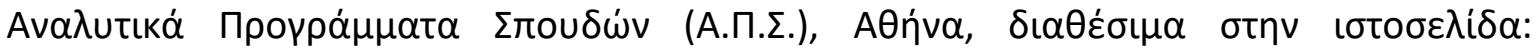

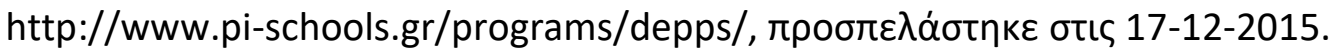

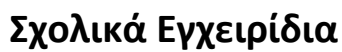

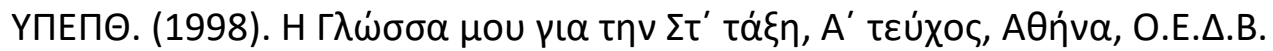

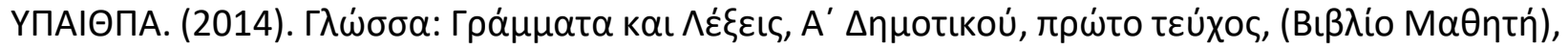

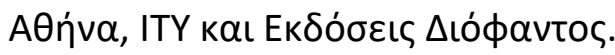

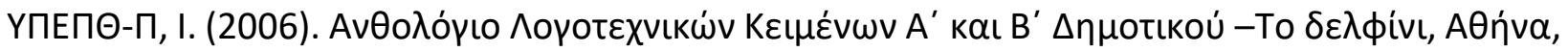
O.E. $\Delta$. B.

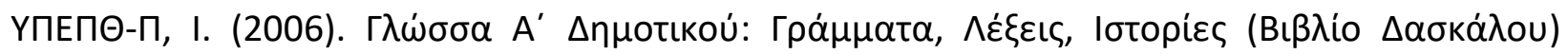

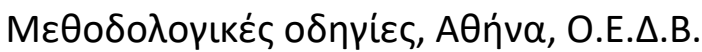

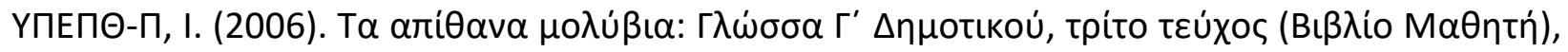

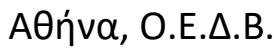

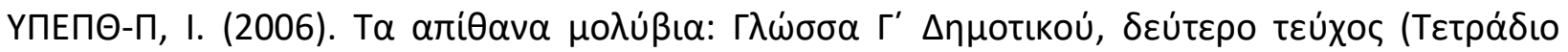

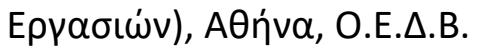

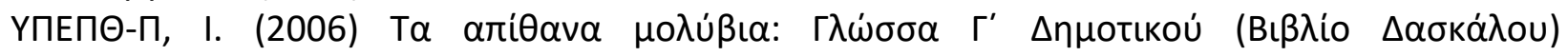

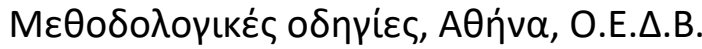

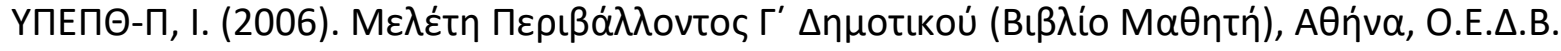

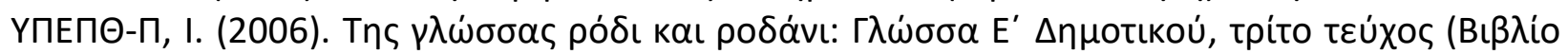

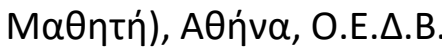

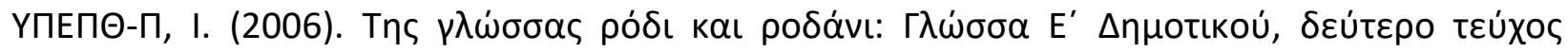

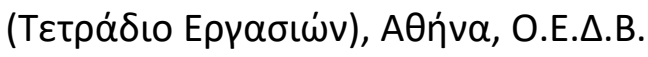

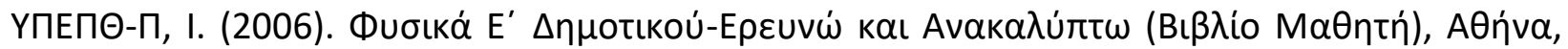
O.E. $\Delta . B$.

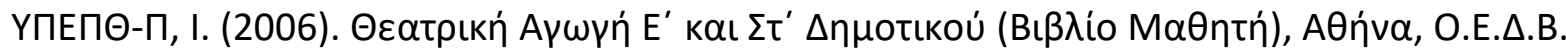

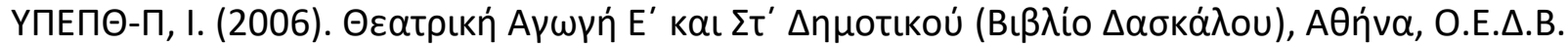

